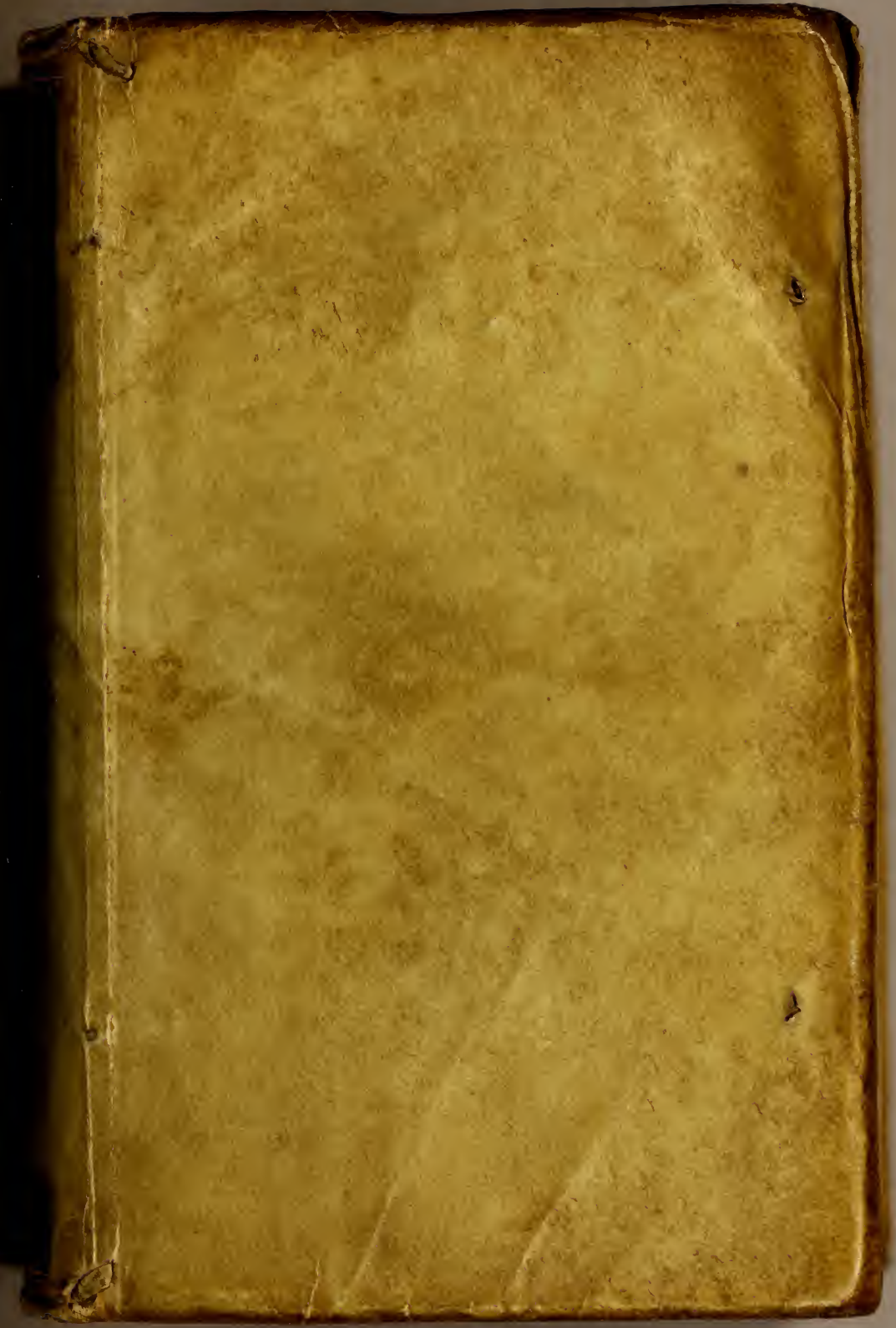




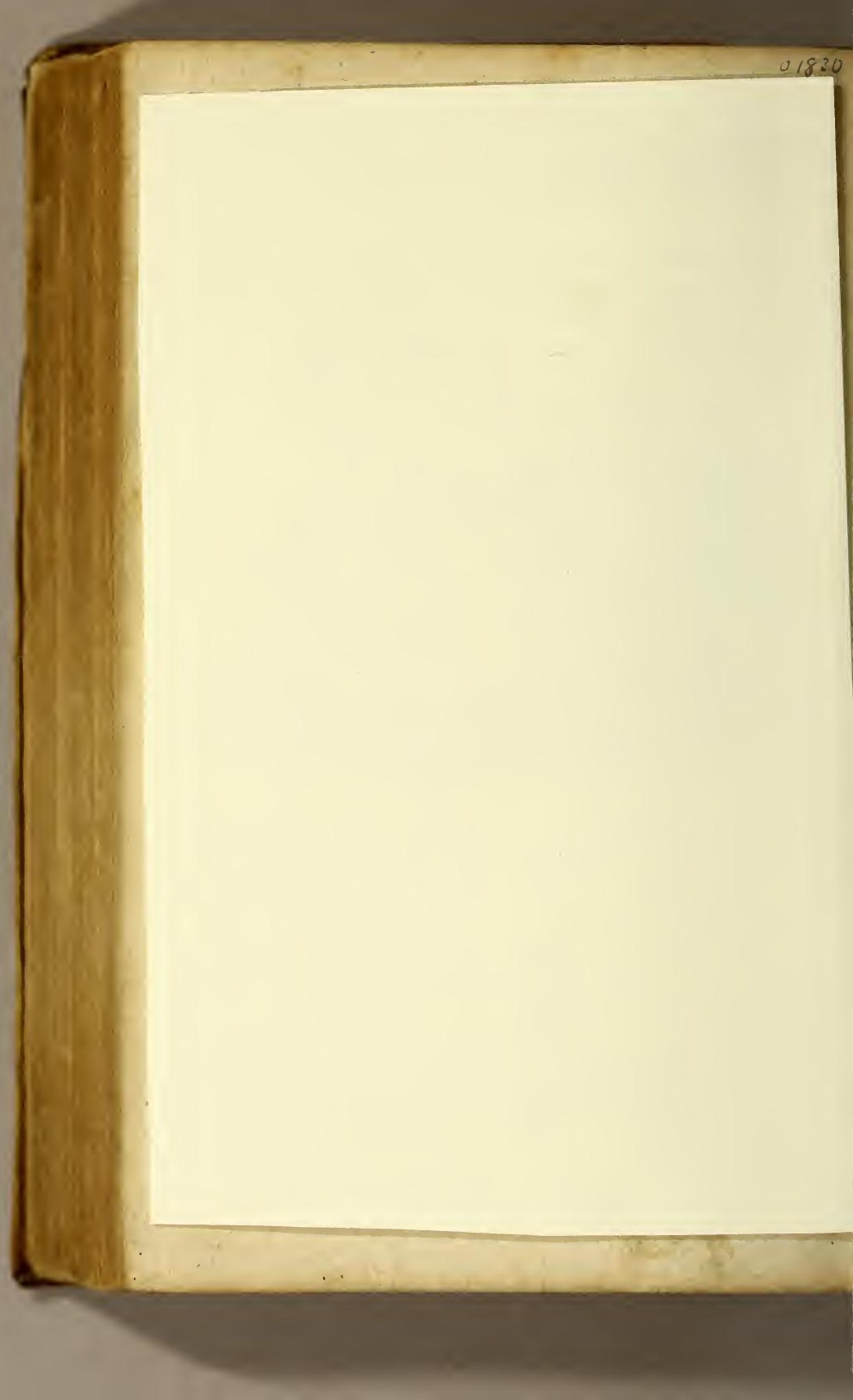




\section{TRAICTE' DE}

\section{C.HR IS T OP H LE D E L A C O S T E $M E D E C I N$ E T CHIRVRGIEN.}

Des drogues \& medicamens qui naiffent aux Indes.

Seruant beaucoup pour l'efclairciffement of intelligence de ce que Garcie du Iardin a efcrit fur ce fubject.

Traduiat d'Efpagnol en Latin, abregé \& illuftré de quelques Notes, par Charles de l'Eclufe d' Arras: Et de nouueau mis en François par Anthoine Colin,M.Apoticaire Iuré de Lyon. Er par luy augmenté de plufieurs figures.

\section{SECONDE EDITION.}

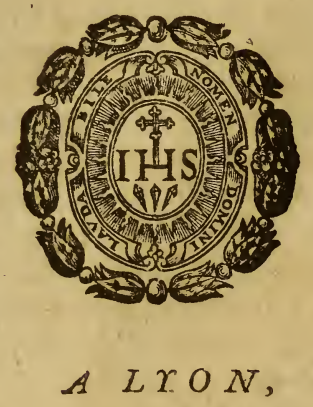

Aux defpensde IE A N PI L I E H O T T à l'enfeigne du nom de IE svs. M. D C. $X I X$. 


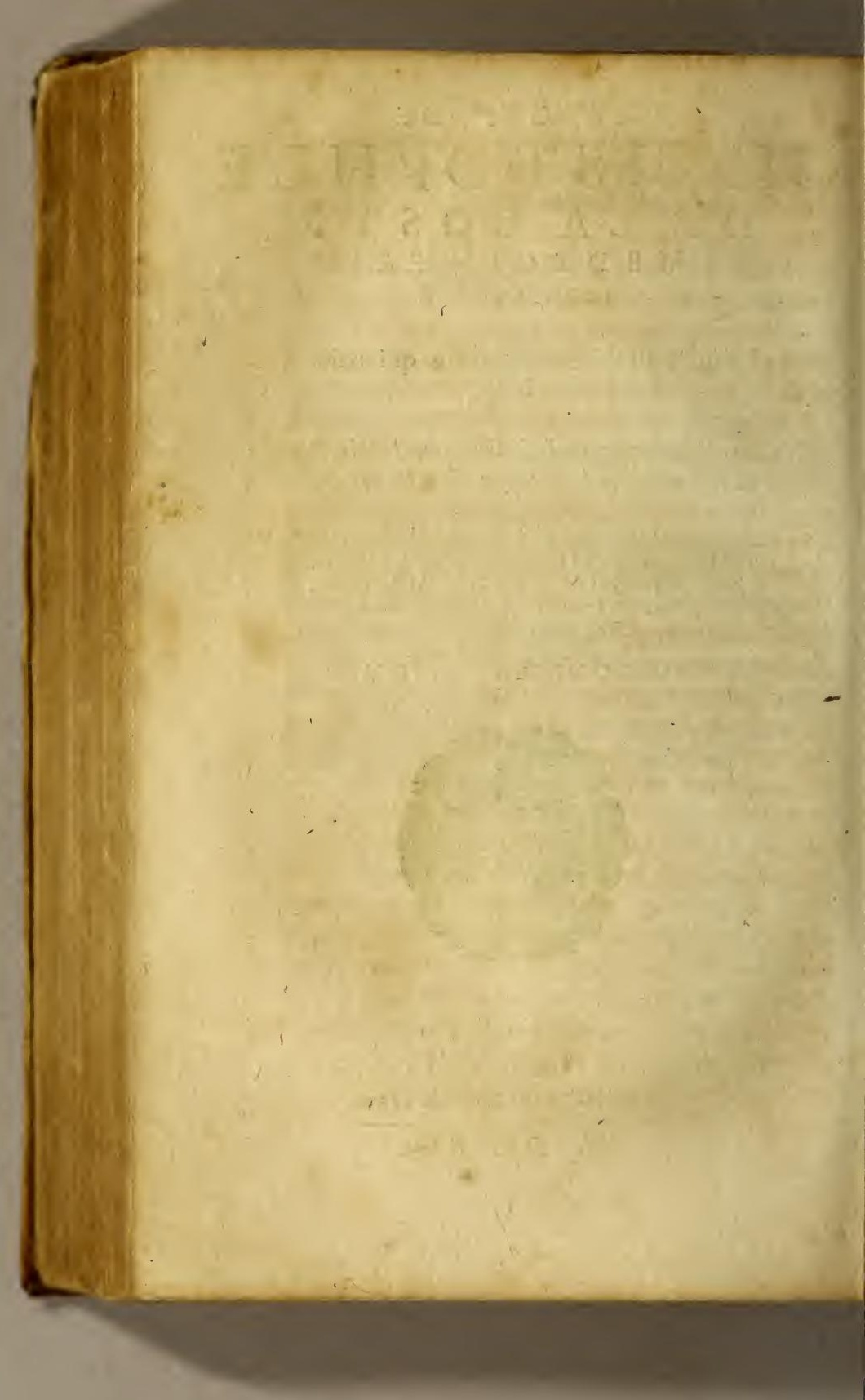




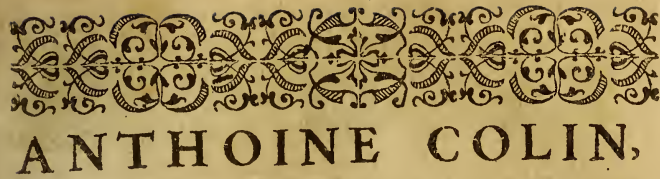

\section{A V LECTE V R.}

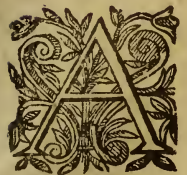

$M Y$ Lecteur comme ie penfois eftre à la fin de mon counre, il m'eft tombé entre les mains vne quatriefme edition de Chriftopble de la Cofte rnedecin du Burgos: traduicte d'Ejpagnol en Latin par Charles de l'Efclufe, pour feruir de plus grande intelligence aux deux liures precedens: qui eft l'occafion que juyuant entierement fon intention, ie lay traduit de mot à mot en noftre langue Françoife, de mefme qu'il a fait en Latin: fors $\dot{\sigma}$ excepté, que ie t'ay fait adioufter plufieurs figures des plantes,defquelles ledit de la Cofte a fait mention, ce qui n'eftoit pas dedans de l'Esclufe. Que fi quelquivn mobiecte, qu'il n'eftoit de befoin d'e frire deux fois vne me fme chofe:Ie le prieray de confiderer, que ie ny ay rien inferé de ce qui a esté dit par les autres Autbeurs. Au contraire il trounera que les tref-doctes Annotations de Charles de l'Eclufe, les additions de ce qui auoit esté obmis par Garcie du Iardin, of les figures le fquelles iy adiouste, apporteront vn fort grand profit of contentement à quiles lira.Reçois donc ce labeur d'vn vijage benin, o d'auffi bon coeur que ie te l'offre, te priant que tu ny apportes ancane paffion, \& que fi tu y trounes quelque chofe à redire, tu penfes quil est beaucoup plus facile de reprendre les efcrits d'autruy, que de mettre la main à la plume, fo faire voir quelque chofe du fien au public.

A Dien.

A A 2 
4

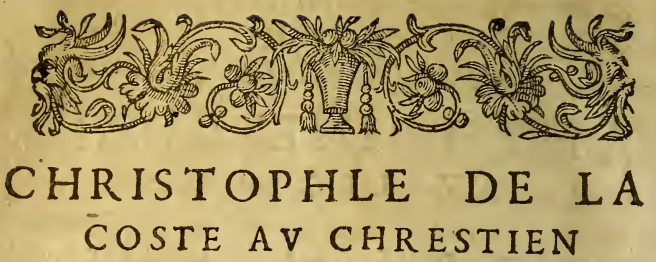

E T $P R V D E T$. Lecteur.

E Philofophe au commencement de fa Metaphifique, dit, que tous les hommes defirent de fçauoir. Ces paroles ont eu tant de pouuoir en mon endroit ( benin Lecteur) quabandonnant mon pays, ie me fuis refolu de chercher par diuerfes contrées \& Prouinces les hommes fages \& curieux : defquels i'euffe le moyen d'apprendre tous les iours quelque chofe de nouueau: comme ont fait anciennement plufieurs prudens perfonnages, felon que dit S.Hierofme, en la preface de la Bible efcrite à Paulinus.

Partant defireux de rapporter quelque fruict de mes longues peregrinations, i'ay efté foigneux d'obferuer en diuers lieux la varieté des plantes refquelles Dieu a crées pour la fanté des hommes.

Or eftant aux Indes Orientales, ie r'encontray de bon heur, M. Carcie du Iardin, Medecin Portugois, perfonnage graue, d'vn rare \& excellent efprit, duquel ie tais les autres louanges, d'autant qu'elles font fi grandes, que penfant en auoir dit beaucoup, l'en ignorerois d'auantage.

Iceluy 
Iceluy a efcrit vn liure en fa lágue, qu'il a intitulé,Dialogües des Simples, Drogues, ¿ó Medicamens des Indes, \& de quelques fruits naifans en ce pays là. Oi tout ainfi qu'en ce liure il traicte de diuers medicamens,plantes, \& autres chofes neceffaires pour la fanté des hómes:auffi fait il bien mention de quelques autres chofes lefquelles femblent eftre inutiles pour l'vfage de l'hoome : la nature des Dialogues le requerant, ou les entreparleurs ont accouftumé d'extrauaguer \& fortir hors de propos. Et qui plus eft il s'y troume plufieurs erreurs, lefquelles toutesfois on ne peut attribuer à l'Autheur veu fa qualité \& merite, mais pluftoft à l'Imprimeur, ou à la nonchalance des ouuriers (qui ne font pas fi bös en la ville de Goa,où il a efcrit,q́ceux de ces quartiers) toutesfois elles apportent de la fafcherie \&r de l'ennuy au Lecteur. Il y a d'abondant ce deffaut en ce liure quile rend moins parfait en tout \& par tout, les effigies \& figures des plantes defquelles il traicte:lefquelles il n'y a peu faire inferer,à cạufe (cóme il eft aifé à croire) qu'il eftoit occupé en des affaires de plus grande confequence.

Au demeurant iay penfé que ce liure feroit grădement profitable aux hommes, silils eftoyent conduits à la cognoilfance des bonnes chofes qui font contenuës en iceluy,en leur en mettant deuant les yeux les figures \& pourtraits : ce que perfonne ne pouuoit faire, finon qu'il les euft veuës de fes yeux propres, \& en euft l'experience.

C'eft pourquoy defireux d'aporter quelque proffit à ma patrie, \& pouffé d'amour enuers mes prochains,ie deliberay de prendre fur moy ce labeur,

A $\mathrm{A} 3^{3}$ 


\section{6}

\& de faire tirer au naturel chafque plante entiere, en y adiouitant plufieurs autes chofes, lefquelles i'ay moymefme veu, \& que Maifte Garcie du Iardin n'auoit peu voir pour les raifons cy deuant dictes.

Ie fçay en quel danger ic m'expofe, principalement en ce fiecle fi miferable, auquell la malice des hommes a grandement la vogue, laquelle a de couftume de reprendre le plùs foutuent ce qu'elle n'entend pas.Mais vine chole me confole, c'eft que plufieurs fages perfonmages ont paffë ce mefme pas: lefquels fi de telle crainte its euffent efté efpoumenrés, nous ferions ignorãs pour le iourd'huy de plufieurs chofes, lefquelles auec grande indutrie, ils ont laiflé à la polterité,au proffit \& vilité des bonnes lettres.

Et bien que ie ne doyue eftre comparé auec eux, mefmes que ma hardieffe fe monfte plus grande en ce que ie veux traicter de quelques erreurs, lefquels ont efté cômis entre les Autheurs Grecs, Arabes, \& Latins, fur la cognoiffance de quelques plantes \& drogues, en partie par leur negligence, en partie auffi parce qu'ils n'ont peu voir les lieux où elles croiffent, mais les ont apprifes par le rapport incertain des autres:on me troutuera digne de pardon, fi ie tafche de rediger par efcrit en celiure les chofes tref-certaines \& veritables, lefquelles i’ay veuës.

Or ie n'ay entreprins c'eft œuure laborieufe pour conuoitife de gloire, ou pour m'acquerir plus grande reputation d'eftre plus fçauant que ie ne merite : mais mon feul but a efté de feruir fincerement à ton proffit, \& pour ta commodité. Or ic me perfua 
perfuade pour certain, qu'encores que parauanture tu n'en louës pas l'vtilité, toutesfois tu prendras en bonne part ma diligence \& labeur, \& que tu ne reietteras mon intention, qui moymefme ay voulu voir,en de fi longs \& diuers voyages, ce que les autres ont redigé par efcrit feulement par ouyr dire.

Et ne nie point auffi,que ces chofes n'euffent peut eftre traictées d'vn ftyle 2 termes plus elegans \& recerchés, mais i'eftime qu'on doit preferer la verite, à vil langage poly \& fardé. Voila pourquoy ie te prie recenoir ma volonté comme il appartient, n'ayant aucunement efgard à la petiteffe de l'œuure: laquelle encores qu'en apparence exterieure, elle te femble peu de chofe, fi eft ce qu'en icelle font contenues des chofes de grand poids.

Que fi tul y rencontre quelque chofe qui ne contente ton appetit,paffe-les comme homme aduifé, en confiderant que ie n'efcrits pas pour toy feul, \&e qu'il y a autant d'opinions diuerfes qu'il y a d'hommes differens:car il fe pourra faire que ce qui ne te fera point agreabie, contentera les autres.

Que fi tu le fairs ie mettray peine de mettre en lumiere, vn autre plus grand liture qui contiendra le refte des herbes, plantes, fruicts, oyfeaux, \& autres animaux tant terreftres que aquatiques qui fe troutuent en ces Prouinces, en Perfe, \&r en la Chine, lefquels iufques icy n'ont pas efté tirés apres le naturel, \& defques on a fort peu efcrit: bref plufieurs antres chofes dignes d'eftre obfernees, lefquelles parauanture te feront plus agreables.

A A 4 
Ie feray doncques fin me foufmettant en tout \& par tout à la cenfure de tous hommes doctes $\&$ benins Lecteurs, qui ont accouftumé de reprendre ce quils entendent, ou bien ce qui eft de raifon. Priant ceux qui efguillonnés de l'enuie feront auzrement, de prendre la plume, $\&$ mettre premierement quelque chofe en lumiere, car alors ils recognoiftront, combien c'eft chofe plus facile de reprendre, que de bien ef crire ce quil faut expoferà la veuë de tout le monde. A Dien.

T R A I

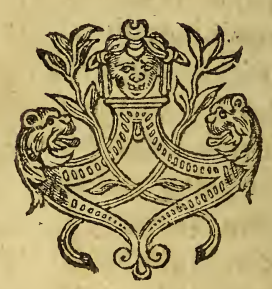


10 CHRISTOPHIE DE LA COSTE, ce pluftolt fon operation : trois heures apes auoir pris cefte eau,ils luy font humer quatre onces de bouillon d'vn poulet,auec quelques grains de $\mathrm{Ma-}$ ftic:vne heure apres il mange, \& boit du vin trempé. On augmente ou diminue la quantité de ce medicamét plus ou moins, felon les forces ou naturel de celuy quile doit prendre: $\&$ cefte façon de purger n'eft moins frequente (principalement aux delicats ) que la Manne ou la mouejlle de cafle recente, \& ce qui eft plus efmerueillable ils reiettét les autres remedes des apoticaires, au prix de ceAtuy cy.

Au demeurant les medecins des Indes, fe feruent du mefme ordre \& regime que nous obferuons en l'Europe, pour l'exhibition des medicamens laxatifs, foit qu'ils foyent de fublance plus liquide, ou plus dure, c'eit afçauoir fur l'aube $\mathrm{du}$ Choses iour, puis cinq heures apres ills les font abotenir de quiper- manger, boire, \& dormir. Dans quel temps fi le derce me malade n'eft purgé,ils luy donnent felon le précedicamët. pte d'Auicenne, deux drachmes de Maftic diffoutes en eau rofe, afin de corroborer \& cóforter l'eftomac, puis il font vn liniment fur le ventre auec du fiel de bouf,\& y mettent vn drappeau trempé fur le ventre, mefme dans le fiel fufdict, pour exciter la faculté expultrice fi befoin eft.

Que s'il eft bien purgé;cinq heures apres auoir pris ce medicamet, ils luy font aualler trois onces d'vn bouillon de poulet tiede, \& rien dauantage: en apres ils luy permettent de dormir vn petit, \& de boire vn peude l'eau rofe : car ils font cómodénét purgés apres le fómeil,\& afleurent que les facultés naturelles font grandemét roborécs par ce- 
DES DROG. ET MED. IIV. III. II Aloës de Mattbiole.

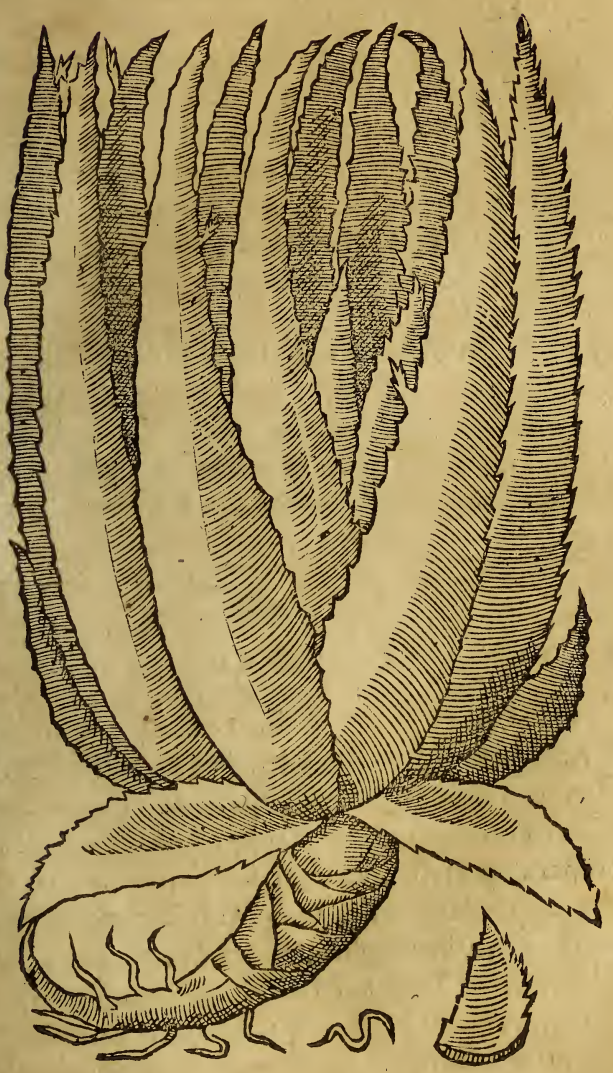

fte eau rofe meflangée auec le Maftic, par le boüil lon \& par le dormir. Car s'ils permettoyent de manz 
12 CHRISTOPHLE DE IA COSTE; manger abondamment, la faculté naturelle feroit occupée à digerer cefte viande, \& feroit que la purgation en feroit plus tardiue.

Cefte icy eft la plus vfitée façon de donner medecine entre les plus doctes medecins de ce pays là,laquelle eft fort confonnante à la raifon: car le fiel appliqué exterieurement eft laxatif,parce qu’il 223. excite la faculté expultrice. Et la deffence de mansraict.2. ger chair en ce temps là,eft appuyée de l'authorité chap.23. d'Auicenne.

\section{ANNOTATIONS。}

* On trounera dans Diofcoride \& Galien lesfacultés 1 de l'Aloës, le fquelles à dire la verité l' Autheur à traduit en Ejpagnol,mais non fi fidelement qu'il eftoit de be foin.

\section{De l'Opium. \\ C H A P. II.}

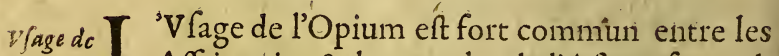
lopiü, LAffriquains \& les peuples de l'Afie: \& font teloù, éo à lement acouftumé d'en vfer,qu'ils ne s'en peuuent quelle abftenir,fans vn apparant danger de leur vie.Ie l'ay est propre. apris par experience, lors que ie m'en retournay en Portugal par la mer Indienne. Car il y auoit dedás ce mefme vaiffeau plufieuts efclaues, entre lefquels eftoit vn Turc natif d'Aden, \& quelques autres,tant Perfiens, Arabes que Turcs, qui anoyent apporté fecrettement auec eux de l'Opium, duqucl ils auoyent vfé en fort petite quantité,comme fi ce fut efté quelque medicament, à caufe qu'ils n'en alloyent 
DES DROG. ET MED. LI V. III. 13 auoyent pas en abondance. Apres qu'ils l'eurent tout mangé,ce Turc natif d'Aden me dit,toy, qui as la charge de la guerifon des malades en ce vaiffeau, faches que fi tu ne donnes à moy \& à mes compagnons de l'Opium, que nous ne ferons pas en vie dans deux iours. Comme ie luy euz refpondu que ie n'auois point d'Opium, il me repliqua le feul remede doncques de nous poutoir deliurer qui fommes accouftumés de manger de l'Opium, eft que tu nous donnes tous les matins à vn chacú de nous vn verre de vin pur,encores que cela nous foit fort difficile \& ennuyeux, à caufe qu'il eft contraire à noftre loy:mais d'autant que de ce remede noftre vie depend,il le faut fupporter de neceffité. Donc ques felon que celtuy cy m'en dit, ie leur donnay à vn chacun du vin, \&. furent gueris en moins d'vin mois, de là en auant ils ne voulurent plus goufter du vin, \& le deffaut d'Opium ne leur nuifit point, l'vfage duquel leur eftoit difcontinué. Ains comme du defpuis ie leur voulus donner de l'Opium, \& du vin,ils n'en voulurent ny de l'vn ny de l'autre.

\section{De la Lacque. \\ C н A P. III.}

T Es habitans du pays d'où elle vient, on accouftumé de la mettre en poudre, \& la diffoudre Maniere en y adiouftant telle couleur qu'il leur plaift, rou- de faire ge,noire, verde, ou iaune, puis ils en forment des la lacpetis baftons,comme font ceux lefquels on appor-que. te en Efpagne pour cacheter les lettres; ou bien $S_{\theta \rightarrow 3}$ viz des baftons grand \& plus gros pour l'vage des ar-lisé. tifans 
I 4 CHRISTOPHLE DE I A COSTE, tifans. Car ceux qui font au tour des lictieres, chaires, \& autres oumrages de bois, s'ils defirent de leur donner quelque couleur, ils ont accouftumé en tournant de les frotter auec ces gros baftons de Lacques, laquelke le venant à fondre parce mouuement foudain \& vifte, le bois reçoit vne tresbelle couleur de Lacque, laquelle dure plufieurs années.

Les Orpheures auffi \& Argentiers pour rendre leurs vafes plus fermes \& beaux, out accouftumé deles remplir de poudre de Lacque, \& les mettre dans le feu à celle fin qu'elle fe fonde $\&$ finalemét la laiffent refroidir de foy mefmes, ou la plongét dedans l'cau.

Comme Au demeurant on la falfifie par fois auec cire \& elle, Se refine:mais la falfification fe defcouure facilement fallifie.

par fon odeur \& molleffe fi on la rompt, ou fi on la brufle.

La Tac- Aymé Portugois en fes commentaires furle que ṅ' est premier liure de Diofcoride,en l'Enarration vingt pan le \& troifiefme,a fort bien remarqué,que la Lacque me de n'eft point le Cancame de Diof coride, comme SeDiofcori rapion a eftimé, la où il defcrit deux efpeces de de. Lacque,en ces termes.

Moyen Tous ceux qui ont eu opinion que le Cancame de difcer eftoit la Lacque, fe font trompés grandemens:veu nerla que le Cancame eft vne gomme odoriferante, \&la Lacque, dauec lacque foit qu'on le mente en des parfuns, foit Canca qu’óla mafche, n'eft recogneuë d'aucune fenteur: me. Celle laquelle les Portugois nous apportét des Indes pour le lourd'huy, qui eft de couleur rouge tranfparante,feruant principalemét pour les teinEturiers, \& de laquelle les appoticaires font vne certaine 
DES DROG. ET MED. LIV. III. IS

Lacque adberante à jes petits baftons.
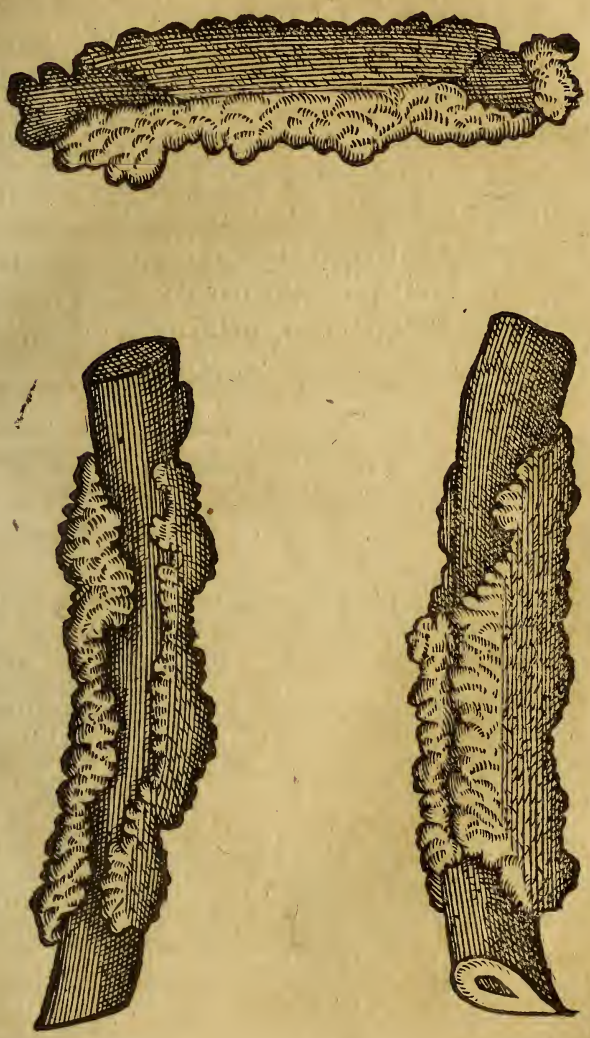

certaine compofition qu'ils appellent Dialaca, la- Dials. quelle comme nous fçauons certainement n'eft ${ }^{c a}$. 
I6 CHRISTOPHLE DE I A COSTE; pas vne gomme, ny vne larme de quelque plante, ains pluftoft vn excrement ou fiente de certains formis qui ont des aifles, comme la cire des auettes,\&c. Et peu apres: Il y a (dit-il) vne autre forte Lacque de Lacque artificielle, laquelle les teincturiers de artificiel draps vendët, qui le faict de la crafle \& lie du Brele. fil dit de Verzine, \& du vermillon: de laquelle fe son vfa-feruent pour la plufpart les peinctres pour faire ge. couleur rouge obfcure. Serapion confond fort mal à propos cefte Lacque auec la premiere:de là vient qu'auiourd'huy plufieurs par vn erreur fort impudent, trompés par l'auctorité de Serapion la meflent dans la compofition du Dialacca.

\section{Du Camphre.}

\section{C н A p. I V.}

Tablet - T'ay eu autresfois des Dames ou tables fort defres ou da liées auec leur boite dãs laquelle on les gardoit, mis fai- faites du bois de Camphre, comme on pouuoit aicles du fement cognoiftre par leur odeur,toutesfois elles
bois de cäphre ne resndirent iamais du Camphre, mais fi on les manioit, elle fentoyent tant feulement plus fort le Camphre.

EeCäfre Le Camphre de Burneo,dautant qu'il eft beaude Bur- coup plus cher \& plus excellent que celuy qui neo ef $l^{\text {e excel }}$ vient de la Chine, fe vend par Care (qui eft vne plent que forte de poids pefant vingt onces) \& celuy de la reiuy de Chine fe vend par Bares. Bar,eft certain poids qui lachine. eft de la pefanteur de fix cents liures: car la liure Cate, du Camphre de Burneo vaut autant que cent liBar. ures du Camphre de la Chine. 


\section{DES DROG. ET MED. LI V. III. I7}

$V$ eu doncques que fon prix eft $f i b a s$, il faut du tout reieter-l'opinion de ceux qui penfent que le Roy de la Chine le falfifie, veu qu'il eft vn des. plus Roy de puiffant Roy du monde : duquel, \& de fes prouinces,fi quelqu'vn vouloit parler, il luy faudroit efcri- tre? puif re vn grand voulume. Car fi l'on confidere la gran- Excellerz deur \& longue eftendue de fes terres, la frequence ce dis de fes fubiets, l'excellence de la police \& gouuer- Royaune fo nement, \& auffi fes grandes richeffes, il ny a en chine. toute la rondeur de la terre ancun empire, lequel puiffe eftre comparé à celuy de la Chine. Et ne fçache homme de fi grand entendemét qui fut fi haidi d'entreprendre d'ef crire vne Hittoire des chofes qui en ces contrées là font excellentes \& digned'eternelle memoire:veu qu'elles furpaffent tout ce qu'on en fçauroit dire \& raconter. Toutesfois fi quelqu'vn defire de fçauoir vne partis de l'infinité des chofe qui font dignes d'obferuatió en la Chine,qu'il life vn liture qu'en a efcrit le renerend pe-Gafpard re Gafpar de la Croix Moyne de l'ordre Sainet ${ }_{\text {Croix, }}^{\text {dels }}$ Dominique,

Authess

Et affin qu'en peu de paroles ie touche en paf- de l'Hifant quelques vnes d'entre plufieurs merceries qui stoire de font apportées de ce pays là, on en apporte de la vaiffelle d'argent de diuerfe efpece, enabourée \& Marcbä mife en @uure anec vn merueilleux artifice $\&$ di- font ap. ligëce,en outre tous vtenfiles de mefnage,comme portées lictieres, chalits ou petis lits à fe repoferfur iour, $\mathrm{Cle}_{\mathrm{ln} \text { e }}$ tous faits d'argent graué, \& tref-ingenieufement Vafa mis en cuure, grande quantité de foye grande Murthyn quantité d'or, mufc,perles, argent vif,du cuiure, de $x a$ la Mine,plufieurs vafes de Porcelaine, dont quel- Ce fone gues vins font eftimés au double du poids de l'ar- pesfaistes B B 


\section{CHRISTOS IE DE IA COSTE,}

"une cer gét:\& plufieurs autres chofes necelfaires pour l'vcertaine lage de l'hóme. I'en ay eu des eftuits d'argent mafcieufe, fif, garnis de tous les inftrumens de Chirurgie gui viët grans \& petits, comme font des fers ou boutons à d'Orient cauterifer, efprouuettes,efpatules, \&c. faits d'araume des gent auec autant d'artifice qu'on peut defirer d'auParthes, cun orpheure que ce foit.

boras

manie.

De la Manne.

CH A P. V.

Espece Vtreles efpeces de Manne defcrites par ce de Man ne quife vend exs Ormus. Sesver. quelle eft vn peu plus groffe \& nette, que celle sus. qui vient de Calabre, \& d'autant qu'elle eft beaucoup plus laxatiue que les autres efpeces, $\&$ à meil. Moyen leur marché,la populace l'eftime meilleure, $\&$ s'en dela gar fert beaucoup. On la doit fort foigneufement garder. der de l'humidité, autrement elle fe corromproit fort facillement. Or iay recogneu que ceftoit vn medicament compolé, en cefte maniere.

Il y auoit vn medecin Brachamane mien amy, habitant de Cochin, lequel fe feruoit fort de cefte forte de Manne, \& la loüoit grandemēt, difant que la vilitéde fon prix,n'amoindriffoit point fa bonté, \& qu'elle eftoit a bon marché, parce qu'il s'en rrouuoit plus grande quătité que des autres efpeces. Et dautant que ladicte Manne me fembloit eftre quelque chofe compofee, ie commençay à foupçonner qu'il compofoit ce medicament en fa maifon: 
DES DROG. ET MED. LIV. III. 19 maifon : car ie fceus vne fois qu'il n'auoit du tout point de Manne, \& vin peu aparauant il m'auoit dit,qu'on luy en apportoit d'Ormus, \& quelques i'ours d'apres il m'en monttra vne grande quantité de toute fraifche, qui eftoit en temps d'hyuer, $8 x$ lors que les vaiffeaux ne pouuoyent ny aller ny venir d'vne \& d'autre part. En fin ce bon B rachmane(apres luy auoir promis de n'en rien dire à perfonne, au moins en ces pays là)me confeffa que luy mefme la compofoit en la maniere qu'il auoit appris en Perfe, afçauoir auec de l'Amidon blanc \& Comms trefnet, de la Manne de quelque forte qu'elle fut, fe contre mais principalemét celle qui approchoir à peu près faifoit en bonté à celle de Calabre, de la Scamonée, \& vne te de forte de femence appellée Vifa, qui vient de Ben-Manne. gala, laquelle eft femblable à la feméce de l'efpurge(en y meflant aucunesfoys de la poudre d'vne certaine racine iettant laict appellé $\mathrm{D}$ ante)lefquel- $D$ ante. les drogues il mefloit auec du fucre, \& vn peu de quelque eau odoriferante, \& puis il l'expofoit aux rayons du Soleil pour la faire feicher.

Or il ne fe faut eftonner fil la Manne fe falfifie, Manne. veu que mefmes les pierres Bezar fe falfifient auec falffíée. tant d'artifice en Ormus, \& en la ville de Cochin, qui eft de la prouince de Malabar, où le Roy demeure, fi bien quelles femblët legitimes \& vrayes: $\&$ trompent les plus experimentés à les difcerner de premier abord, n'eftant pas en leur puiffance de les poiuuoir difcerner fi on ne les met en pieces. 


\section{CHRISTOPHLE DE IA COS TE}

\section{Du Tabaxir. \\ C H A.P. VI.}

Histoire $N$ troune parfoys de ces arbres ou Rofeaux du Taba appellés Mambu, dedans lefquels croift lè xir. Tabaxir,fi grands \& fi gros, que d'iceux on en fait Mansbu. des petis efquifs, qui contiennét deux hómes, non qu'ils les creufent,mais ils les f́cient par le milieu, en laiffant feulement deux nouds de part \& d'autre. Dans tels petis efquifs fe mettent feulement deux Indiès tous nuds(car c'eft leur couftume d'alVtilité ler tout nud en ce pays là)\& s'affeoyent chacun aux du Mă- deux bouts en ioignant les cuiffes, tenans en chafque main des auirons de la longueur de trois ou quatre empans, auec lefquels ils conduifent ces efquifs auec telle dexterité,que mefmes ils peuuent remonter auec vne grande vifteffe contre le fil d'vn fleuue rapide, cöme moymefine i'ay veu au fleuue Cranga Cranganor, fur lequel tels efquifs font grandement nor riuic en vfage, d'autant que ceux qui font dans iceux s'er. ftiment eftre plus en feurté contre lesCrocodilles, Crocodil qu'ils appellent, Caymanes, lefquels font en grand Zes,Cay- nombre dedans cefte riuiere. Car eftäs fort cruels, fouuentesfois attaquent \& fe ruent fur des nauires tant petites que grãdes, pour attraper ceux qui font dedans. Car fi, ou dans la riuiere, ou fur le riugage ils peutent happer vn homme, vn bœuf, vne vachesvn făglier,vn pourceau,ou quelque autre animal que ce foit, foudain ils l'engloutiffent. Ceux du pays affeurent, que iamais on n'a veu qu'ils attaquent ceux qui font portés dedans des efquifs faits de Mambu,mais que biê founet on lệs ayeu nageãs 
DESDROG. ET MED. L t V. III. 2t Mambu,oubien l'arbre appellé Tabaxir, de Acoffa.

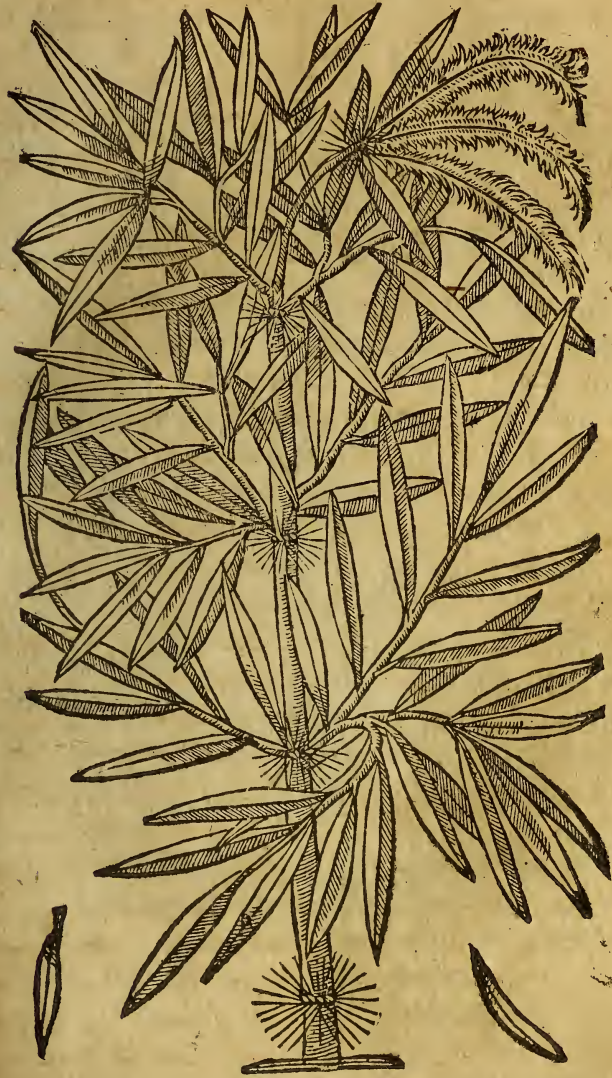

aupres d'iceux; \& que toutesfois ils paffoyét fans faire aucun mal.

B B 


\subsection{CHRISTORHLE DE LA COSTE:}

De l'Elephant.

Chat. vit.

seruice TEs Elephans font animaux d'vn grand feruice, ón hiftoi - non feulement pour tirer grands fardeaux , \& re des
Elephäs. changer le canon 8 autres inftrumens de guerre
d'vn lieut en autre, mais auffi pour d'autres feruices domeftiques.Ils ont acouftumé de lier auec leur trompe ( de laquelle il fe feruent comme d'vne maini)les fardeaux, d'vne groffe \& ferme corde prenans la corde auec la bouche, ils l'entortillent auec leurs dents fi il eft de befoin, lefquelles leur fortent hors de la bouche puis ils enleuent les fardeaux en l'air,ou les trainét s'ils font trop pefant, auec telle dexterité \& adreffe( principalement s'il y a quelque chofe aifée à caffer, ou qui fe puiffe efpancher) que telles chofes requierent: que fi ils ont vne foys fait vn chemin, il n'eft aucunemét befoin le leur monfter d'auantage, figrande memoire ont ils. On les conduict quelques foys en guerre: ayans la tefte \& la poictrine armee, à la faço des cheuaux bardés ou armés de toutes pieces, leur pédans plufieurs clochettes à la poictrine, \&font fanglés de fangles ou courroyes auec lefquelles on leur attache fur le dos des chafteaux de bois $\&$ outre ce, les foldats armés de toutes armes, qui font enclos dedās ces chafteaux, vn chafcun porte fon gounerneur, \& attache-on en leurs déts des ef pées ou faux, afin qu’auec icelles il puilfent tuer \& bleffer les ennemis : mais s'ils font bleffés, ils font voltê-face, craintifs, \& comme enragés, tellement 
DES DROG. E T MED. LIV. III. 2S

Figure des Elephans.

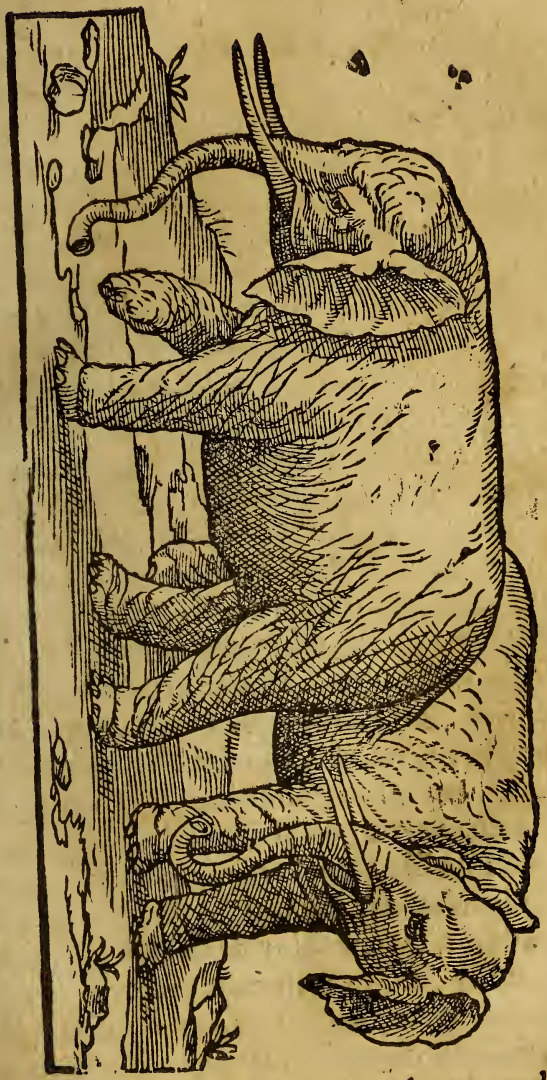

que le plus fouuent, ils rompent les rangs de leurs gens.

B B * 


\section{CHRISTOPHLE DE IA COSTE;}

Pline en plufieurs paffages du premier liure, ra conte beaucoup de chofes dignes de recit des Elephans:nous en mettrós icy quelques vnes des plus dignes de foy.

Elephăs L'opinion conimune eften la Prouince de Mas'enten- labar, que lés Elephăs s'entr'entédent les vns les audentl'vn l'astre. tres. Or il cölte \& appert par tefmoignage public, qu'il y en a eu vin qui autresfois a parlé en la ville de Cochin(qui eft vin de premieresvilles de la Prouince) en cefte maniere.

Us par- Vn certain Elephant couftumier de trauailler fint auf- au riuage de la mer proche de la ville, s'en retourgiuesfois. noit en la maisó las \& recreu du trauail pour repofer, le gounerneur de la ville le prioit de cótinuer fon trauail, \& qu'il trainalt dedans la mer vn vaiffeau qu'il auoit deja commencé à remuer : ce que l'Elephãt refufant, le gouuerneur le prie derechef, \& l'amadoue par belles parolles qu'il fit cela pour lamour de luy, car il eftoit ainfi feant, veu quil eftoit auferuice du tref-Chreftien Roy de Portugal. L'Elephant proferant ces deux mots boo boo (qui en langue Malauarique commune \& vfitée en cefte Prouince, en laquelle l'Elephant eftoit nay, fignifient, ie le veux, ie le veux) s'en retourna au vaiffeau \& le pouffa dedans la mer.

Le mefme Elephant, vn iour que fon gouterneur ne luy donnoit à manger à fon heure accouftumée, il fe plaignoit à luy de ce qu'il tardoit aina fi:fon gouuerneur luy refpondit que cela eftoit aduenu parce que le chauderon dans.lequel il auoit accoufumé de cuire fon manger, eftoit perçé, \& partant qu'il le portaft au chauderonnier pous le racoufrer.L'Elephant le porte. Le chauderonnier

ne le 
DES DROG. E T MED. L I V. III. 28 ne le $r^{3}$ habille pas bien : le gouuerneur reprend \&c dit iniure à l'Elephant, \& auec le chauderon le renuoye au chauderonnier pour le mieux rhabiller: iceluy feignant tout exprés de le bien r'acouftrer, accroift le trou, \& le rend à l'Elephant, lequel empoignant le chauderon auec fa trompe le porte en la riuiere \& le remplit d'eau, \& voyant qu'il refpadoit, il cogneut qu'il eftoit beaucoup plus perçé que auparauant, \& partant le rapporte au deuant de la maifon du chauderonnier hurlant \& criant. où ceux qui auoyent en charge les affaires du Roy, \& plufieurs autres accoururent: le chauderonnier flattant \& amadouiant par belle parolles l'Elephát, luy demanda pardon, luy racoutra fort bien fon chauderon, \& le luy rendit:iceluy ne s'y fiant point, retourna à la riuiere à le veuë de tous, puyfa de l'eau; \& voyant qu'il ne refpandoit point, le monftrant aux affiftans, comme sil les euft voulu prier d'eftre tefmoins de cequi s'eftoit paffé,le rapporta à fon gouuerneur. 11 eft de nature recognoiffant, \& Les Elequi fe foumient d'vn bien fait, \& ne porte nuifance phans à perfonne finon qu'on luy face iniure, ou quand il tifs dis eft faifi d'vne certaine maladie, par laquelle il eft bië fäiz. comme tranfporté de furie, ce qui aduient toutes Maladie les annees:car en ce temps là ils n'efpargnent per- $\frac{\text { des Ele- }}{\text { phans. }}$ fonne, \& foulent tous ceux qu'ils rericontrent.

Il aduint en la ville de Goa, ou demeurent ordi-Goa vilnairement les Lieutenans dit Roy de Portugal, le. qu'vn d'entre les Elephans du Roy eftant faifi, de telle maladie, rompit les chaifnes \& les liens, defquels il eftoit lié(car on a de couftume de les attacher auec des chaifnes de fer, \& de les ferrer en quelque lieu,iufques à ce qu'ils foyent deliurés de B B S 


\section{CHRISTOPHIE DE IA COSTE,}

cefte maladie)\& couroit par les ruës; comme cha. cun fuyoit deuant luy ${ }_{2}$ il rencontra en la rüë vn efclaue qui portoit vn petit enfant entre fes bras, le. quel ef́pouuenté de voir cert Elephant, s'enfuit visftement vers fa maifon, où ayant pofé ce petit enfant deuant l'huys pour ouurir fadite maifon, $\& \mathrm{e}$ ftant entré foudain dedans icelle, ferre la porte, \& de crainte oublia dehors ce petit enfant:'Elephant aperceuant cefte petite creature, la foubs-leua doucement auec fatrompe, \& la mit fus vn toict bas, qui eftoit vis à vis de cefte maifon, \& puis regarde fi c'eft enfant pourroit demeurer là fans aucun dáger,d'ilec tout enragé \& furieux paffa outre:\& encores bien qu'il fuffe en furie, fi demonftra il qu'il eftoit memoratif d'vn bien fait reçeu, n'ayant voulu tuer ce petit enfant,mais il recóneuft que c'eftoit lé fils d'vne femme laquelle demeuroit en cefte maifon là, \& qui auoit accouftumé de luy donner à luy \& à tous les autres Elephans domeftiques, du paiin ou fruict, toutesfois \& quantes qu'ils palfoyét par là.Car elle vendoit au deuant de fa maifon des fruicts, \& autres telles denrées.

Ie raconteray vn autre exemple de recognoiffance.Il y auoit vn Elephät qui couroit parmy vne place de ladicte ville, eftant en femblable furie, \& ayant par cas fortuit rencontré vn homme malade qui s'en voulant fuyr tomba en terre tout à plat. l'Elephant fans luy faire mal, le prend auec fa trópe,\& le mit fus vn certain banc. C'eft homme du defpuis affeura qu'vn peu au parauant qu'il tombaft malade, il auoit donné de fa propre main, au mefme endroit, \& au mefme Elephant, vn cer- 
DES DR O G. ET ME D. LIV. III. 27 tain gros fruict nommé laca, duquel nous parlerons lacs cy apres.

Dans la ville de Cochin y eut auffi vn Elephant qui agité de mefme furie, s'eftoir retiré dedans vn marés ou folfé proche de la ville, auquel comme quelques petis enfans furent par fortune venus, apres auoir veu c'eft Elephant fe mirent en fuitte, excepté vn qui s'arrefta là:l'Elephăt s'approche de luy en l'amadoüant \& comme flattant l'empoigna tout doucement auec fa trompe, \& le iette fur fon dos,puis le promena par tout le marés ou folfé, \& le remit au mefme lieu,où il l'auoit pris comme tout ioyeux. J'enfant racontant ce qui luy eftoit aduenu,plufieurs perfonnes luy firent compagnie;mais fe tenans elloignés dudit marés, ils monterent fur des arbres, à fin de voir en feurté ce qui fe failoit. L'enfant s'approchiant de plus pres, l'Elephant le prend \& mer fur fon dos comme au parauant \& le promena. Il fit cela par plufieurs \& diuerfes foys, iufques à ce qu'auec belles parolles(comme or luy auoit enfeigné) il rendit l'Elephant du tout appriuoifé, \& le r'amena dedans la ville.

Auant que les Elephans tombent en celte furie d'amour,leurs gouverneurs ont acconfumé de Indicede les mener aux champs, \& les y attacher auec des lamalafortes chaifnes de fer:car ils ont pour indice de ce- die ou fte furie, vne certaine matiere oleagineure quileur furesr, coule parles oreilles. Or ils font gueiris de ceite ó lesremaladie par leurs gouuerneurs, quiles reprennerit auec parolles aigres(car ils comprennent \& entendent fort bien) \& auffi leur donnent à entendre par viues raifons, que c'eft auoir le cour lafche \& abiect, que d'entrer en telle furie pour l'amour : puis 


\section{CHRISTORHLE DE L COSTE;}

ils leur font prendre certains medicamens vfités en ce pays là.Le plus grand chaftiment qưils ayent c'eft de les tencer auec parolles picquantes \& iniurieufes, encores que par fois on leur falfe leuer haut les pieds de deirant, les plantes defquels ils leur picquent auec des vergettes de fer,leur difans qu'ils les chaftient conmme petis enfans pour leur folie.

A caufe de cefte furie veneriéne laquelle trauaille tous les ans les Elephans, quelques vns difcourent par raifons, que les femelles font leur portee de douze moys : car leurs gouuerneurs $\&$ autres gentils, nont rien peu affeurer de certain touchant le temps qu'elles faonnent, encores que ie m'en fois enquis fort foigneufement.

Or Alian \& autres qui ont effrit de la nature des Elephans, ont eftimé qu’elles portoyent vn an \& demy, ou deux ans. Les habitans du lieu où ils naiffent affeurent que chafque Elephant a fa femelle particuliere, fans qu'il fe mefle auec les autres:non pas mefmes auec leurs femelles d'efpuis quils les recognoiffent eftre pleines.

Defa- Les Elephans font auffi defireux de gloire \& $z$ reux de d'honneurs, pour lequel on les void parfois faire
gloire. des actes fignalés. $N$ 'a-on pas veu vin Elepant s'eftre creué par le milieu au riuage proche de la ville de Goa, voulant foulleuer vn gros double canon, à caufe que fon gouuerneur l'auoit repris aigremét, \&luy auoit dit plufieurs iniures, luy monfrant d'eux ieunes Elephans qui venoyent pour leuer ledit canón?

Or tout ainfi qu'ils fe foumiennent des bien faits receus, \& font coumoiteux de gloire, auff font ils grande 
DES DROG. E T ME D. I I V. III. 29 grandement vindicatifs, ainfi que peuuét faire foy les chofes qui font aduenues en la ville de Cochin. Vncertain foldat ietta contre vn Elephant apriuoifé vn Cocus ou Noix d'Inde, \& l'attaint au frōt, l'Elephát recuillit la dicte Noix d'Inde, \& voyant que pour l'heure il ne poutuoit venger l'iniure qui luy auoit efté faicte, il la cacha dedăs fa gueule,iufques àce qu'apres quelques iours, il apperceut ledit foldat qui fe promenoit en vne certaine place: alors il fortit de la gueule la Cocque d'Inde aúecla trompe, \& s'eftát approché de luy, la luy ietta contre, \& puis s'en va comme tout ioyeux de s'eftre vengé de l'iniure qui luy auoit efté faite.

En la mefme ville auffi il fembla à vn Elephant qu'vn certain foldat ạuoit fait tort à fon gouuerneur, parce qu'il ne luy voulut point ceder fe rencontrans au chemin. L'Elephant defireux de venger ce tort, fon goumerneur le tuy deffendit.Quelques iours apres comme il trauailloit au bord de la riuiere de Mangate ( qui paffe tout au long de la ville de Cochin) \& que foin gouuerneur n'y eftoit point, il apperçeut ce foldat deuifant auec d'autres il l'empoigna auec fa trompe; \& fans efcouter les prieres de ceux qui le prioyent de laiffer ce foldat, ille plongea par plufieurs foys dans l'eau, l'efleuant coup fur coup en haut,iufques à tant que l'eau dóe il eftoit trempé, fe fut efcqulée:en fin comme il luy fembla d'eltre alfés végé du. tort fait à fon gounerneur, il remit derechef ledit foldat fus pieds au mefme lieu où il l'auoit pris.

Or d'autant que tout ce qui a efté icy traicté des Elephans, eft le plus vray d'entre toutes les referches qu'on en peut faire, ie lailfe les chofes que

Matthioke 
30 CHRIS TOPHIE DE IA COSTE, Matthiole \& plufieurs autres ont efcrit. Noftre rrefdocte Garcie du Iardin a fait auec grand foing \&z diligence des Commentaires tant de l'Elephant que de plufieurs autres medicamens qui font ap. portés des Indes en l'Europe, ce qu'il a fait fur le rapport d'autruy pour la plufpart, \& moy (le leoteur en iuge) pour l'auoir veu moymefmes. Car pour en auoir le pourtrait au vif fur les mefmes lieux où telles chofes croilfent, ce n'a pas efté fans Nosto danger de ma liberté \& de ma vie,tant pour celles Ausheur que ie recite en ce traicté, que pour les autres dont a efrit ie traicteray en vn autre volume que iay entre on autre mains, où $i$ efpere defcrire le refte des medicamés, lisre. plátes, oyfeaux, \& $x$ beftes à quatre pieds qui fe trouuent en ce pays là.

Ie pourrois reciter en ce lieu beaucoup d'hiftoires vrayes femblables à celles cy, lefquelles ie laiffe pour nieftre troplong. Que ceux qui ne fe contenceront de ce que nous en auons dit, lifent ce que Ariftote,Pline, Aelian, Oppian \& plufieurs autres Atheurs ont efcrit des Elephans.

\section{De la Canelle. \\ C н A P. VIII.}

T'Arbre de la Canelle eft de la grandeur d'yn Histoive LOrengier, aucunesfois plus grãd,aucunesfoys we la ca plus perit, fort branchu, duquel les rameaux plus Ear de tendres font droits, fes feuilles font femblables à Cansle. celles du Laurier, plus larges toutesfoys, de couleur vn peu plus claire, \& moins feiches, marquees de trois nerueures: fa fleur eft blanche, n'ayant prefque point de fenteur:fon fruit eft fauuage, fembla 
DES DROG. E T MED. LIV.III. 3 I

L'arbre de la Canelle de Acofta.

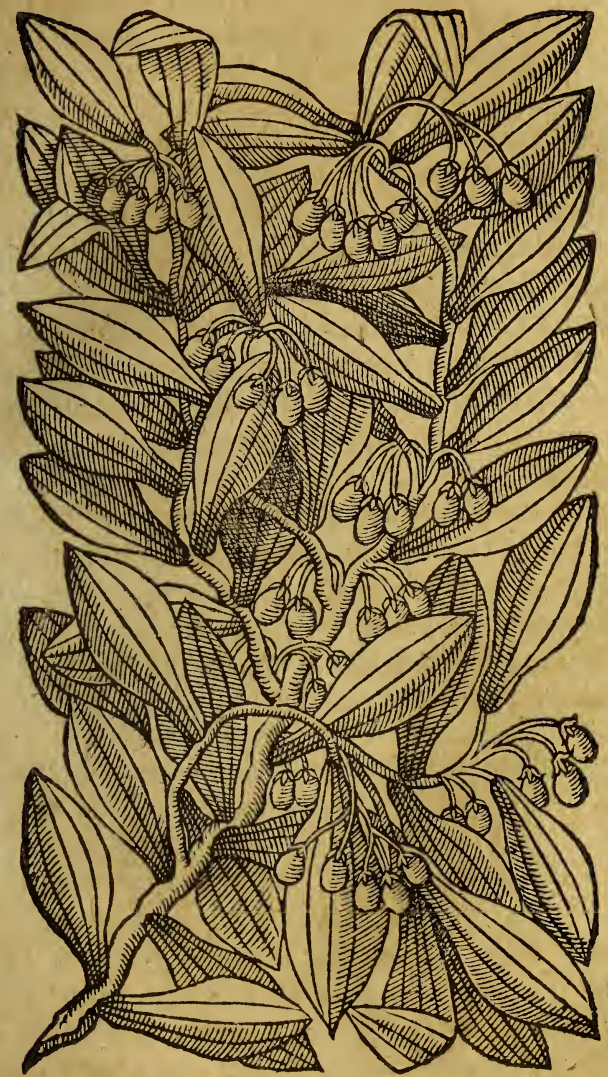

femblable aux oliues baftardes, verdoyảt au commencement $\&$ roux fur la fin, \& ayant atteint $f_{2}$ parfaide 


\section{CHRISTOPHLE DE IA COSTE;}

parfaicte maturité, il deuient noir \& reluyfant (c'eft en ce temps là qu'on le doit cueillir) conte. nant dans foy vn petit os femblable aux oliues fauuages, \& ayant vne chair toute femblable, delaquelle defcoule vne certaine liqueur oleagineufe, aucunefois verde, de l'odeur des bayes de Laurier, d'vne faueur acre conioincte auec vn peu d'amertume : ce fruict icy du cofté qu'il eft plat, eft attaché auec vne petite coppette plus lifee, \& moins crefpuë, que celles qui viennent aux chefnes, \& qui tiennét les glands atțachés. Il y a vne grande quã.rité de ces arbres dans les forefts de la Prouince de Malabar, mais en bóté \& fenteur,ils font moindres que ceux qui croiffent en l'Inle de Zeilan.

Qúand à l'eau diftillée de la Canelle, extraicte en desalambics de verre, ou de plomb, cefte là eft la meilleure laquelle a êté tirée de l'efcorce verde, principalement des racines couppées en petites Ses ver-pieces:car elle ne cóforte pas feulement la foibleftus. fe de l'efromach, \& les douleurs du colúm prouenătes de caufe froide, mais elle fait viner, \& fi faict bóne haleine:outre plus elle eft profitable aux maladies du foye, de la Rate, du cerueau, \& des nerfs, comme aufli aux Syncopes \& deffaillances du cour:elle refifte aux venins, aux morfures des animaux veneneux, elle efmeut les puígatiós naturelles des femmes, elle eft aufi propre aux maladies dala matrice, elle empefche les vomiffemens \& ouure l'appetit:elle eft auffi vtile cótre les fpafmes $\&$ mal caduc, \& pour le faire court, elle incife, digere, efchauffe, \& corrobore.

On tire auffi par diftillation de l'eau des fleurs de Cancl 
DES DROG. E T ME D. LI V. III. ; 3 Canelle, mais en beaucoup moindre quantité, $\&$ de moindre vertu que la fuldicte.

\section{A N NOT A T I O $\backsim s$.}

Quifera curieux de f̧avoir d'anantage de la Canelle, quil life le Chapitre is. du prernier liure de Garcie du Iard in:fenlement diray-ie, que quel gues curieux pourroit demander que nous n'auons point faicte de diftinction du Caffia lignea d"anec la Canelle, parce qu'il y a quelque apparence que ce foit vne efcorce differente de l'autre.

Qu and à moy ie Juis de l'opizïo de Garcie du Iardin, quil ny a qu'vne forte de Canelle, que la bonté ou election de l'vne plus que de l'autre vient de la region ó prouince qui produict les arbres quiles nous fourniffent.

Auffi bien void on de la Cafjia lignea meilleure l'vne que l'autre:tout de me me en ponnos nous dire de la Canelle, les feules regions où elles naifsĕt en font la differéce.

Encores faut-il en pajant que ie refute l'opinion de Cathelan apotieaire de mont-pelier,leguel en la page 177. Se feruant de l'autborité de Galien, qui au defaut du Cinnamome, mettoit au double le Caffia lignea, dict quil a faitt des long voyages, pour la cognoij]ance d'icelle; on ne troune point pourtant qu'il aye voyagé en Zeilan, d'ou eft apportee la meilleure Canelle.Il dict pour ces raifons qu' il vaut mieux conclure que le Cinnamome eft perdu parle malbeur dutemps, cornme plufieurs autres chofes rares, qui neantmoins fe trouuent (cornme $i$ ay dit cy deuant à la fin de mó liure du Baume) que de croire à Garcie du Iardin, autbeur moderne of te fmoing oculaire voulät fortifier fon opinion, pour dire grion embaulmoit les corps ancienemêt anec le Cinnamome, qui furpafjoit par fon odeur toutes les autres drogues plus exquifes que l'on y mettoit pour refuter, cefte opinion ie n'ay autre chofe à luy dire, finost que les corps des grands potentats, 'embaulmoit tant fertlernêt auec Baulrne, Myrrbe, ơ Aloës:o diutout point auec le Cinnamorne.

c C 


\section{Du Santal.}

\section{С нат, IX,}

CEfte forte de bois odoriferant quicroift en Malabar, du tout femblable au Santal blanc, duquel les habitans du lieu s'oignent quand ils ont Sambo- la fiebure, \& l'appellent Sambarane, n'eft pas Santal, rane. \& n'a pas auffi les facultés d'iceluy : toutes fois les, medecins de cefte prouince là , affeurent que c'eft Efpece vne efpece de Santal, \& qu'il profite aux hommes de San- de petite eftoffe, \& en font grăd cas contre les erypre aux fipeles \& inflammations, \& s'en feruent de mefme pre aux que du Santal rouge. Quand à ce qu'Antoine Mumations fa tient que nous receuons le Santal des Portuón Erifí gois, il dit tres-bien:mais il fe trompe grandemét, peles. quand il dit qu'il en croift au territoire de Calecut, ou les montaignes hautes \& inacceffibles abondent en Elephans, porcs fangliers, tigres, onces, bafilics \& autres efpeces de ferpens, \& beftes fauuages : \& le plat pays fablonneux eft remply de Palmiers, ou arbres portans les noix d'Indie: \& non d'aucun Santal. Certes on auoit bien accouAtumé ancienniement, de l'aller querir en Calẹcut, lieu fameux \& celebre pour le traffic:Car on y apportoit toutes fortes de marchandifes precieufes, des autres contrées d'Orient. Et les marchands de 1a Chine tref-puiffans \& opulens qui faifoyent traffic fur cefte mer Indienne, auoyent en ce lieu là des grands magafins (qu'encores auiourd'huy on appelle Chinacota) dans lefquels ils ferroyent leurs marchandifes, \& entre celles le Santal apporté de Malaca, 


\section{DES DROG. E T MED. L I V. III. 35}

Malaca, lefquelles ils vendoyent par apres \& diftribuoyent en autres contrées.

Mais apres que les Portugois qui du commencement prenoyent port en Calecut furent proditoirement affaillis \& prefque opprimés par le Roy \& par les habitans de la ville, ne fe fians à l'inconftance \& mefchanceté de cefte nation, fe retirerent pour plus grande feurté vers le Roy de Cochin,qui non feulement les receut humainement, mais auffi les garda \& deffendit fort vaillammét.Pour lequel bien-fait les Portugois luy rendirent bien la pareille:car ayant ruiné Calecut, ils firent le Roy de Cochin le plus puiffant Seigneur de Malabar, \& encores pour le iourd'huy ils ont vne tref-eftroite amitié auec lay. De cecy eft aduenu que la fplédeur floriffante, le celebre renom \& traffic de Calecut perduë, \& toute la nobleflè de cefte contrée à efté confumée: \& les Portugois font maintenant Seigneurs de cefte Prouince. Nous ne fommes donc pas moins redeuables à ceux cy, à caufe de leurs longues nauigations qui nous ont defcounert tant de mondes, d'ont on nous apporte \& auons la cognoiffance, d'vn fi grand nombre d'excellens medicamens, \& de plufieurs marchandifes de tref-grand prix,qu’a Ptolomée pour fa doctrine \& defcriptió d'icelles. Mais on pourra voir quelque chofe d'auantage touchant les affaires de Calecut, dans l'hiftoire des Indes.

Or les plus fameux lieux de traffic des Indes font auiourd huy,les villes de Cochin \& de Goa, qui fourniffent maintenant à toute l'Europe, \& autres Prouinces, toutes ces merceries des Indes, 


\section{CHRISTOPHLE DE IA COSTE}

\section{A NNOTATIONS.}

Piece de En l'année 1581. Huigues Morgan apoticaire trefexpert Sanial de Londres,me fit pre fent d'une piece de Sätal citrin trefCirrin. excellent,pe fant vne liure, comme iay fait mention en mes Commentaires fur Garcie. Il eft pe fant, folide, plein de noends, de couleur iaune au dedans; recreant le cerueau aues vne odeur fonëfue, \& adouciffant le palais d'vne faueur agreable.

\section{Du Betele. \\ C н А P. X.}

Defcri-

pition du Betele.

A plante du Betele eft fi femblable à celle qui 1 porte le Poyure en fermens, feuilles, \& en la façon de naiftre, que eftans cultiuées l'vne pres de l'autre, à grand peine ceux qui ne les cognoiffent, tres-bien, les peuuent ils difcerner de loing:car elle monte \& s'étortille aux arbres aupres defquels elle eft plantée, tout ny plus ny moins comme fait le Poyure:fa feuille eft vn peu plus efpoiffe que celle du Poyure, mais elle luy eft du tout femblable en grädeur, en nerueures ou en fibres. Les Turcs l'appellent Laprach Industani.

Il eft aromatique,robore le cœur \& le ventricule, diffipe les ventofités, purge le cerueau \& l'eftomach, mafché au matin à ieun auec du Cardamome, \& fait bonne haleine.Il eft en grande eftime en Mofambique, contrée de la Chine, \& en Sofala, où il n'en croift point à caule de la froideur $\&$ intemperie de l'air : \& en ceftuy cy $\&$ autres à caufe des grander 
DES DROG. ET ME D. LI V. III. 37 grandes chaleurs:car cefte plante requiert les contrées temperées \& proches de la mer.

De la Noix Mufcade, of de fa fleur.

\section{H A. XI.}

Efte noix eft femblable à vne poire, vn ped plus ronde, ayant la derniere pelure charnue \& aucunement dure, dont les habitans de l'Ine de Bădan n'en font pas grand eftat, fi ce n'eft que aucu- $1 / e_{0}$ nefois ils la mangent toute verde auec fel \& vinaigre, parce qu'elle eft d'vne faueur fort agreable $\&$ altringente.

Les Portugois confifent en fucre la noix toute entiere, lors quelle n'eit pas encores meure:car outre fon odeur fouéfue \& bon gouft, marques, pour lefquelles elle eft recerchée: les medecins Indiens \&les Brachmanes s'en feruent beaucoup en toutes maladies froides du cerueau, aux paralyfies, \& autres maladies des nerfs, \& de la matrice. Ils font plus de cas des plus groffes noix que nous ne faifons pas.

On fait auffi en cefte mefme Ifle de Bandan vn huile de Macis, lequel eft fort recommandé aux maladies des nerfs, $\&$ autres maladies froides.

On rireaufl de l Noix Mufcade batrue efchauf de la On tre aufl de la fée $\&$ mife au prefloir,vne liqueur fort fouc fue \& $m$ m $\int$ cade ville aux maladies froides des nerfs:car elle adou- ó fes cift la poictrine \& le poulmon, d'où elle rend la proprievoix plus claire, fait deuénir gras, \& augmente le ${ }^{t e z}$ fperme. Les Axabes appellent la Noix Mufcade Iarifi-do, Mu fes Huile de $\mathrm{CC} 3$ 
38 CHRYSTOPHLE DE IA COSTEg

Figure de la noix mufcade magle.

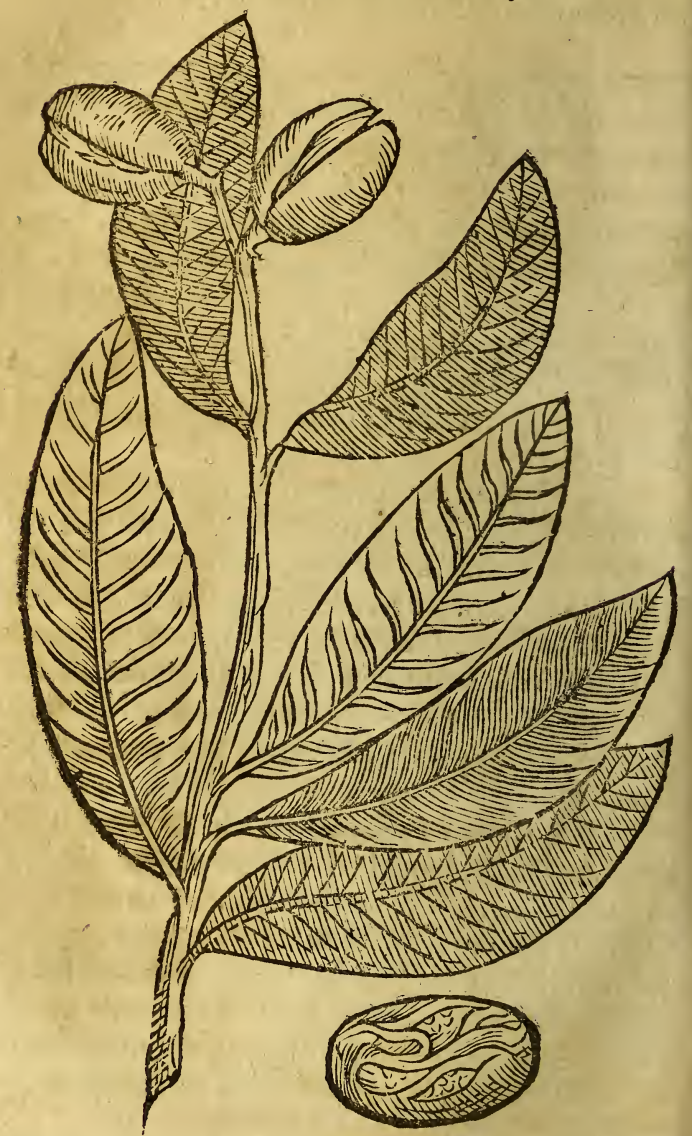

band, \& Seigar. Et le Macis Bisbele, of Besbaca, lequel 
DE S D ROG. E I ME D. L I V. II I. 39

Figure de la noix mufcade fernelle.

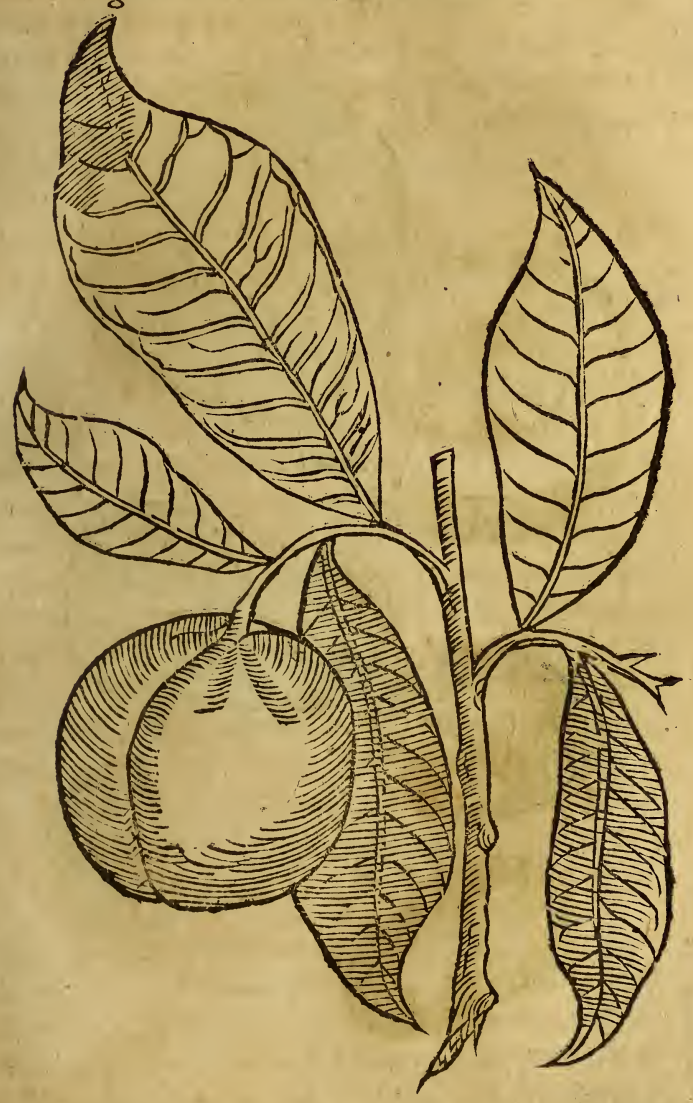

quel mot fignifie proprement efforce de noix. Les Diuerfes Perfiens appellent l'arbre Drach les Turcs Agache: inpellaC C 4 
40 CHRISTODHZE DELA COSTE, Figure de la noix mufcade verde couppée.

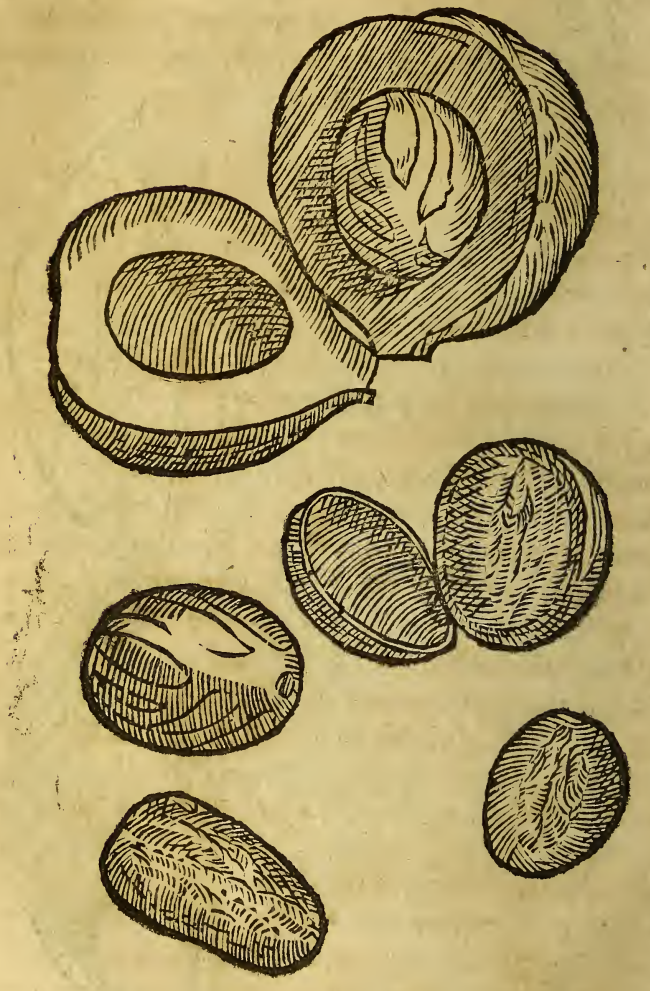

a Mus- Les Arabes appellent l'huile de Macis Geuffarami, ade. Les Perfiens Genfierugant, les Turcs Genziat. 
DES DROG. ET MED. LI V. III. $4^{\text {I }}$

Il n'y a point de doute que ce Macis ne foit gran- Differes. dement different du Macer des Grecs, fi nous cóf1- ${ }^{-}$e $d u$ ire faculté de l'vn \& de l'autre Macisas nous traicterons du Macer au chapitre fuyuant. Ie des ray icy fait adioututer la figure de la noix mufcade Grecs. malle \& femelle, \& de la verde couppée.

\section{A NNOTATION.S.}

I'ay veu autresfois l'buile de Macis ou defleurs de Mufcade apporté des Indes dedans des grands pots de terre quion tenoit à fort baut prix, \& eftoit fort loüé pour les maladies froides du ventricule. Il estoit efpoiffi $\%$ formé à la maniere du fauon de France, en forme de tablettes efpoiffes \& larges, qui pe foyent enuiron trois onces, graffes, iannaftres, of odoriferantes. I'ay vew auffi à Londres en cefte année 1581.en la maifon de maiftre Hugues Morgan apoticaire tref-dodte 0 diligent perfonnage, fort courtois ๙o bumain, cefte forte d'buile fraifchement apporté des Indes, lequel me fit prefent de quelques tablettes de ceft buile; de l'buile de Baulme des Terres neufues, d'buile de Liquidambar, anec quelques autres fimples fort rares.

\section{, Du Macer de Acofta: \\ C н А P. XII.}

T L croift en certaines ifles Orientales, principale- Hiftoire 1 mét en la prouince de Malabar,\& en l'ille Sain- cer. cte Croix,qui eft du Royaume de- Cochin,comme Iflefainauffi du long des bords du Heuuc Mangate, \& de Cranganor, vn certain grand arbre \& branchu, \& Groix. beaucoup plus grand qu'vin Omeau, les feuilles duquel font fix ou fept onces de longueur, largès de 


\section{CHR IST O PH L E D E I C OSTE,}

de deux, d'vn verd clair en dehors, \& d'vn verd brun en dedans.

On tient que c'eft arbre n'a autre fleur ny fruict, qu'vne certaine femence de la grandeur d'vn denier, defliee, faicte en façon de cour , de couleur iaune, du gouft des amandres, ou d'vn noyau de pefches,enuironnée d'vne counerture deflice \& blanche, laquelle eft enclofe d'vne certaine vefcie, cópofée de deux membranes ioinctes enfemble, fort deflices, lucides \& tranfparantes. Or cefte vefcie croilt au milieu de la feuille, ne refiemblant point mal en groffeur aux autres, finon que elles, ne font pas fi poinctues, \& font vn peu plus eftroidtes vers le pecoul,de couleur entre rouge $\&$ iaune inefgale,\& ayant plufieurs fibres qui prennent en droicte ligne defpuis le pecoul iufques au haut,crefpeluë \& ridée, retirant à celle de l'Omeau, vn peu plus larges toutesfoys \& plus vnies.

C'eft arbre eft rempli d'vn fuclaictetix comme le Meurier, ayant des racines comme le Chefne; grandes, grolles \& efparfes en large \& profond, counértes d'vne groffe efcorce \& dure, de couleur grife par dehors, \& par dedans blanche, remplie d'yn fuc de laict, mais tandis qu'elle eft recente, \&quand elle eft deffeichée, iaune \& fort aftringente : \& encores bien que ce fuc foit vn peu mordicant auec vne aftrinction, toutesfoys celte certaine infenfible mordication s'efuanouit tout auffi toft.ll fe plaift attx lieux fabloneux \& humides, faifant Diueres mourir prefque toutes les autres plantes qui luy appella- naiflent aupres,

tions $d u$ Le nom commun de c'eft arbre entre les PortiMacer. gois eft, Arbore de las Camaras, \& Arbore Sancto, c'elt 
DE S DROG. E T MED. LI V. III 43

Macer de Acofta.

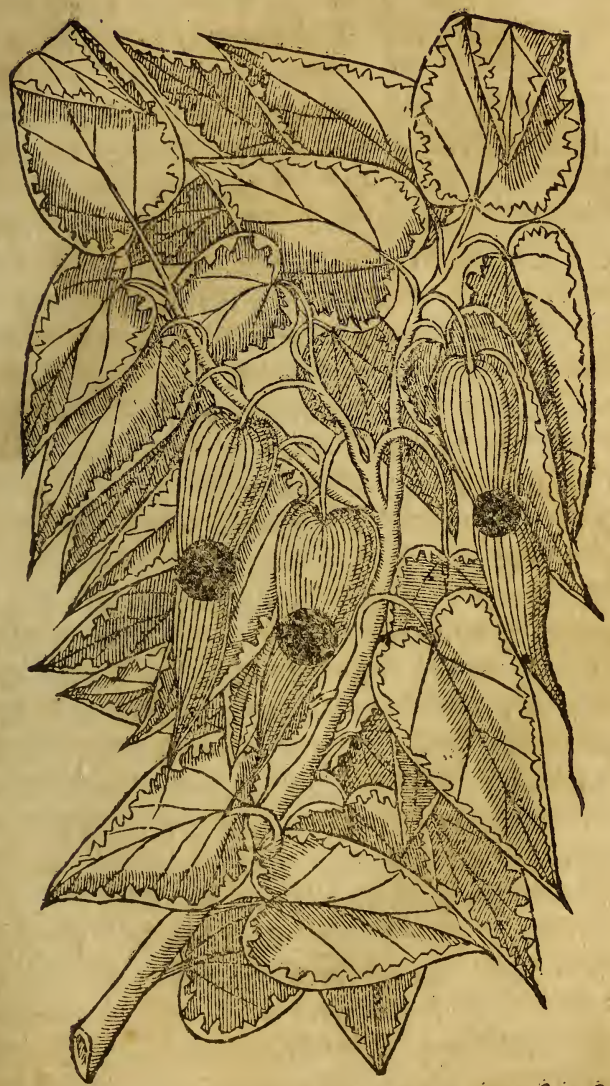

ceft à dire arbre de diflenterie, \& arbie fainct:par les Chrefiens qui font venus habiter là, il eft nommé 


\section{CHR IS TOPHIE DE IA COSTE,}

nommé Arbore de Sancto Thome, c'éf à dire arbre de Sainct Thomas \& Macruyre : les medecins Brach manes Macre, lefquels font grand eftat de fon efcorce.

L'efcorce Les Medecins Brachmanes de Malabar, \& de cine $d u$ Canarie, gueriffent toutes fortes de diffenteries \& Macer thux de ventre fort heureufement, auec l'efcorce profica- recente de la racine de ceft arbre mife en poudre, ble aux anec d'oxygale ou laict aigre. Quelques vns dediffente- frempent le long d'vne nuid, demy once de cefte flux de efcorce feiche \&z mife en poudre, auec quatre onventre. ces de petit laict, \& en font prendre deux foys le iour, foir 2 matin : apres cefte prife, ils leur font manger tout incontinent du riz cuict fans fel, \& fans beurre, \& des poulets cuicts en la decoction du riz:\& aucunesfois fi la neceffité preffe, ils y adiouftent vn peu de l'Opium, pour corroborer le medicament: les Arabes auffi ont accouftumé de guerir toutes fortes de flux de ventre auec de l'O.

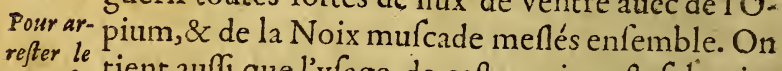
vefter le tient auffi que l'vfage de cefte racine eft falutaire ment. pour arrefter les voinillemés, \& corroborer l'eftomac, prinfe auec eau de méthe \& poudre de maftic.

Vn medecin Brachmane mien amy, homme de bien, de bon iugement, bien renommé parmy Cité de rousles habitans de la ville de Saincte Croix du Saincte Royaume de Cochin, tant gentils que Portugois, Croix. parce qu'ils s'eftoyent foument feruis de fa fidelité: prié d'expofer fidellement les facultés de cefte Macré. efcorce qu'ils appellent Macré, refpondit en ces mots: fi vous autres Portugois cognoiffiez bien cefte efcorce, vous en feriez beaucoup plus grand eftat que du poyure : mais parce qu'en ce pays de Portugal 
DES DROG. E T D. LIV. III. 45 Portugal vous ignores fes facultés, voila pourquoy vous n'en tenés compte. La poudre que i'ay accouftumé de faire prédre auec du laict aigre en toutes fortes de flux de ventre, eft compolée de cefte efcorce, de laquelle vous vous enquerés.

Ie t'en pourrois montrer vne grande quantité en ma maifon, laquelle ie veus enuoyer en Bengala \& Iapan. Tu peux iuger toymefme fi ceft vn medicamét inutile, car tu en as veu fouuét des effects.

Ie montray auffi cefte ef corceà vn certain $R i$ fotome Iogue (c'eft vne forte de charlatans, lefquels en voyageant font profelfion en ces pays là de faire penitence)\& luy demanday que celtoit(encores que ie le fçeuffe fort bien)il me refpondit que ie le fuyuiffe, \&\& qu'il me feroit voir l'arbre d'où fe tiroit cefte efcorce : \& me móttra c'eft arbre q́ ie fçauois auparauant, \& adioulta, en nos quartiers, dit-il, on l'appëlle Cura Santea macré niftu fa garul. c'eft à dire Macré monftré par les Anges aux hömes pour leur falut. Il me dit dauantage qu'entre eux on fe fernoit de cefte efcorce pour arrefter les flux de ventre \& autres vomilfemens, \& qu'vne petite quantité de celte efcorce, auoit beaucoup plus de vertu qu'vne grande quantité d'efcorce de Myrobalans ou d'A reca, \& qu'elle eft plus excellente que le Coru de Malabar, duquel nous parlerons cy apres. Il difoit dauantage que le fruit du Macré faifoit mourir, \& iettoit hors du corps de l'homme toutes forces de vers qui s'y engendrent, \& aufi qu'il rompoit la pierre dedans les reins: $\alpha$ que ceux qui en prendroyent tous les matins, feroyent exempts de la pierre, \& douleuts coliques; \& ne pourroyent eftre enyurez, 


\section{CHRISTOPHLE DE I A COSTE,}

Il y a vne grande controuerfe entre les moder= nes, afçauoir-mon fi les Grecs ont eu cognoilfance du Macis, \& les Arabes du Macer. On ne peut nier que pour le prefent nous ne cognoiffions beaucoup plus de medicamens que le anciens : ny que plufieurs chofes n'ayent efté cogneuës, defquelles nous fommes en doute. Car c'elt vne chofe tres affeurée que les Grecs ont fort bié cogneule Macer dont nous doutons, \& eft encores incogneù à plufieurs, \& qu'ils n’ont pas eu la cognoilfance du Macis, ny de la Noix mufcade, que nous cognoiflons trefbien, comme il appert par leurs efcrits.

J'ox's'ap Galien au liure feptiefme des Simples, dit que le porte le macer eft apporté des Indes, \& qu'il eft pour lapluslon Ga-part d'vne qualité froide terreftre, mais qu'il a bien iien. per de la froide:\& qué à caufe de fon aftriction, il eft fingulierement propre aux diffenteries \& flux de fang.

D'oùsap Diofcoride au liure 1.chapit.94. Le Macer dit-il porte le que l'on nous apporte de Barbarie, eft vne efcorce Mactr iaunaftre, grafie, \& fort aftringéte au gouft, laquelfelö Diof-le on boit pour fubuenir à ceux qui perdent le făg soride. ou par le nez ou par la bouche, aux diffenteries, \& aux Aux de vétre. Touteslefquelles facultés fe trouuent en l'efcorce du Macer, \& non au Maciş, qui eft vne petite coumerture de la Noix mufcade, laquelle eft chaude \& f feiche à lis fin du fecond degré, ou au commencement du toifiefme,efant de parties fort fubtiles \& tenuës,participant de quel pcu d'amertmme \& d'aftriction : \& partant l'vn \& l'autre pour cercain'parlent del' $\phi$ f corce de noftre arbre, $\$$ non du Macis qui leur a efté incogneu,

Datนaุก 
DES DROG. ET MED. L I V. III. 47

Daunantage vn certain Medecin du Roy de Co-Cefte ef. chin m'aduifa, que ie ne filfe doute, que cefte efcor- corce eft ce ne fur le Macer d'Auicenne: \& que c'eftoit vne d'Aucer grande ignorance de difputer d'vne chofe fi claire: $n e$. car les facultés de ce Macer du tout femblables à celles que les anciens ont attribuées à leur Macer, le moniftrent ayfement.

Pline aufsi an liure I 2.chap. 8. Le Macer dit-il,eft apporté de Indes, qui eft l'efcorce rouge d'vne racine qui porre le nom de fon arbre.

Nous ne deuons aufsi troutuer eftrange que Diof- Acrord coride affeure le Macer eftre apporté de Barbarie, le- rent qui quel Pline \& Galien efcriuêtt êftre amené des Indes: est entre car il leur peut eftre aduenu de mefmes en ce medi- Dioforiticament comme en la defcription du Cinnamome \& de éra du Caffia, veu qu'on n'a as bien cogneu le lieu ou lien,tersdu croiffent, parce qu'ilis font apportés de pays loin- lient ois gtain,

Ptolomee toutesfois dit:qu'il y a vne certaine Ine Macer. dăs le fleuue Inde, ou'bien vne ville appellée Barba- Inde ririe , de laquelle on apportoit anciénement le Macer: icelle est ou biē d'autant qu'óle fait v́enir d'Arabie par ce gol- vne Ifle fe de mer qui eft appellé Barbarique, à caufe de cefte ou vine Inle de Barbarie, A l'opinion duquel s'accorde Stra- ville apbon,toutes les chofes, dit -il, qui prouiennent aux In-barie. des.à fçauoir du cofté qui eft deuers le Mydi,croillent auff en Arabie.

La Differêce du Macis d'auec le Macer,a efté tresbien cognetië par Auicenne, d autant qu'au chapitre Differens 456. il defcrit le Macis eftre vne couuerture de la Macis Noix mufcade. Et au chap, 694 . foubs le tiltre de $T_{a}$ - d'anecile lisfar, le Macer eftre l'efcorce d'vne racine.

Elle n’a point efté auffi incogneuë à Serapion, qui 
48 CHRISTO PHIE DE, I A COS TE, de l'auctorité d'Ifach a efcrit que le Macis eftoit la couuerture d'vne noix mufcade, different à celuy duquel fait mention Diofcoride, lequel à laiffé par efcrit que le Macis eft l'efcorce ou cuir d'vn bois.

Combië Il appert donc que le Macis \& le Macer diffeils font rent entre eux en qualité, fubrtance, figure, plante l'vn de \& contrée, d'autant que le Macer qui eft vne efcor-

l'autre. ce de racine d'arbre,croift en Malabar: \& le Macis qui efla conuerture de la Noix mufcade en Bandan, qúi font lieux bien efloignés les vns des autrés. Bien que les Moynes qui ont commenté Mefue, affeurent qu'il n'y a point de difference entre eux,monftrans par ce moyen leur negligence, pour ne dire ignorance.

L'vfage decefte efcorce macer eft fort commun en tous les hofpitaux des malades des prouinces de la Chine,Iapan,de Malaca \& Bengala, \& ce aux diffenteries, flux de ventre, \& flux de fang : voila pourquoy ils en vont querir en Malabar.

\section{ANNOTATIONS.}

Seă Moc Le fieur Iean Mocquet Garde du cabinct des finguquet. Larite $Z$ du Roy tref-chreftien Louys treziefme, qui à faid tant de longs, penibles, \& laborieux voyages en Afrigue, Afie, Indes Orientales, on en l'Amerique : me fit prefent

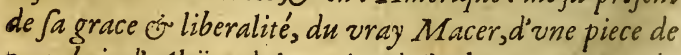
vraybois d'Aloës, de la racine de l'arbre Iangomas, du Cocos de Maldiua, o d'vn nombre infini de plufieurs autres belles drogues, \& curiofitez que luy me fmes apporsa des parties du monde cy deffus mentionnees: lor's gu' it paffa en ceste ville de Lyon, pour aller en Syrie of terre faincte: me fit cest bonneur de demenrer en ma maifon 
DES DROG. E T ME D. LI V. III. 49 fept ou buict iours, il a faict voir en lumiere le liure de Liure fes voyages, ounure auffibelle que l'on f̧̧auroit defirer, des vay pour anoir faict voir à la posterité, la dexterité de fon gean eprit, imprimée à Paris,l'an I6 I 7.

Du Coru.

\section{CHA P. XIII.}

A Vx mefmes lieux outre l'arbre furdit, il y en A. croift auffi deux autres fort differens l'vin de l'autre, mais toutesfois qui ont quafi les mefmes proprietés que le Macer.

La premiere (de laquelle nou's parlerons en ce Dirers chapitre) s'appelle en Malabar Curodapala, \& Curo, noms en Canarin Corus, des Brachmanes Cura.

C'eft arbre reflemble à vn petit orenger, mef- $\delta a$ defcri mes quand à fes feuilles, finon qu'elles ont la ner-ption. ueure du milieu vn peu plus grofle, \& $x$ tantoft huict rantôt neuf qui s'eftendent aux coftés : fa fleur eft iaune, n'ayant prefque point d'odeur: l'efcorce de Vertusde fa racine eft d'vn verd clair, vnie \& defliée, laquelle l'efcorce fi on vient à rompre ou picquer, rend bonne quantité de laict, vn peu plus lent \& vifqueux que celuy qui vient du Macer, d'vn gouft infipide, ayant toutesfois quelque peu d'amertume, froid \& fec,ayant auffi plus de ficcité que de frigidité, qui eft le degré auquel le conftituent les medecins de cefte Prouince là.

Les habitans du lieu tant gentils que Chreftiens, fe feruét fort du fuc de cefte efcorće encor verde, bien qu'il foit fort def-agreable, à caufe des gìnds \& admirables cffets qu'il produict en toute forte

D D 
SO CHRISTOPHIE DE I A COSTE, de flux,tant en lyenterie, dyarrhee, que diffenterie pronenantes de quelque caufe que ce foit. Toutesfoys les medecins Portugois vfent d'vne certaine metode pour le mettre en vfage.Ils fe ferucint auffi de l'efcorce eftant feiche comme dụ Macré : mais l'efcorce d'iceluy eft beaucoup plus excellente. Or ils diftillent le Coru, \& en vfent en cefte maniere.

Ils prennent huict onces de cefte ef corce mife en poudre auec de l'Ameos, femence d'ache, coriãdre fec, cumin'noir(apres les anoir vn peu torrifiés \& mis en poudre) trois drachmes d'vn chacun, de l'efcorce de Myrobalás. Quebules fept drachmes, plus deux onces beurre de vache qui ne foit point falé, puis ils prennent autant du laict enaigri, qu’il en faut pour incorporer ces poudres cy, \& mettent le tout dedans vnalambic de verre (le preparent pour gens delicats) ou dans vn commun (comme il fe faict pour la plus grand part) \& en tirent vne liqueur diftillée, de laquelle ils en font prëdre quatre, ou cinq onces, auee de l'eau d'auel. laines des Indes appellées Areca, ou deux onces, d'eau de pecouls de rofes à ceux qui font affligés de flux de ventre (aucunefois aufíils y adiouftent fi befoin eft, des trochifques de Charabe ou de terre feelleé ) vne fois le iour ou deux fi befoin eft, $\&$ dés auffi toft apres cefte prinfe,ils leur donnent du riz auec du laict aigre. Car on en fair des cliferes quion fait prendre principalement fur la nuict.

Et encores que cefte eau foit finguliere, fi cft ce pourtắt que l'efcorce du macer eft beaucoup plus excellente, bien qu'elle ne foit pas fi plaifante au gouft, \& plus difficile à prendre.

Cette racine aufi eft fort bonne contre les he- 
DES DROG. ET MED. LIV. III. SI morrhoides \& fciffures du fondement, foit qu' elle Verus de foit prinfe auec la decoction du riz, foit qu'on en cefte raface vin vnguent pour la partie.

La vapeur fortant de la decoction de fes feuilles, $\begin{gathered}A \text { quoy } \\ \text { profitent }\end{gathered}$ auec celles des Tamarins, eft fort propre contre lesferiblentleure des cuiffes:comme auffi fion en trempe les. vn linge dedans la mefme decoction, cela fert de grand remede à l'hydropifie que nous appellons tympanite.

\section{Du Pauate. \\ C н A P. XIIII.}

T'Autre efpece de ces plantes à fçauoir la troiL fiefme efpece de celles qui font propres pour les flux de ventre, s'appelle communement en $\mathrm{Ma}$ labar Panate, des Brachmanes, \& Canarins Vafaueli, des Portugois Arbol contra las Erifipolas: c'eft à dire, arbre qui guerit les eryfipeles. re, arbre qui guerit les eryfipeles. qui guePauate, Vafaueli Arbre Ceft vn arbrifleau qui neft pas trop branchu, rit lese-
de la hauteur de huict ou neuf pieds, portant fort ryfpeles.
Sadefcri peu de feuilles femblables au plus petites feuilles stiow. d'Orenger, fors qu'elles n'ont point de pecoul, doüées d'vne tref-belle couleurverde, d'vn \& d'autre cofté:fa fleur eft fort petite, blanche, ayant quatre petites feuilles, du milieu de laquelle fort vne fibre blanche, ayant vne belle pointe verde, de l'odeur du cheurefeuil, auquel elle reffemble fort quád on la regarde de loing, fa feméce eft róde, de la groffeur du lentifque, d vne couleur verde tirant fur le noir,\& dés auffi toft qu'elle eft meure, elle eft noire. Le pied \& les rameaux font de couleur grife,

$\mathrm{DD} 2$ 


\section{S2 CHRISTORHIE DE IACOSTE, Panate de Acoftu.}

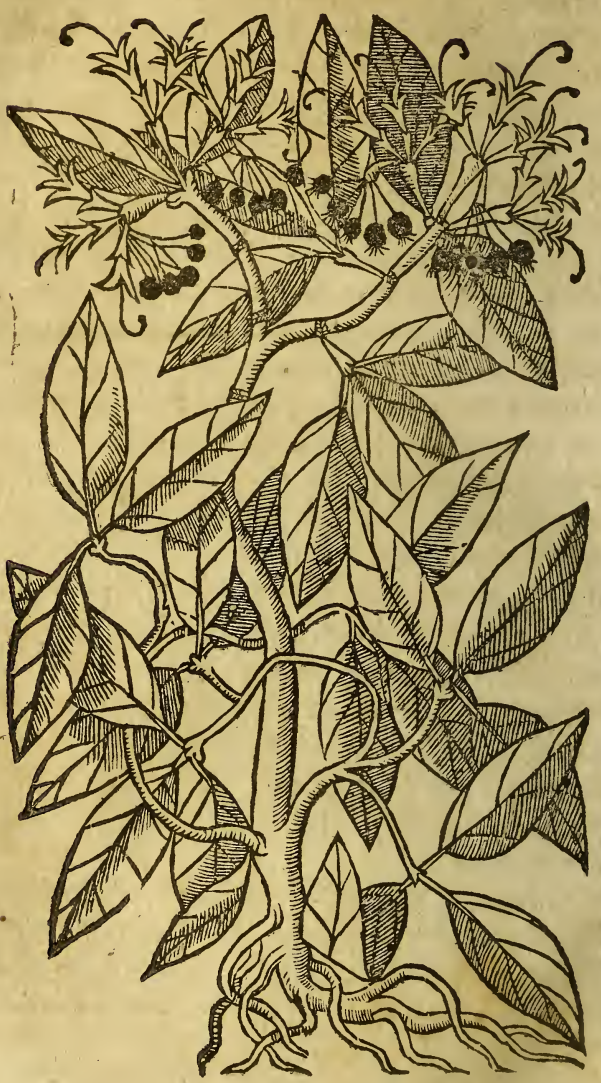

fa racine eft blanche $\&$ infipide auec quelque petire amertume,n'ayant prefques aucupe odeur. 


\section{DES DROG. ET MED. LIV. III. 53}

Et encores que cefte plante foit vtile contre les Vtilite flux de ventre comme les deux efpeces, toutesfois d'icelwy, il n'y a point de comparaifon, d'autant qu'elle n'a pas tant de vertu:partant celuy qui cognoit les fufdictes, ne s'en feruira aucunement au flux de ventre, mais pour la guerifon tant feulement de toutes fortes d'eryfipeles, principalement de celle qui furuiêt de la pure cholere,car on a recogneu qu'elle a vne excellente vertu contre cefte maladie.

L'on met en poudre le tronc de cefte plante, ou bien fa racine, \& puis on la fait tréper dedans vne decoction de riz(laquelle ils appellent Canje) \& la $C_{\text {arjo }}$ laiffent repofer quelques heures deuant, à fin que cefte eau deuienne aigre, puis apres ils en oignent \& humectent l'erifipele, \& en font prendre fuffifante quantité deux fois le iour, ayant premierement purgé l'eftomach.

lls font prendre en mefme maniere la racine infufée en decoctió de riz à ceux qui ont des fiebures ardantes, ou inflammations du foye : \& quand ils veulent empefcher qu'il ne fe faffe fluxion d'humeurs, \& inflammation fur le bord des playes, ils adiouftent à la fufdicte infufion quelque peu de fuc des feuilles de Tamarins, puis en font liniment fur lefdites playes.

Et d'autant qu'en ces Prouinces cefte troifiefme efpece croift en beaucoup plus grande quãtité que le Coru, les habitans du lieu la mettent en vfage.

\section{Du Poyure.}

\section{C $\mathrm{H}$ A P. X V.}

L y a deux fortes de Poyure, l'vn domeftique, perxef1 qu'eft celuy duquel on fe fert, l'autre eft fauuage poyure. 


\section{CHRS TOPHLED I IA COSTE;}

duquel on ne fait point de conte, à caufe de fon aDefcripmertume.

jiondu La plante du domeftique eft farmenteufe, mon. domesti- tant en hat comme le lierre, s'entortiflant autour que. des arbresqu'elle peut rencontrer:doiiée de nœuds par interualles, prés defquels croiffent des feuilles iemblables à celles du'Betele, fort verdes en dedãs, \& en dehors plus defcouuertes, elles ont vne poincte acerée, \& font d'vn gouft qui vlcere la langue. Entre fes feuilles il y en a qui font plus noires les vnes que les autres:celles qui ne font pas fi obfcures, \&ront des fibres qui nailient efgalement, ils les tiennent pour femelles ( car ils conftituent l'vn \& l'autrefexe, és feuilles de cefte mefme plante ) \& pour mafles, celles qui font plus noires, \& ont des fibres \& nerueures inefgales. A chafque noud, d'où pendent les feuilles, de la mefine place des feuilles, croiffent des grappes, dont les plus grandes contiennent quarante grains ou enuiron, \& les plus petites trente la racine eft petite laquelle neantPoyure moins plante fes fibres fort auant dedans la terre. mas iso Oril y a vne grande fimilitude entre la plante qui blanc. produit le Poyure noir, \& celle qui porte le Poyure blanc:toutesfois les feuilles qui portét le Poyure blanc femblent eftre plus defliées \& molles:\& só fruict plus aromatique \& de meilleur gouft que Yirus ferul le noir. Or on ne fe fert point des feuilles de ceftuy dus Poy. cy entre les habitans de cefte contrée là : mais on stre noir. recerche feulement les feuilles du Poyure noir contre la cholique paffion, \& aux autres maladies du ventre prouenantes de caufe froide : on les applique furle ventre auec vin merueilleux effect, apres qu'on les a engrailfées d'huile de Noix Indi- 
DES DROG. ET MEDILIV. III. Sf Poyur enoir de Acefta.

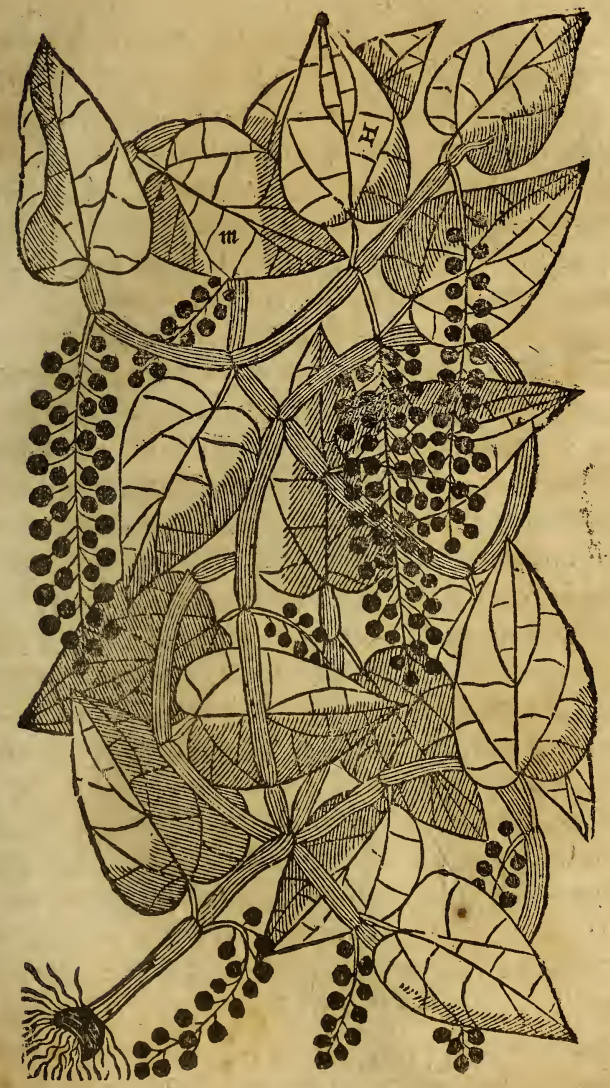

que,\& puis chauffées.

On cultiue la plante du Poyure en cefte manjeD D 4 
Maniere 56 CHR ISTOPHIE DE IA COSTE; de le plä re:On enfouyt le farment ou rameau d'icelle, tout ser.

- pres de quelque pau, \& 8 y met on deffus des cendres, de fiente de vache \& de l'eatrau bout de l'annee cefte plante porte fruict, \& tant plus elle eft vieille, tant plus elle eft ferrille, d'autant qu'elle a accouftumé d'efcheller en s'entortillant iufques au sómet de l'arbre, auec lequel clle a efté mariée. Ie t'ay fait icy adioufter la figure du Poyure noir, felon la defcription de Acofta.

\section{Des Cubebes. \\ Ch A P。 XVI.}

Ts medecins Indièns s'en feruét non feulemër L pour conforter l'eftomach, \& pour guerir les tumeurs \& opilationș du foye, mais auffi pour chaffer les vétofités, \& corriger les frigidités de la matrice:mais fur tout pour exciter à luxure.

\section{ANNOTATIONS.}

Te n'eftimois pas de be foin traduire ce chapitre, parce que tout eft tiré de Garcie: tontesfois i ay voulu adioufter les proprietés of vertus le fquelles il lny attribue.

De l'Auellaine des Indes.

Defcriptionde Cн A P. XVII. lisullai $C_{\text {nes }}$ 'Ef arbre eft fort haut $\&$ droict, mince, rond, sodes. 1 d'vne matiere fungueufe:il a les feuilles plus longues 


\section{DES DROG. ET ME D. LIV. III. 57}

\section{Auellaine des Indes de Acofta.}

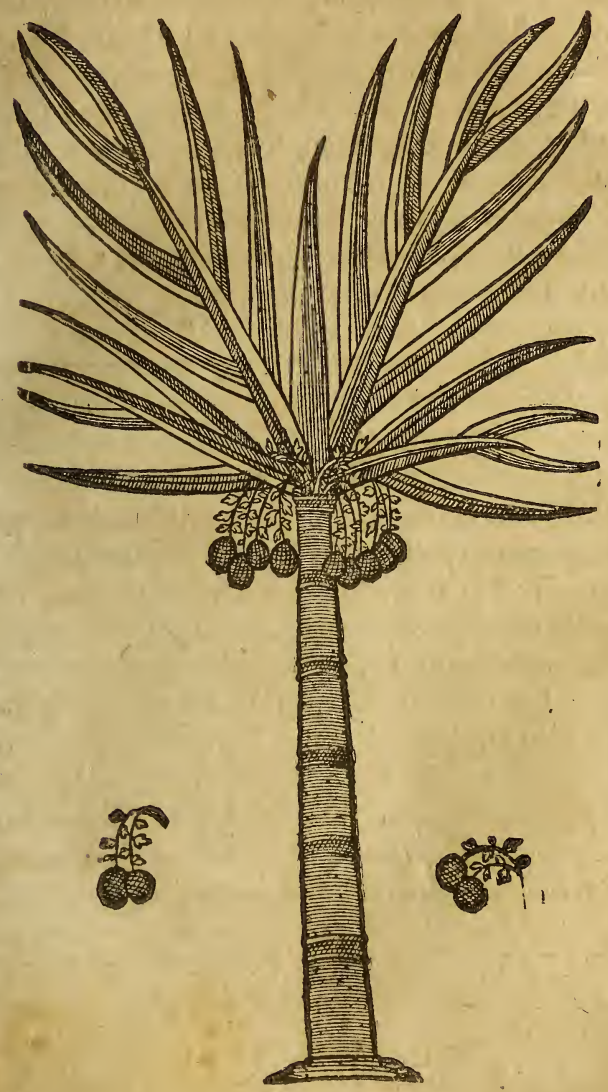

longues \& plus larges, que la Palme qui produict le Coccos ou la Noix Indienue, lefquelles croif: D D s 


\section{$\int^{8}$ CHRISTOPHLE, DE IA COSTE;}

fent au fommet de l'arbre , entre lefquelles naiffent certaines petites verges minces \& defliées, chargées de petites fleurs blanches, \& prefques fans odeur, lefquelles fe transforment puis apres

Areca. en fruict, appellé Arecaiqui eft de la groffeur d'vne noix commune, lequel toutesfois n'eft pas rond, mais long comme vn petit œufde poulet, ayant vne efcorce fort verde au dehors quand elle eft recente, mais fortiaune dés auffi toft qu'elle eft meure,fi bien que ceux qui le voyét de loing-penfent que ce foyent dattes meures:cefte efcorce eft d'vne matiere molle \& bourruë, contenant au dedans vn fruict de la grolfeur d'vine chaftaigne bien grolfe, qui eft plat d'vn colté,blanc, dur, remply de veines rouges, lequel les habitans du lieu man. gent.

Commẽt Ils font coufumiers de la mettre foubs le fable il le faut lors qu'il eft encores tout verd, affin de le rendre cóferuer. plus fauoureux \& plus agreable à manger. Ils le mangent commuriement auec les fueilles du Betele. Ils le rompent aufi, \& le font feicher au Socheca: leil,(\& lors ils l'appellent Checani,)\& s'en feruent 3i. fort, tant parmy les viandes, qu'aux lauemens aftringens: \& fe nettoyent les derits auec fon efcorce \& counerture.

Or comme ainfi foit que la matiere de ceft arHouff- bre foit fungueufe, elle ne fe rompt que malaisenes de ment: voila pourquoy vne verge de ceft arbre de bre, auec la groffeur de deux doigts, peut retenit aisément, lefquel. vin Crocodille, foit en eau, foit en terre, fi on la luy les os paffè à trauers le gofier (car ils ont accoutumé de prend les les prëdre en cefte maniere) comme moymefmes les. iay veu pluficurs foys. Ie tay icy faict adioufter la figure 
DES DROG. E T M D. L I v. III. 59 figure de l'arbre portant l'auellaine des Indes de Acofta.

\section{De la Palme Indienne.}

\section{C н A P. XVIII}

Êf arbre eft fort grand \& droict, \& non trop Histoire gros, principalement au fommet:car defpuis de la le pied iufques à la poincte, il va peu à peu en e- Palme froiffilfant, \& eft d'vne couleur grife : ils enuiron- Indiĕrne. nent le tróc depuis la racine iufques au haut, comme de petits degrés $\&$ efchellós faicts de ioncs ou autres chofes femblables, lors qu'ils veulent monter au deffus:fa fleur eft femblable à celle des chaftaignes:\& le fruict tout entier, plus gros que la tefte d'vn homme, d'vne figure longue triangulaire, $\&$ de couleur verde fort claire.

Et encores bien que les Arabes \& Perfes appel- Naret. lent communement cefte noix $N$ arel, les Perfes toutesfois difent que cela n'eft pas fon vray nom, mais qu'il faut dire $N$ argel:les Perfes appellét ceft arbre Darach,les Arabes Siger Indi : Les Turcs ap-Diuerfes pellét l'Aubre Agach, le fruict Cox Indi:Les Brach-appellas. manes appellent l'arbre Maro, \& la Noix Naralu.

De ceft arbre on en fait dans les Ifles Naledi- Ifes Ni ues, des nauires \& des clouds, des mats, des voilles, lediues. 'des cordages, \& autres chofes neceffaires:comme En quoy elles font equippées, ils les chargent des marchan- on fe fert difes faictes du mefine arbre, c'eft à fçauoir d'hui- arbres. le, de vin, de fucre noir, de vinaigre, de l'eau, de fruits, \& d'eau ardante. On en baftit auffi des maifons affez fortes auec leur foliueaux, puis auec fes

rameaux 
ด้\%. 6 O CHRISTOPHIE DE IA COSTE, rameaux ( quils appellent Ola) ils en couurent comme de tuiles leursmaifons, car ils contregardent bien de la pluye. De ces rameaux ils font des counertures fur leurs vaiffeaux en hyuer, ils les mettent puis apres fur terre, anec vn inftrument propre à ce faire.

Ily a Or ils font deux efpeces de ces Palmes: car de deux ef-l'vne ils ent tirent le Sura, qui eft vne liqueur compeces de
Pal. miers. l'appellent Orraca:l'autre forte ils la gardent pour A quoy porter des fruicts.

elles fer- On tire le Sura, en cefte maniere ils couppent sura. vn des rameaux plus proches de la tefte de l'arbie, laiffans la longueur de deux pieds, aufquels ils attachent des grands vafes larges, qui toutesfois ont la bouche fort eftroicte, qu'ils appéllent en leur

Caloins. Patois Caloins: l'arbre diftille le Sura cy deuant dit par cefte branche couppée, lequel mis dedans l'alambic, ils en tirentà force de feu de l'eau ardanFula. te : La plus pure, qu'ils appellent Fula, c’eftà dire feur, elle fe brufle plus aisément que noftre eau de vie que nous appellons eau ardent, ce que ne Orraca. fait l'autre appellée Orraca : mais ils ont accoufumé d'y mefler quelque peu de la plus pure.Du Sura auant que le mettre fur le feu:on en fait du vin aigre tres-bon fr on le met au Soleil, encores bien que l'on ny iette point dedans de la menthe,ny de l'efcorce de l'arbre des Myrobalans, qu'on a accouftumé de mettre dedans le vin-aigre, pour le rendre plus fort. Apres qu'ils ont ofté le premier vafe de Sura,il en fort encores vn autre liqueur,laquelle efpoiffie ou par la chaleur du feu ou du Sosagra. leil,on en fait du Sucre appellé des habitans Iagra: ou 
DES DROG. E T M D. L I V. III. 6 I on eftime celuy meilleur qui eft cueilli aux Nalediues,que celuy de Malabar.

Le fruit recent a au deflous de cefte premiere 2 uel est couverture groffe \& verde, encores vne autre ef -so fruicz. corce noire, qui couure la moëlle, laquelle eftant encores recente, \& auparauant qu'elle deuienne noire, eft tendre \& blanchaftre, \& fe mange auec du fel, ou fans fel, ou bien auec du vin-aigre \& du poyure, \& à le gouft des artichaux:mais lors qu'elle commence aucunement à s'endurcir, elle a le gouft de la tefte d'vn carde. La moëlle qui eft attachée à l'efcorce eft tendre \& douce, contenăt bonne quantité d'eau claire fort fouëfue, \& laquelle par fa douceur n'eft point ny ennuyeufe à la bouche,ny fait point mal de cour, qu'ils boiuent communement durant les grandes chaleurs.

L'vfage de celte eau rafraichie au ferain \& du Commze Iagra,elt fort frequent contre les trop grădes cha- de ceste leurs du foye \& des reins, \& auffi pour ceux qui $\boldsymbol{e a u}$, o font les vrines purulentes:cefte eau fe refroidit en $d u$ Ia. fa noix verte, qu’ils appellent Lanna: elle fe con- ${ }^{g r a .}$ ferue longuement, car tout le long de l'annee on trouue des noix verdes, dont quelques vnes contiennent trois ou quatre liures, ou vne pinte d'eau. Apres que cefte noix eft endurcie, \& que fa sa noix. moëlle eft deuenuë plus ferme, il demeure en la cauité de la noix vne eau, laquelle eft claire voirement, mais non fi douce que la premiere : En ce temps là les Malabariens appellent la noix Eleui. Eleui.

Céte eau dans les noix qui ónt vn an, fe change en vne fubltance ronde comme vne pomme, blăche,fpongieufe,legere, \& douce. Les habitans du lieu ne mangent que la moëlle ${ }_{n \theta i x .}^{g e}$ cestr. L'On mä de 


\section{CHRISTOPHE DE LA COSTE,}

Palme des Elephans de Acosta.

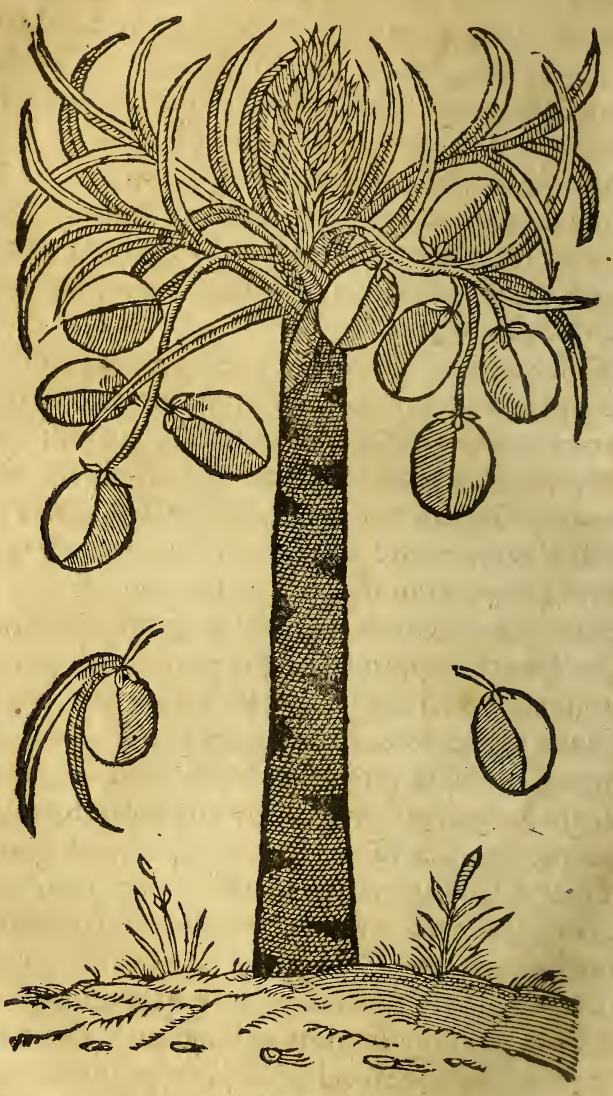

de la noix recente, tendie, blanche, \& douce auec du Iagra, c'eft à dire du Sucre Fait antec du Sura, ou bien 
DES DROG. ET MED. LI V. III. 63 bien atec de l'Auela, qui eft vn gafteau faict auec Auelm du riz cuit en eau,puis broyé \& bien feiché au Soleil :ils la mangent auff auec vne certaine efpece de poiffor fec, venant de Nalediua feichéà la cheminee comme le beuffalé, qu'ils appellent Coma-Comala lafama, \&x eft vn bon appreft pour ouurir l'appetit. masa । Car telle ineflange eft non feulement fort vfitée entre les habitans du lieu, mais auffi recerché par les Portugois. De cefte mefme moëlle l'on en fait du laict femblable à celuy des amandres, bon pour faire des faulfes.

Cefte moëlle deffeichee au Soleil s'appelle Co. Copra, pra:elle eft fouëfue,ils la referrent, \& s'en feruent comme nous en l'Europe des chaftaignes feiches.

On tient communement \& eft auffi experimen- $V$ Jage de té, que le frequent vfage de cefte noix engédre les ceftenoix, vers:aufquels font grandement fubicts tous les habitans de la prouince de Malabar.

De cefte premiere efcorce ou groffe counertu$x$, au dehors vnie, \& au dedans veluë, apres qu'elle eft emplo eft feichée on en fait des gros cables \& autres cor- yée l'esdages de nauires, comme l'on fait en Efpagne du geneft. Les Malabarois appellent cefte bourre Cai-Cairo. ro,qui eft entre eux de grand vfage:car d'autát que l'eau marine ne le peut aucunement pourrir, pour celte occafion ils en calfultrent toutes fortes de vaiffeaux:\& fert à ces peuples là, de layne,d'eftouppes, de cotton, de lin, \&x d'oufier ou genent.

De cefte feconde noire $\&$ dure efforce, que les noftres a ppellent $\mathrm{Coco}$, \& les habitans du lieu $\mathrm{Xa}$ - Xareta reta,on en fait des efcuelles, \& autres vafes à boire pour l'vfage du menu peuple. L'on en fait auffi des charbons propres pour l'viage des Qrfeures qui y

Cont 
$64 \mathrm{CHRISTOPHIE} \mathrm{DE} \mathrm{IA} \mathrm{COSTE,}$ Cont experts \& induftrieux, \& nó trop fomptueux. Car ils vont criăt leurs ouurages par les carrefours, portás auec eux vn marteau, vn pot de cuiure à te. nir de l'eau,\& deux Burins à grauer,auec vn tuyau de canne en la main de la longueur d'vn empan,auec lequel ils allument le feu.Ils trauaillent dedãs les maifons, \& font des vafes d'or \& d'argent, felon la volonté de ceux qui les ont appellés.

vage On fait aufi des chapeaux grands \& petis des des feril feuilles de cefte Palme,lefquels font propres pour les de ce fe garder des rayons du Soleil \& de la pluye : l'on te. en fait auffi des nattes ou portieres, \& plufieurs Coccus autres chofes. Or le Coccus dit de Nalediue, eft telde Nale lement prifé entre les habitans de ce pays là, \& de sisse. ceux de Malabar, non feulement de la populace, mais auffi des Roys \& Princes, qu'en toutes fortes de maladies ils ont recours à iceluy, comme à vn ancre facré. Pour ceft effect ils en font des couppes, lefquelles ils font mettre en cuure, tantoft en Efmer= or, tantoft en argent, leur donnans la figure d'vn bles ver. nauire ou gondole pour boire de l'eau, dans lefsusquion quelles ils font trêper vne petite piece de la moëlbuy attri le dudit Coccus attachée à vne petite chaine : \& buecom- croyent fermement que ceux qui boyuent de l'eau ment. auec telles couppes, ne peuument eftre empoifonnés en quelque forte que ce foit, \&. qu'ils feront exempts de plufieurs maladies,aufquelles à dire la verité,i'en ay veu tomber plufieurs, encores qu'ils euffent accouftumé de boire dans telles couppes. Et encores que i'aye faict toutes les diligences qu'il m'a efté poffible, ie n'ay toutesfois iamais peu obferuer,que telles taffes ayent peu guerir quelqu'vne des maladies aufquelles ils les difent eftre profitables: 
DES DR O G. E T MED. L I V. III. 6,5 fitables:ie crois donc pluftoft quil a vn fi grand renom par l'opinion du commun peuple. Quelques vins couftumiers de boire dedans tels vafes, m'ont affeuré d'auoir appris par experience que le foye en eft enflammé, \& les reins chargées, \& la pierre ou calcul engendré : toutesfois ils fe vendent fort cher,\& font beaucoup plus prifés fur le lieu où on les troulue, que aux autres elloignés de là:car telles noix toutes fimples \& nuës făs eftre enrichies d'or ny d'argent, font prifées iufques à cinquante efcus d'or, \& aucunefois d'auantage.

La diffe-

Ce Coccus icy eft plus lucide, noir, plus long, \& rence $d$ plus gros que les autres noix du Coccus commun.

uecle

Coccuss

commun

\section{Des Myrobalans, C}

T y a cinq efpeces de Myrobalans, qui naiffent peces de en diuers arbres, \& en diuerfes contrées.

- Les Citrins appellés des medecins Aritiqui,\& de lans. la populace Arare, croiffent en vin arbre de gran- Citrins, deur mediocre, garny de beaucoup de branches răgées par ordre,\& ayant les feuilles du Cormier. Emblics, Les Emblics diots Annuale, ont les feuilles def- Annua. chiquetées menu, préque femblables à la fougie-le. re,mais yn peu plus efpoiffes.

Les feuilles des Indes ainfi appellées, \& par les Indics. habitans du li eu Rezanuale, font femblables à cel- ale. les du Saule.

Les Bellerics font de figure ronde, \& font appel- Belerics. lés des habitās du lieu Gotin, \& ont les feuilles fem- Gosino blables au Laurier, toutesfois vn peu plus petites \& minces. Toutes ces quatre efpeces fe troument

EE 


\section{CHRISTOPHLE DE A A COSTE, Mirobalans.}
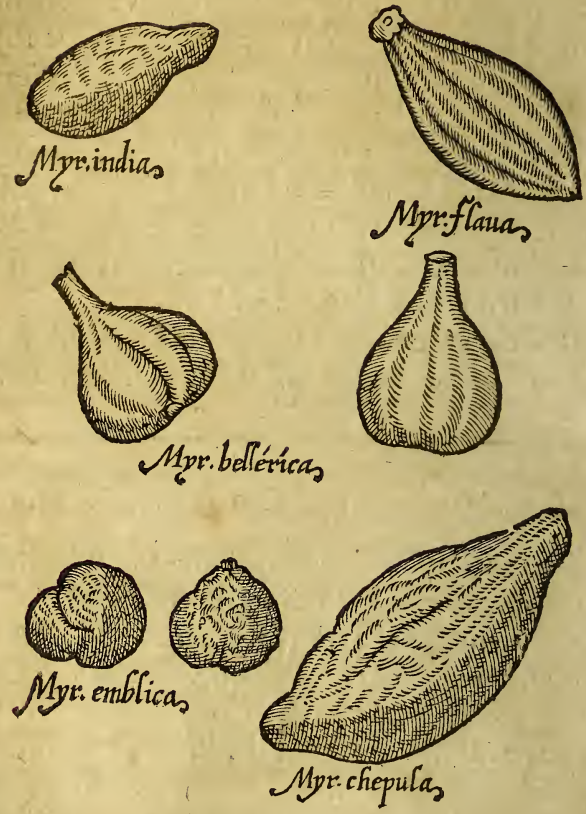

* MYROBOLANI EMBLICAE
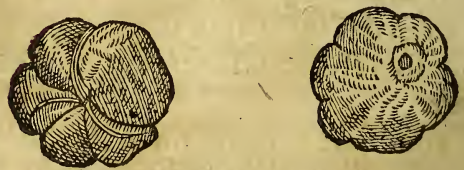

par toute la Prouince de Malabar,Dabul, Cambaya, \&atecala, celont ces quatre efpeces lefquelles font 
DES DROG. ET MED. LI V. III. 67 Cont apportées en l'Europe, feiches \& confites.

Ie n'ay pas veu l'arbre des Chepules, qu'ils appel- Chepules lent Aretca, mais on dit que fes feuilles font fembläbles à celles du Pefcher, \& que l'arbre qui les porte eft de mefine grandeur que les aurres:or tous Ies arbres portans ce fruict font de la grandeur d'vn Prunier, mais ils ont plus de branches, \&2.mieux rangées en rond.

\section{Des Tamarins.' C н A P. X.X.}

Es Tamarins font fruicts d'vn arbre tref-beau Histaiyes $\mathcal{L}$ \& plaifant a voir, de la grandens d'vn Cerifier, ${ }_{\text {marins. }}$ ou d'vn Chaftagnier, fort branchu \& dont les feuilles font vn grand ombrage, d'vne matiere fort folide: $\{$ es feuilles font fort femblables à celles de la fougiere femelle (que lus Efpagnols appellent Heleco, Helecho, les Cantabriens Ariftora) d'vne couleur Arifor verde, fort claire, belles, d'vin gouft aigrelet \& a- Cantagreable, defquelles on fait vne faulce, tout ainfi que du perfil. Ses fleurs font blanches, prefques femblables en dehors à celles de l'Orengier, \& en rois. odeur: toutesfois elles ont huict feuilles, dont les quatre de dedanrs font blanches, $\&$ vin peu efpoiffes comme les feuilles des fleurs de l'Orengier, \& les quatre de dehors plus minces, deux defquelles font parfilees d'vne nerueure tres-belle:du milieu de la feuille fortent quatre fillets voutés en forme de cornes, qui font blancs \& minces. Son fruict eft fort femblable aux carrouges, verd a en dehors au commencement, puis gris à mefure qu'il deuient fec, contenant au dedans des petits offelets ronds

$$
\text { E E } 2
$$

\section{briens} ce söt les Nauar- 
68 CHRISTOPHLE DE IA COSTE,

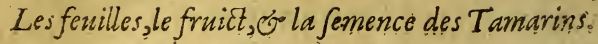

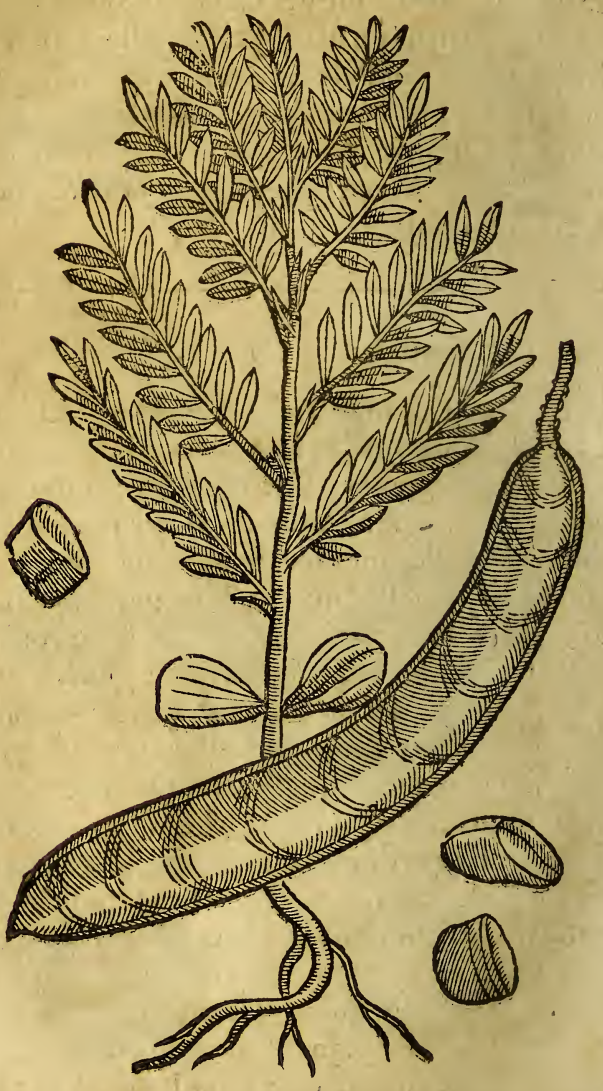

comme la Cafte laxatiue, ou femblales à des petis Lupins, durs eftrangement, \&x d'yne couleur reluifante 
DES DROG. ET MED. L I V. III. 69

Tanarins de Acofta:
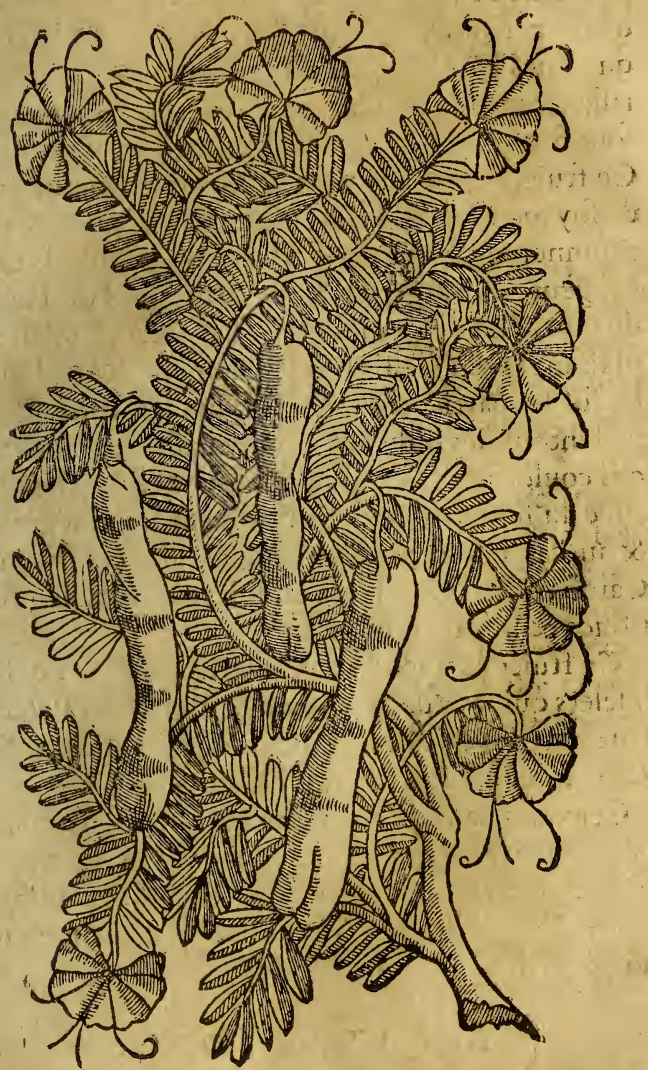

luifante tẹrreftre, nullemết iamnaftre comme qualques vas difent: nous ne nous en feruoris point EE 


\section{CHT IS T O P L E DE IA COSTE,}

mais de la poulpe tant feulement, qui eft quelque peu lente \& vifqueufe, agreable toutesfois à caufe d'vne petite aigreur qu'elle a, encores bien que quelques habitans du lieu afieurent que les os torrifiés \& mis en poudre, pris auec du laict enaigri font fort ytiles \& wrofitables atix Hux de ventre: Ce fruict éft tiré aif'́ment de l'arbre, \& tombe aufi de foy mefme. Les feuilles fe ferrent la nuict, \& enuironnent le fruic: :que sil ny en a point, ils embraffene les veregtes \& rameaux : puis fur l'aube du iour, elles s'dfoniffent \& eflargiffent, qui eft vn

Vertus fowil plaifant fpectacle. Ils broyét \& appliquét les feuills. les fur les parties affligées d'eryfipeles, comme aufi aléntour des phlegmós pour chafler les humeurs qui coulent dedans: auec icelles mefmes meflees auec du fel Ormulien, ils refoluent les phlegmós, \& au cás pareil mixtionnés auec des cendres de Cambaya, elles refoluent auffi les tumeurs flegmariques \& melancholiques.

Disers. Ce fruict eftappellé en Canarin Chincha, \& les noms. offelets qui font dedás Chincaro, en Malabar Puli,en Guzarate Ambili: des Arabes, Perfes\& Turcs; Tamarindi, les offelets Abes, \& l'arbre Siger Tamarindi.

Ceux quinailfent aux montagnes \& lieux tournés contre le Septentrion, font eftimés les meilZ'ombre leurs: On a recogneu par experience que l'ombre deeffar de ceft arbre, n'eft noins nuifible à ceux qui s'enbre cft dorment deffous, que celle des noyers.
nuifible.

\section{A N N O TA T I O N S.}

Tu trouneras la de fcription de ce fruict des Tamarins plus veritable en Garcie:or pour en voir la figure vraye, 
DES DROG. E T D D. LIV. III. 7 I tirée au naturel, tu la trouneras dedans les doctes ob eruations de Lobeb, anec le crayon de la femence de l'arbre nou. uellement creu. I'ay fait icy adioufter la figure des Tamarins de Acofta, co auffi celle de Garcie du Iardin.

\section{De la Caffe Laxatiue.}

\section{C н A P. XXI.}

T L croif à foifon de la Caffe laxatiue au grand Hiffoire Cayre, \& en plufieurs autres Prouinces, tant des de la Indes Orientales que des Occidentales. Celle tou- Purgatitesfois qui vient de Leuant eft eftimée la meilleu- ue, ér le re,mefmes celle qui prouient aux endroits qui ap- lieu où eb prochent plus du Septentrion.

L'arbre qui porte ce medicament eft de la grandeur d'vn Amandrier,ayant les feuilles femblables à celles d'vn Pefcher, quelquesfois plus eftroictes, principalement croiffant en lieu plus fec:il porte fa fleur iaune, qui neft point de trop mauuaife odeur; lefquelles eftát tombées, des ef́coffes longuettes croiffent en leur lieu, d'vine couleur verde bien belle lors qu'elles font recentes, \& eftant meures, elles deuiennent noires en peu de temps.

Il y en a fi grande foifon en Cambaya, d'où on en apporte de tref-excellente, que le poids d'vn Can-Candilo. dil (qui eft de cinq cens \& vingt \& deux liures ) the coufte point d'auătage qu'vn efcu valant trois cens $\&$ foixante marauedis, qui font des oboles de cuiure en Efpagne.

Aux montagnes de Cranganor \& par toute la Prouince de Malabar(lors quelle eft la plus chere) on vend chafque liure vingt Maranedis, c'eft à dire EE 4 
72 CHKISTOIHLE DE LA COSTE: Cajse Purgatine.

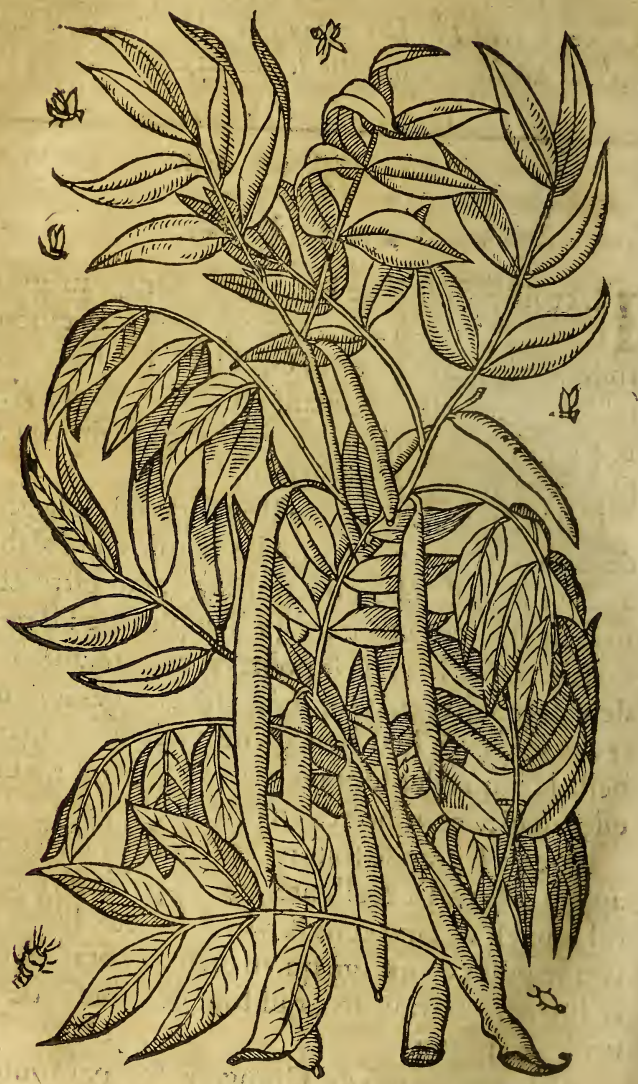

qutelque peu dauãtage qu'vn demy real de Caftille,ou qu'v Batz d'Alemagne. 
DES DROG. ET MED. LIV. III. $7 \dot{3}$ Les Gentils Camarins appellent le fruict HaJan-Diuers guia \& Bauafengua, comme aufil les habitaris de la noms Prouince de Decan, \& les Brachmanes l'arbre Ba- Sauna. boo \& Bana:les Guzaratois Granala:les Malabarois Condaca: les Arabes Perfes \& Turcs Hiarxamber: toutesfois Cogecela expert medecin de Perfe, malleura que ce mot eltoit vray Perfien, \& que Guzatfalus eftoit vray Arabique.

De la moëlle on en fait liniment par le dehors à son $v$ fasceux qui ont des inflammations \& eryfipeles.C'eft $g e_{0}$ la couftume maintenant par toutes les Indes, de faire prendre aux petits enfans \& aux femmes delicates, vne once de Caffe encores verde \& confite en fucre auec vn heureux fuccés : on la prend alors qu'elle eft encores recente \& tendre, auant que l'êfcorce s'endurciffe.

On la fait tremper dans l'eau froide, auant que de la faire cuire auec le fucre. Elle fait vuider le ventre moderément \& fans molefte.

\section{ANNOTATIONS.}

Les feuilles de ceft arbre retirent aucuirement à celles du Pefcher, fi on fepare of defunit les feuilles. Et d'aucant quelles croiffent deux à deux of par enfemble en wne nerueure longuette, la plus grande fenille fait le derniernombre imparfaid: il euffe mieux fait à mon ingemeut, s'il les euffe comparées auec les fenilles du Frefne ou femblables arbres qui portent des feuilles aiflées, o lés laiffent tomber toutes entieres comme fait le Noyer, le Cormier, le Sumach des tanneurs, of le C'arrongier.

Bernardin Paludan perfonnage tref-docte, me fit prefent il $y$ a quelques deux ans, down rameau de ceft arbre

EE S 


\section{CHRISTOPHIE DE I A COSTE;}

auec les fleurs of feuilles de Cuci, of du fruict de Cedre, auec quelques autres femences diuerfes qu'il anoit apportées du vojáge quil anoit fait en Syrie, Arabie, *o Egypte.

\section{De l'Anacarde. \\ C н А P. XXII.}

Defcri- TL y a vne grande abondance d'Anacardes en ption de Malabar, \& autres Prouinces des Indes. Il ref$l$ Ana. Semble fort aux febues commune, tandis qu'il eft
carde. carde. encores verd \& recent, eftant $f e c$, il deuient noit $\&$ reluifant:il contient vne moèlle femblable à l'amandre, entre laquelle \& la derniere efcorce, on trouue vin huille fort caufique \& bruflant.

Le docteur Gaicie efcrit que ce fruict eft mis en vage en la medecine, \& qu'en ces trois contrées là, apres l'auoir infusé dedans du laict, ils le font prendre aux afthmatiques, \& contreles vers: dauantage qu'eftant verd ils le confifent en fel, \& le mangent en guife d'oliues confites.

Vtilité Il dit auffi qu'eitant feiché, les habitans du pays quap- s'en feruent aux efcrouëlles en lieu de cauftic, \& porte ce que par toutes les Indes ils s'en feruent mellé auec fruict. de la chaux pour marquer les draps.

A dire la verité i’ay veu ce fruict tout verd, quion auxoit mis à la faulmoire comme les oliues d'Efpagne, qu'on vendoit publiquement au marché, \& qu'on nele mangeoit pas feulement ainfi accoufré, mais auff meflé auec du riz cuict pour exciter l'appetit, comme ils ont accoufumé de faire du Mangas. fruict qu'ils appellent Mangas, \& quelques autres fruicts aigrelets \& aftringens,autrement non.

Quelques 
DES DROG. T MED. LI V. III. TS

Anacardes.
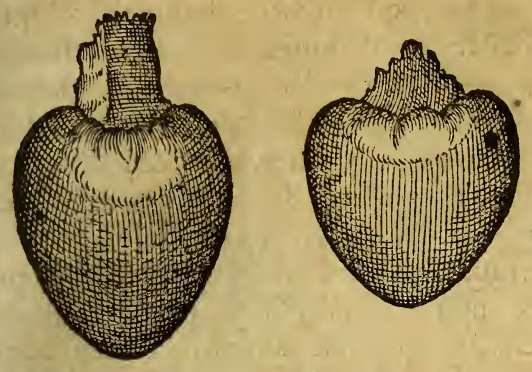

Quelque vns auffi apres qu'ils l'ont fait feicher, en oftent la premiere efcorce, \& cefte membrane qui couure la moëlle, puis mägent la moelle pour s'exciter l'appetit de boire. Quand à moy i'ay goufte $\&$ du verd mis en compofte, \& de la moëlle du fec : mais ie ne le troute point delicat ny en l'vne, ny en l'autre façon. Au refte c'eft vne chofe trefcertaine, que l'huile qui eft entre l'efcorce \& le noyau, Huile eft cauftique \& venimeux.

Par toute la prouince de Malabar,on s'en fert au lieu de cauftic. Si on en fait degouter dedans vne $\begin{gathered}A \text { quoy } \\ \text { fert } c^{\prime} \mathrm{e} f\end{gathered}$ dent creufe \& pourrie, il la brufle, la rompt \& cor- buile. rompt facilement.Il leur fert a marquer les draps :de cotton, \& diuerfes autres chofes, en y adiouftant de la chaux:car il imprime fi fort la marque qu'on : as ne la peut ofter par aucun lauement.

Les indiens ont accouftumé parfoys de picquer Autres ce fruict auec la poincte d'vn couteau, \&le faire vertus bruffer à la chandelle. Quand il brufle, c'eft chofe de ce efmerueillable du bruict qu'il fait, des eftincelles fruiz. 


\section{CHRISTOPHLE DE I A COSTË,}

\& Aammes du feu qu'il iette de diuerfes couleurs, comme fi c'eftoyent des foudres:faifans par ce moyé accroire à quelques idiots \& femmelettes; qu'ils voyent dedans ces flammes \& rayons de feu,cerrains efprits qui leur parlent,\& leur enfeignét tout ce quils veulent fçauoir. Partelles fourbes doncques ils trompent ces miferables, \& leur font accroire ce qu'ils veulent, donnant des refponfes à ceux qui leur demandent confeil felon qu'il leur plait. Et tout ainfi que tous ces gentils enchăteurs, deuins \& augures ne parlent guèreš, \& refpondent lentement $\&$ auec poids, auffi font its coufiours fi ambigus en leurs refponfes, \& fi rufés, que en quelque forte que la chofe de laquelle on les à interrogé puifre acuenir, ils ne font pour cela en danger de perdre leur reputation, \& difent qu'ils ont predit ce qui eft aduenu.

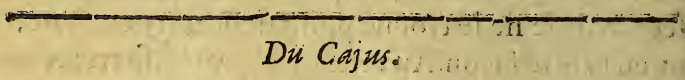

\section{CHA t: XXIIT.}

Hiftoire C Estarbre eft de la grandeur d'vn Grenadier; du Cajus. fleur eft blanche, \& prefque femblable à celle de - l'Orengier, mais elle à beaucoup plus de feuilles, \& n'eft pas de fi bonne fenteur : c'eft arbre porte vn

Cajw. fruict communemét appellé Caju,lequel pour eftre de tresbon gouft, eft profitable à l'eftomach, eft en grande eftime d'vn chafcun.

Defcri: Or il eft comme vne groffe pomme fort iaune, $\&$ ption de de bonne fenteur, fpongieux au dedans \& plein de söfruict. fuc, d'vn gouft douçaftre, qui toutesfois referre le goufier 
DES DRO G. ET ME D. LI V. III. 77

Cajous.

\section{MEDIVS.}

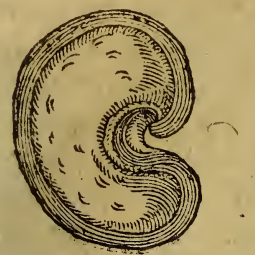

INTEGER

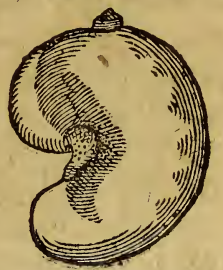

goufier aucunement. Il croift deux foys en mefme annee en cefte maniere:comme la fleur vient à fleftrir,il s'engendre vne groffe febue, a entre laquelle \& la fleur, s'êfle ie ne fçay quoy femblable à vne pomme, qui petit à petit atțire le fuc de la febue à foy: \& tant plus que cefte pomme va en croiffant, tant plus cefte febue ou noix va en diminuant $\&$ amoindriffant, iufques à ce que ce fruiçt Caju, c'eft à dire cefte pomme, aye attaint fa parfaicte maturité,ce qui fe cognoift par la couleur iaune ou rouffe(car on voit l'vne \& l'autre couleur en ces pommes) \& par la séteur:cefte febue demeure toufiours attachée au fruict encores qu'il foit meur, \&ron les cueilt tout enfemble, Ce fruict fert de deflert prins auec du vin, ou fans vin, car outre la delicateffe de fon gouft,on a trouué qu'il eft fort bon pour les foi- Vititié blelfes d'eftomach, pour les vomiflemens, \& re-fruict. couurer l'appetit perdu. Ceux qui n'en ont point befoin pour ces occafions le mangent apres l'auois trempé dedans l'eauë quelque peu.

Ce fruict ne croift par tout, mais feulement aux où it jardins 
78 CFRISTOPHIE DE LA COSTE, iardins de la ville de Saincte Croix, qui eft au Royaume de Cochin.

\section{ANNOTATIONS.}

2 Ie ne peux affe n'eshabir de noftre Autheur, quine defcrit point la forme, couleur, confiftence of l'buile enclos dans l'e fcorce (comme en l'A nacarde) de cefte noix, laquelle croit au bout du fruict, ou de laquelle, comme il dit, la pornme prend accroiffement of tire fa fubftäce, veu gu'entre les Brefiliens qui l'appellent Caius ou Caious,car il faut ainfi dire, il n'eft parauanture moins en v fage, que la pomme me frne, comme $i$ ay apris de ceux qui ont vefcu e demeuré longuement en Fernanbuco, \& l'ay auffi remarqué aux Annotations fur le chapitre de l'A nacarde, au liure des Drogues of eppiceries de maiftre Garcie du Iardin aufquelles ie renuoye le Lecteur. Or ieftime que ce fruict à efté nounellement apporté an Royaume de Cocbin, \& que pour cefte occafion il n'eft encores bien cogneu. A dire verité tous ceux qui infques à prefent ont efcrit des plantes qui viennêt des Indes Orientales, n'en ont fait aucune mëtio,ny mefmes maiftre Gurcie du Iardin, quide fpuis quelques annees a efcrit l' Hiftoire des Drogues of eppiceries.

\section{Du Spica Nard. \\ Cha p. XXIV.}

TOuchant le Pifon venin que Lucuna en fes 1 Commentaires fur le 6.chapitre de Diofcoride efcrit eftre fait du Nard Indique, ny maiftre Garcie, combien qu'il s'en foit enquis diligemment, ny moy, bien que ie l'aye demandé à plufieurs, 
DES DROG. ET ME D. LIV. III. 79

Nard de Garcie du Iardin.

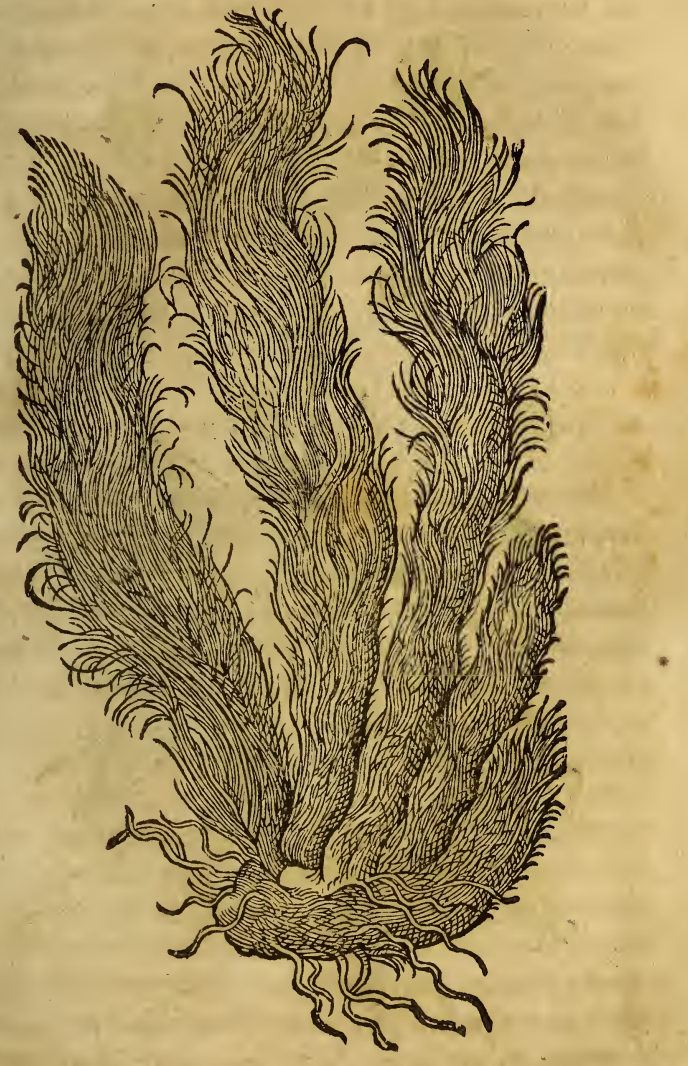

fieurs, n’auons iamais peu fçauoir aux Indes que c'eltoit. 


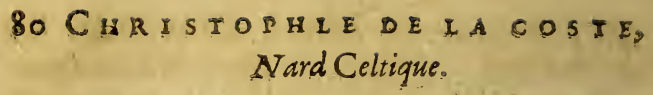
Nard Celtigue.

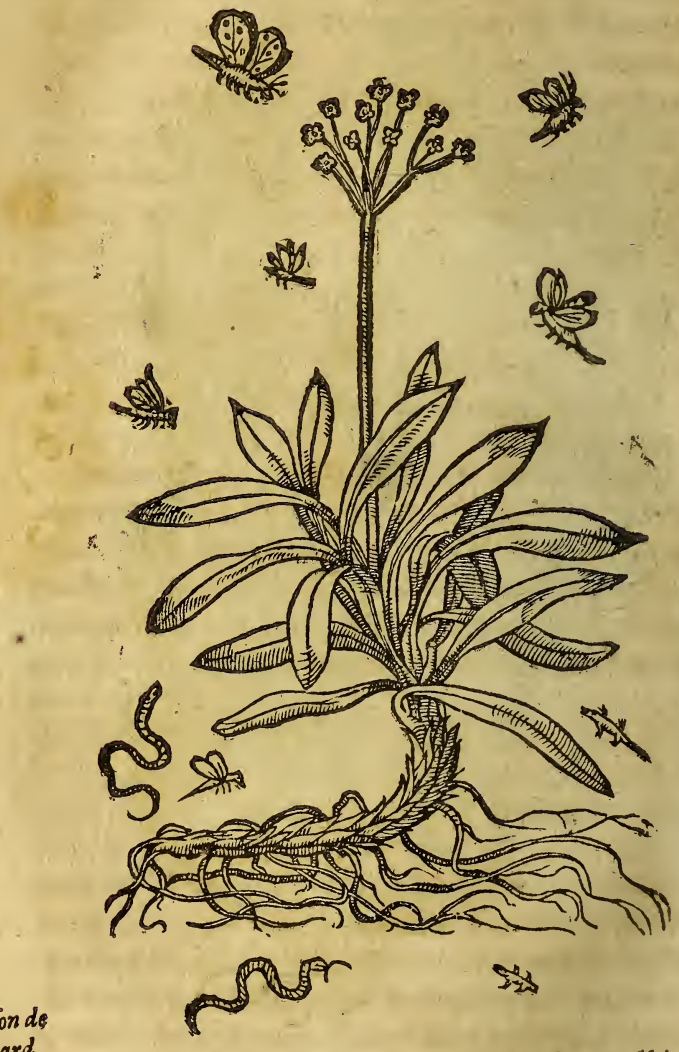

Poifonde

Iezard dor-

Le Plus fubtil venin qu'ils ayent eft appellé $B i_{\text {. }}$ mus. cho de Ormus, c'eft à dire Lezard d'Ormas, qui eft fembla 
DES DROG. ET MED. LI V. III. $8:$ femblable à vn Stinc marin,duquel, \& du trefpernicieux venin d'iceluy, enfemble de la maniere diabolique auec laquelle ils empoifonnent les hommaes, nous en traicterós au liure des anímaux. Le fecond eft le Mangas fauuage, duquel nous parlerons cy deffous.Le troifiefme venin, eft celuy qui fe fait du poil de Tygre:\& finalement celuy qui fe fait d'vne certaine plante qui iette laict, laquelle croift à foifon en Malabar.Le Nappellus auffi tient fon rang.

Du Ionc odoriferänt.
Cн A s. X X V.
Tout ce chapitre eft tiré de Garcie, que i ay eftimé ne deuoir eftre repeté:c'eft pourquoy ie l'anois laiffé en la premiere edition. Si toutesfois quelquivn à enuie de f̧̧auoir ce qu'il a emprunté d. Aymé Portugois : quil feuillette pluffoft l'Enarration d'iceluy Aymé, fur le premier liure de Diofcoride au chapitre du Ionc odoriferant.

Du Cofte.

C и а . XXVI.

-Ce chapitre auffi eft tiré de mot à mot de Garcie : mais d'autant que ledit Garcie ne de fcritpoint les faculte $Z d u$ Cofte comme il aroit promis, o que de La Cofte les a adiouffées de Diofcoride o de Galien, nous les mettrons icy. auec les figures du Cofte de Syrie appellé abufinement d'Arabie, le Cofte Arabique defcrit par Garcic du Iar. din,o le Cofte Indiaue de Diofcoride. 
8. CHRISTOPHLE DE LA COSTE, Cofte de Syrie appellé abufinemént d'A rabie, refermblant augingembre.
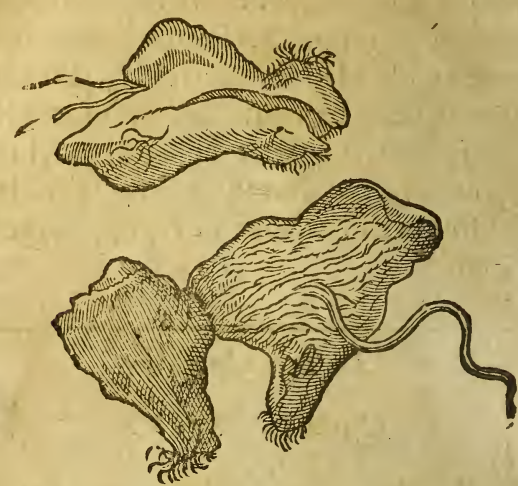

Il a yne faculté d'êchauffer, il fait vriner, il fait fortir les menftruës aux femmes, il eft vile aux Cofte Arabique de fcritpar Garcie du Iardin.
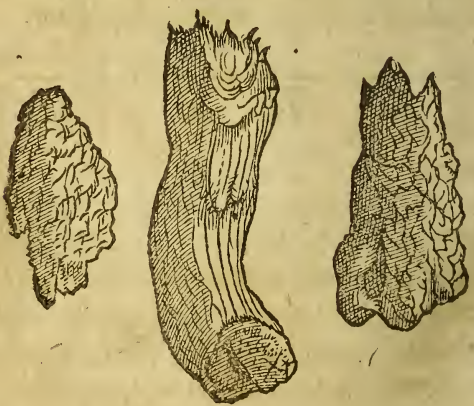

maladicy de la nature de la femme,non foulemen: 


\section{DE S DROG. E T ME D. L I V. III. 8 ;}

\section{Cofte Indigue de Diofcoride.}

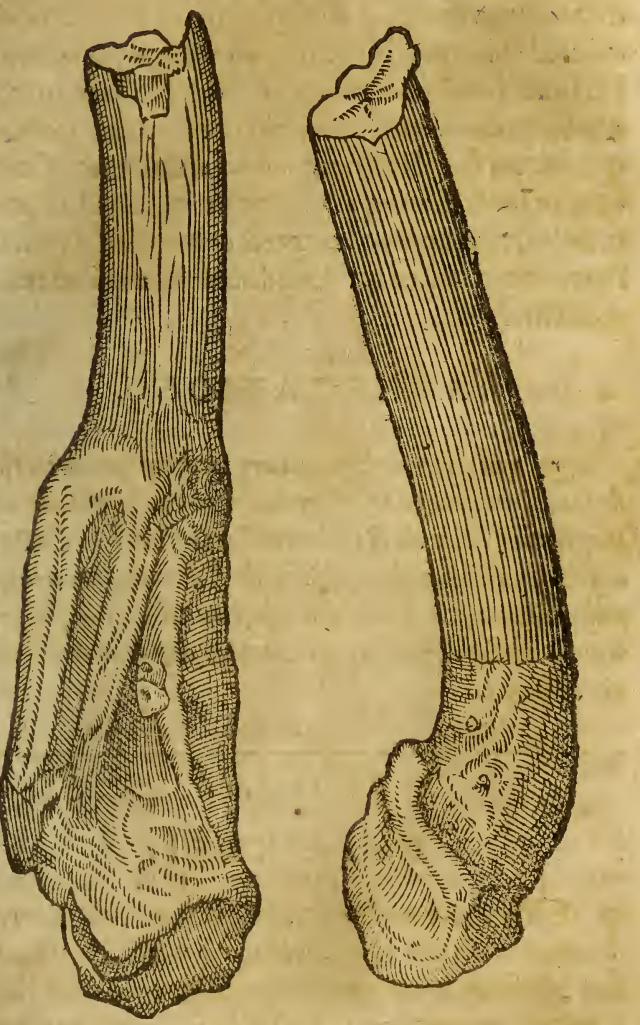

par pefiares, mais par fomentations \& fuftunigto tions, il eft profuable auid contre la morime de FF 2 
84 CHRISTOPHLE DE IA COSTE, viperes, $f$ on en prend le poids de dcux onces : pris auec du vin \& de l'abfinthe, il eft bon aux ruptures, conuulfions \& douleurs de Cofté:beu auec du vin doux il prouocque à luxure : beu auec de l'eau il chaffo les larges vers hors du ventre, il ofte auffi les lentilles prouenantes du Soleil eltans oingtes d'iceluy auec eau $\&$ miel: il eft auff profitable quand on fait liniment auec d'huile de Coftus, contre les friffons qui viennent deuant l'acçez de la fiebure, \& contre les refolutions des nerfs. On lincorpore dans les Antidotes \& emplaftes remollitifs.

\section{ANNOTATIONS.}

24i voudra voir vne extiere defcription des especes de Coste qu'il voye ce que nous en auons cy dewant eforit au premier liure de Garcie du Iardin:là où le Coste Indique de Diofcoride, le Cofte de Syrie abufinement appellé d'A rabie, le Cofte qui croift aux Indes defcript par Garcie du Iardin, font entierement depeints de leurs vines couleurs.

\section{Du Rhubarbe. \\ CH A P. XXVII.}

E R hubarbe eft vn medicament fingulier, \& Ldigne d'eftre honnoré parmy toutes nations,

Lien ò̀ croist le

$R h:$ bar

be. qui croilt tant feulement au milieu de la Chine, d'où on l'apporte en Cantan(le plus fameux \& renommé port en lieu de traffic de toute cefte proCanta, uince oụ habitent les Portugois) \& de là on l'éuoye 
DES DROG. ET MED. LIV. III. 85 aux Indes par vaiffeaux. De cefte mefme contree ville qui eft des plus auät dans $l_{2}$ Chine, on en emporte marcha auffi par chameaux en Ormus, paflant à trauers la de port rens Tartarie \& V v sbeque, \& de là en Perfe, Arabie \& mé pout Alexădrie, d'où puis apres on en fournit toute l'Eu-le nega rope. Ceftuy n'eft pas fi vermolu, \& eft preferé à ce. ce. luy qu'on enuoye aux Indes par vaiffeaux, d'autant quil eft gafté pour la plufpart, car il fe corrompt aif'ement fur mer.

C'eft ce quon peut fçauoir touchant le lieu où croift la rhubarbe, \& ny Garcie du Iardin,ny moy, quelque diligence que nous y ayons peu faire, n'E auons peu apprendre autre chofe.

Quand à ce que quelques vns efcriuent: que les Erreur habitans de ce pays là font infufer la R hubarbe, $\&$ de quel. en expriment le fuc, duquel ils forment des tro- ques vns chifques, apres l'auoir depuré \& deffeiché au So- la prepa. leil,propres pour purger les plus grands feigneurs, ratson \& que puis apres ils enuoyent les racines efpuifées $d_{\text {du }} R$ hus de leur fuc $\&$ inutiles, ce font fables, que i'ay opi'nion eftre vienuës de ce que quelques marchands gentils iettent fur le Rhubarbe le plus fongueux \& vieil (affin qu’il ne fe corrompe, \& que la vermolure ou carie ne s'y engendre)nó de l'eau boüillante,mais tiede, \& puis l'ayant bien nettoyé auec du linge, ils l'enfilent dans des petits baftons, ou dans du filet, $\&$ le font feicher bouchans quelques trous auec du poyure fubtilement puluerisé, \& va peu de cire:\& apres l'auoir bien feiché, ils le conferuent dans la femence du Pfillium oq herbe aux puces.

I'ay appris cecy d'vn marchand de Canarie homme de bien, qui me dis que cela ne fe faifois

$$
\text { FF } 3
$$


86 CHR I S TOPHLE DE I A COST Plante de Rbubarbe tirée apres le naturel.

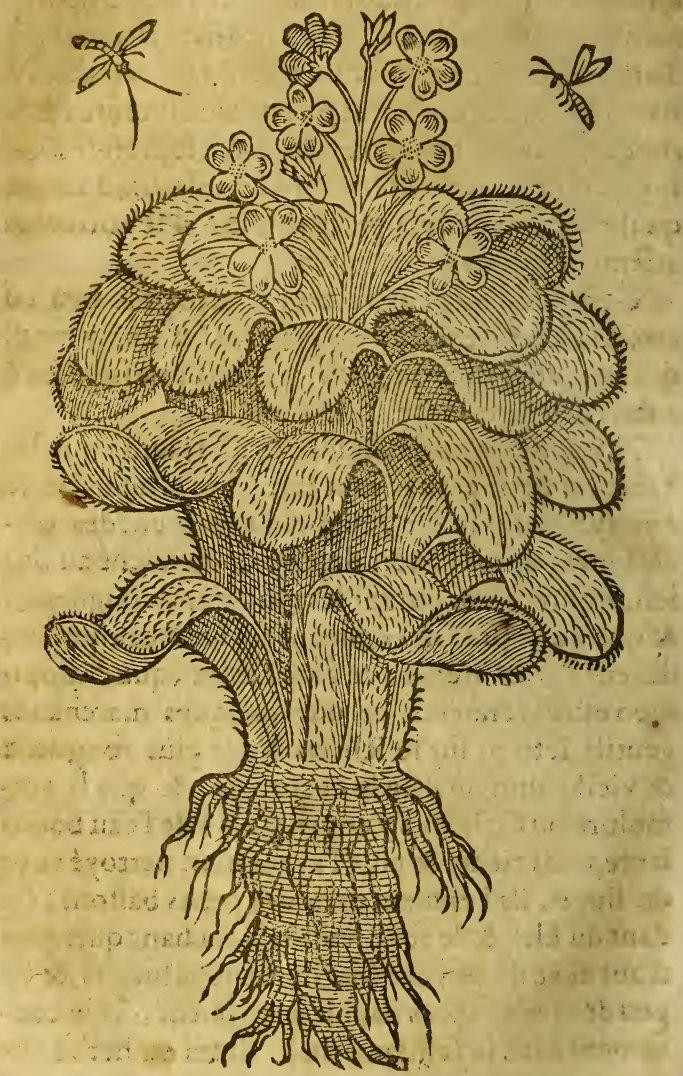

finon que pour empefcher que le Rhubarbe ne fe corrompit, difant outre plus que le R hubarbe au- 
DE.S DROG. E I MED. LI V. III. 87 quel l'on apperceuoit vn trou par lequel il anoit efté percé \& fufpendu, auoit efté preparé en celle maniere;mais que pour cela il ne le falloit moins prifer; \& que l'eau qu'on luy auoit ietté fus, ne luy auoit pas beaucoup ofté de fes forces.

\section{De la racine de Chine. \\ C н A P. XXV VIII.}

Efte excellente drogue s'appelle en la Chine Diuers Lampatan, en Decan Lampaos, en Canarin noms de Bonti, des Arabes, Perfes, \& Turcs Chopbchina. la racine Il en croift en abondance en la Chine il s'en de Chitroume auffi en Malabar, Cochin, Crăganor, Cou ne. lan, Tanor \& autres lieux. C'eft vne plante garnie crasz Cr efpineux, quine Sadefor les plus point mal au Liferon pigt, ayant feuilles femblables au Plantain à larges fcuilles: les racines font aucunesfois de la grofleur d'vn poing,quelquesfois plus petites, folides, pelantes, blanches, aucunefois rougeaftes, \& pour la plufpart du temps attachées les vnes aux autres.

On fe fert fort de cefte racine par toutes les revius prouinces Orientales des Indes, contre plufieurs maladies: voire ils l'eftiment fi peu nuifible, que ceux qui en vfent, bien qu'ils n'obferuent aucun regime de viure, mais mangent librement de chair $\&$ de poilfon, cela ne leur apporte aucune incommodité. Or la façon commune qu'ils obferuent à prendre la decoction de celte racine aux Indes, eft qu'ils font cuire vne once de cefte racine atice deux drachmes de racine d'ache, à petit feu \& fans F F 4 


\section{CHRISTOPHLE DE IA COCIE,}

Racine de Chine de Acosta.

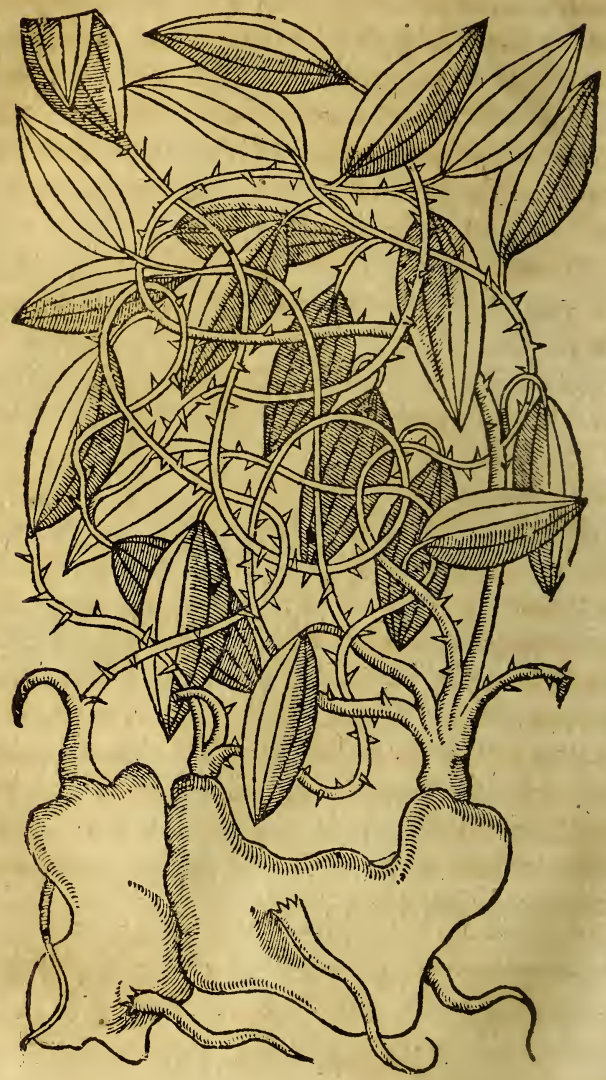

fumee, dans feize liures d'eauriufques à la confumprion de fix liuresiles aurres dix liures reftantes, ils 
DES D R OC. ET MED. LIV. III. 89 les gardent dans vn pot de terre vermilfe, \& font tous les iours de 12 decoction recente, d'autane qu'elle eft fort facile à fe corrompre,ne fe pouuant garder plus d'vn iour. Le malade prend vn plein verre de cefte decoction tiede, \& demeure deux heures dans le lict, puis il fe leue, \& en boit tout autant le foir deux heures deuant fouper, \& parfois il en boir de froide fur iour.

Plufieurs toutesfoys, mefines pendant qu'ils font leurs affaires $\&$ voyagent par mer, prennent tous les jours, foir \& matin, deux dragmes de ceIte racine en poudre deftrempée en vin, ou áuec la decoction d'icelle racine, dont ils fe troument fort bien.

L'on tire auffi par diftillation l'eau de celte racine recente, qui eft fort familiere aux plus delicats: bien que les autres en confument vne grande quãtité, parce qu'ils s'affeurent beaucoup fur icelle, non feulement aux maladies recitées par Garcie, mais auffi en la migraine, aux hernies humorales $\&$ venteufes,aux durillons du col, de la vefcie $\&$ de la verge, \& en leurs vlceres: on tient auffi qu'elle excite grandement a luxure:toutesfois la decoction eft plus excellente que l'eau diftillée. La racine fe' conferue fort bien fi on l'enfeuelit dedans du poyure conquallé.

Eau de Chine. 
CHRISTOIHLE DE IA COSTE. Saffran des Indes do Acofta.

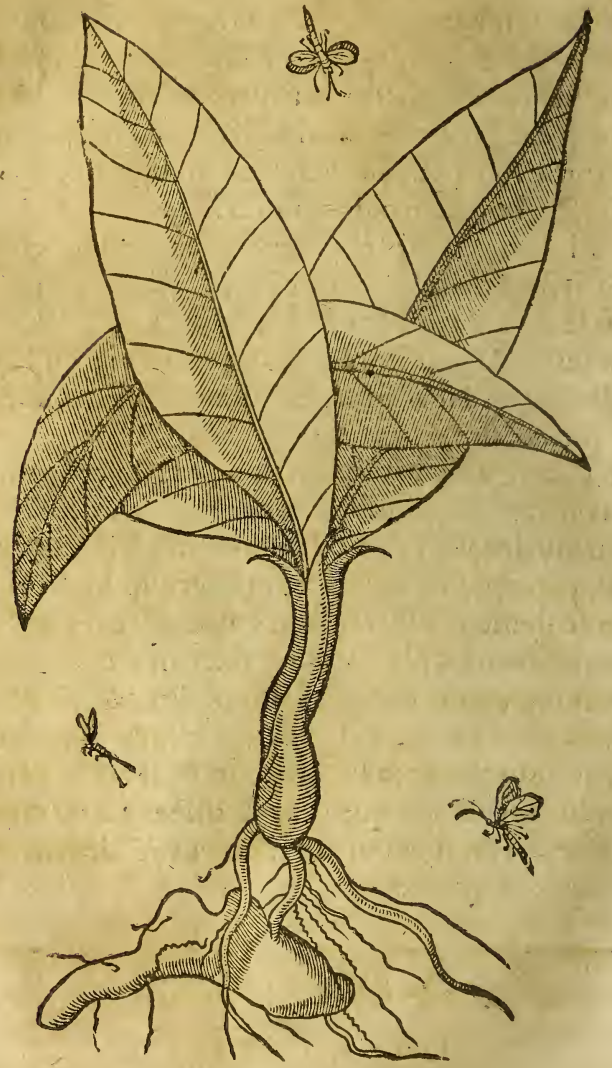

Serapias, elles font de la couleur des fenilles de Scille, mais vin peu plus claires \& minces, $f_{2}$ tige eft faite 
DES DROG. E T MED. L I V. II I. 9 E faite de feuilles, plicées l'vne dans l'autre, \& s'ébraffans mutuellement: fa racine eft en dehors femblable au Gingembre,\& au dedans iaunaftre.

Outre les noms que recite Maifre Garcie du

Iardin, les Arabes l'appellent Curcum.Les Turcs $S a$ - Curcums
Saroth. roth.

\section{Du Galanga.}

\section{C н.A. XXX.}

T L y a deux efpeces de Galanga, qui eft vn medi- Deux if cament fort neceffaire pour l'vfage du genre hu-peces de main, \& digne que les apoticaires en ayent conti- Griang a nuellement en leurs boutiques.

La premiere eft petite \& odoriferante, laquelle eft apportéc de laChine aux Indes, auec le rhubarbe, \& de là on l'emporte en portugal, que les habitans du pays appellent Lauandou. L'autre eff le plus Lauangrand, qui croilt à foifon en Iaua \& Malabar, de la- dow. quelle nous mettrons icy la defcription, d'autant qu'elle eft en plus grand vfage. Elle croift de la hauteur de deux coudées \& aucunefois plus, principalement lors qu'elle rencontre vn terroir fertile:cefte plante à les feuilles femblables au couillon de chien defcrit par Diofcoride au liu. 3.mais toutesfois vin peu plus longues\& larges, d'vne couleur de verd obfcur en haut, \& d'vn verd clair par le bas:fa tige eft faite de rouleaux de feuilles comme aux efpeces de couillon de chien : fa fleur blanche \& fans odeur:fa femence fort petite, de laquelle on ne fair point de conte : la racine pres de lá tefte eft groffe \& bulbeufe, \& au demeurant reffemble at

Gingembre 
92 CHRISTOPHIE DE LA COSTR Galanga de Acofta.

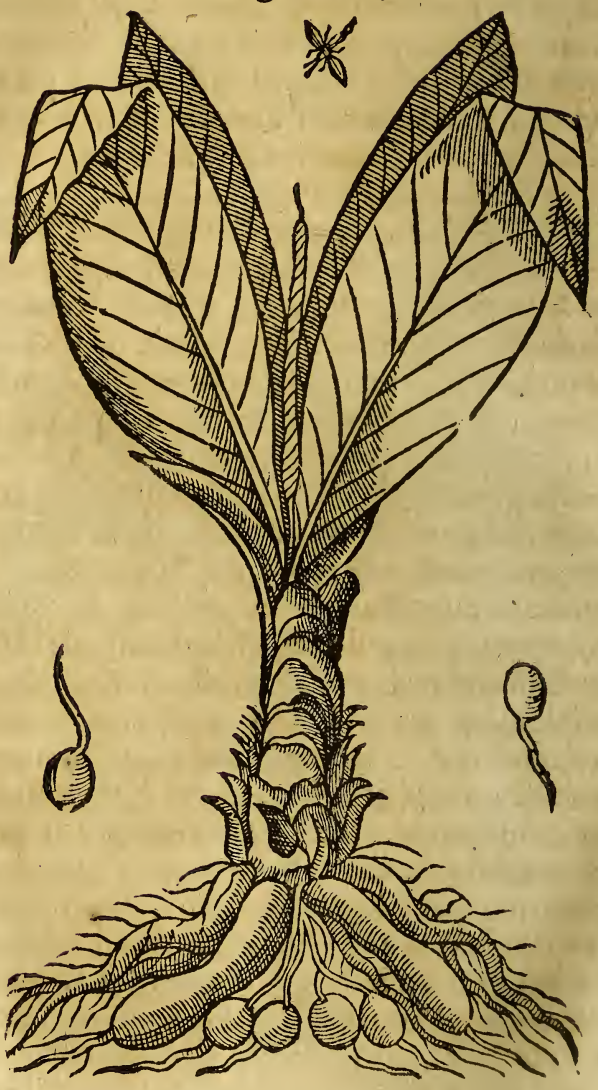

Gingembre, mais plus grande, qui produict par fois des perites reltes comme le grand A phodelle. On 
DES DROG. ET ME D. LIV. III. 93

On le feme par la racine laquelle croift à merueille. Les Brachmanes \& Canarins qui s'en fer- Diuers uent beaucoup, non feulement aux maladies des noms. hommes,mais auff des cheuaux, \& le mangent ordinairement auec du riz, ou auec du poiffon,ou en falade, l'appellent: Caccharu, les Arabes Caluegia, en Iaua Lancuaz, \& en Malabar Cua.

Or l'vfage de celte racine eft fi commun parmy Vlage dus les Malabarois, que non feulement ils s'en feruent Galang pour la guerifon des maladies, mais ils la conuer- or fes tiffent auffi en farine, de laquelle auec du laict, du Coccus ou noix d'Indie, aucunesfois auec du Sura, ou Iagra, ils en peftriffent vne certaine forte de pain, en forme de petis gafteaux, qu'ils appellent A pas:ce pain eft delicat, ils en font prendre à ceux qui ont l'eftomach froid \& debile, aux douleurs de vétre, aux maladies de la matrice, $\&$ aux difficultés d'vrine : en laquelle derniere maladie, ils experimentent vne merueilleufe efficace; foit que la difficulté d'vrine prouiéne de groffes \& choleriques humeurs, ou des ventolités, ou fables ramaflés, aux vreteres,ou au col de la vefcie, ou bien pour quelque carnofité engendrée au col d'icelle, ou aux conduits de l'vrine. Ils donnent à manger ce pain, puis ils font boire vn traict de $N$ impa, (laquelle eft Nimp comme eau de vie ) \& appliquent fur les aynes, fur le penil, \& fur le col de la vef́cie, les feuilles, de Nymphea,cuictes \& macerées en eau, comme elles font toutes chaudes. 


\section{CHRISTOPHIE DE LA COSTE,}

\section{A NN.OTATIONS.}

La defcription du grand Galang a de Maifte Garcie du Iardin,ny celle de c'eft Autbeur, ne me contentent pas, principalement ficelle de laquelle nous nous feruons en l'Europ'e, eft le vray Galanga grand:car les racines d'iceluy reffemblent beancoup mieux, aux racines de l'Iris, gu'à celles de l'A $p$ bodelle, ou du Gingembre. Et à dire la verité ie me perfuade entierement que noftre plus grand $\mathrm{Ga}$. langa,eft une ejpece de Glayeul, femblable peut eftre à ce- luy lequel iay mis le premier en mon Hijtoire des Plan. tes, qui vient d'Hongrie, toutesfois ie n'en affeure rien.

\section{Du Gingembre. \\ C н A P. XXXI.}

Efte plante fort hors de terre, de la hauteur de trois ou quatre empãs, \& $x$ a les feuilles fort femblablesau grand millet, que communement nous appellons Larme de Iob; fa tige eft de la groffeur de celle du petit Afphodelle,entourée de plufieurs feuilles, fi bié qu'elle femble vn petit rofeau, ayant les racines aucunement femblables à celles de l'Iris. Ie t'ay fait icy adiouiter la figure du Gingembr, felon la defcription de Acofta. 
DES DROG. ET MED. LIV.III. 95

Gingembre de Acofta

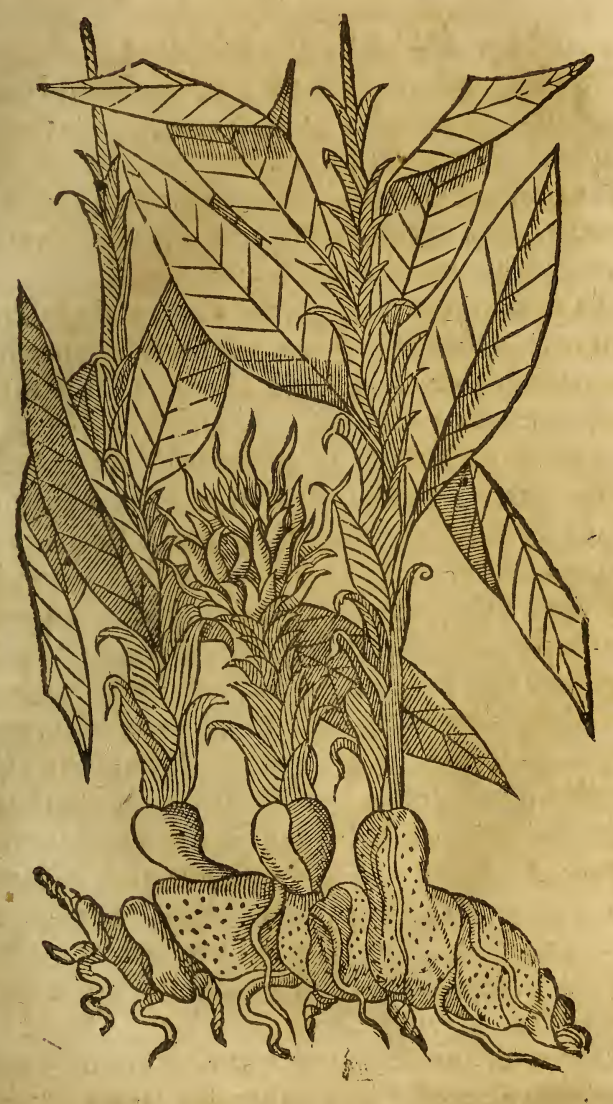

D. 


\section{CHRTSOPHIE DE LA COSTE,}

\section{Dubois de Couleuure. \\ Ch а P. XXXII.}

Deux N trouue en Malabar deux fortes de plantes plaxtes. 1 fort differentes, tant en forme, qu'en la madin bois niere de croiftre, lefquelles toutesfois font appelde Co- Cées de mefine nom, à fçauoir Bois de Coleuure, leusure. d'autant que l'vne \& l'autre font grandement vitiles contre les morfures des ferpens.

Deferi- La premiere croift comme le lierre, de la couption de leur de la grand ferpentine, fes feuilles font prefla pre- ques fémblables à celles du Bryonia ou Coloumiere. urée, entieres toutesfois au commencement, \& qui ont vne nerueure tout le long de la feuille, \& cinq ou fix veines tirans à cofté : par fuccelfion de temps il leur vient des petits trous, lefquels peu à peu deuiennent grands à mefure que les fueilles croiffent, iufques a ce que finalement ils couppent les feuilles \& les rendent femblables à celles de la vigne: car on voit par fois fur vne inefine plante des feuilles entieres, d'autres qui ont de fort petis trous, d'autres qui les ont plus grands, toutes lefquelles font fi diffemblables entre elles, qu'il ne femble point que ce foyent feuilles d'vne mefme plante. Or ce bois a vne fi grande reffemblance aux coleuures, que ceux quine le cognoiftront point, ou qui ne l'auront point veu de iour, s'ils le regardent de nuict au clair de la Lune, ils penferont que ce fera vn ferpent vif.

On tient communement que c'eft vn tref-excellent remede contre $l_{a}$ morfure des ferpens \& des viperes. Les habitans certes s'en allans aux champs, 
DES DROG. ET MED. L I V. III. 27

Premiere eppece du bois de Coleuure.

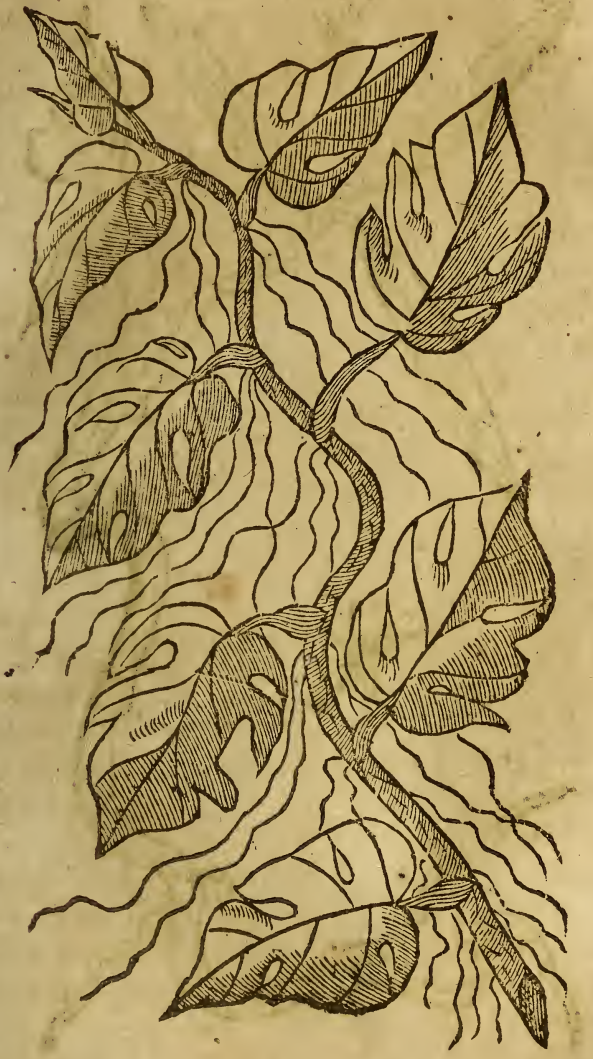

ont accouftumé pour la plufpart de porter de ce bois ( car encefte Prouince la il y a bon nombre de

G G 
29 CHRISTOPHLE DE IA COSTE, Seconde epece du bois de Coleuure de Acofta.

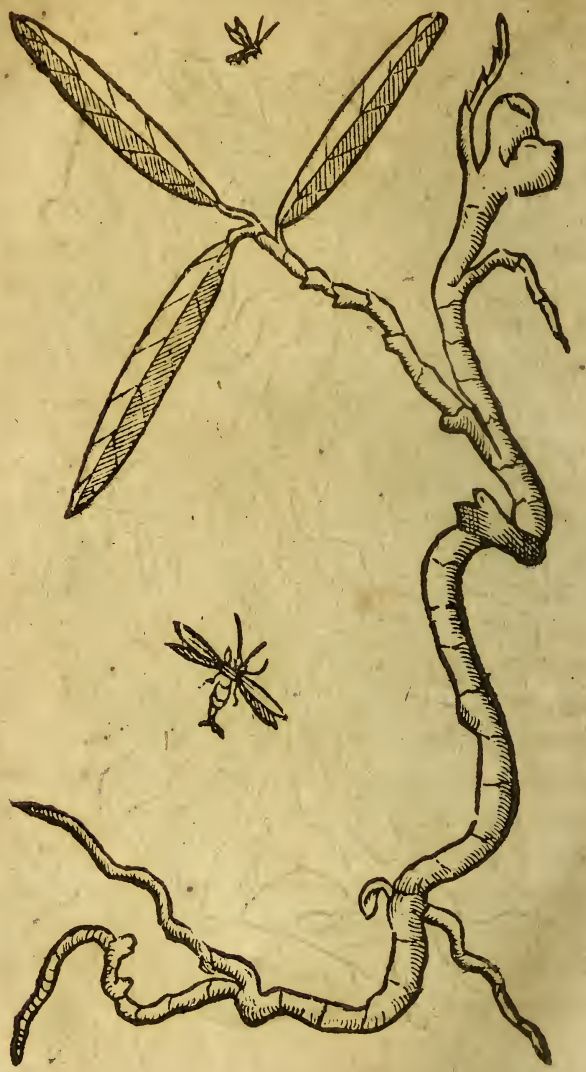

viperes \& diuerfes fortes de ferpens) \& difent que fa fenteur feulement chaffe les coleuures, \& que lors 
DES DROG. ET ME D. LIV. III. 99 lors qu'ils chaffent aux coleuures sils peuuent les toucher auec ce bois, foudain elles fe mettent en pieces \&'meurent.

L'autre eft fort petite \& menuë, \& n'a que trois Defcrifeuilles feulement, molles, liffes, \& d'vne couleur prion ds verde obfcure: ie n'ay point veufa fleur, ny fon fruict, \& n'ay trouué perfonne qui m’affeuraft d'en auoir veu:fir racine eft longue $\&$ mince, moindre que le petir doigt, fortant par cy par là, \& rampant fui la terre : fon efcorce de deffus eft fort defliée \& grife, fans aucune faueur manifefte quand on la goufte, laiffant toutesfois par apres en la bouche, vin gouft fouëf \& odorant comme le Mufc:cefte efcorce a des fentes de rous coltés, \& fe fepare de foy mefme d'auec vne autre plus grofle efcorce, de couleur iaune, qui croif au défloubs de la premiere, qui a vne odeur du Lotus fauuage, ou du Triollet odoriferant, \& vne faueur plus douce que celle de la regalilfe:quand on la marche, on trouue qu'elle a vne odeur trellouefue, \& vne mordication non defplaifante, qui toutesfois ne dure gueres: Ia mariere du bois eft ligneufe, blanche, dure \& infipide: les feuilles ont le gout des naueaux: cefte racine produict fur terre vn germe de la lögueur enuiron de quatre onces, qui s'enfle au formet.

Les Canarins appellent cefte plante Duda Sali.

Ils affeurent que la racine, mile en poudre, \& defrémpée auec eau rofe ou eau commune(car ils en vfent indifferemment.) eft vu remede fouterain \& certain contre la morfure de toutes fortes de ferpens. On s'en fert aulfi fort aux ficbures continues, cierces, fincopes, debilités d'eftomach, \& palpitations de coeur: \& la faict on prendre contre toutes G G 2 


\section{IOO CHRISTOPHIE DE LA COSTE,}

fortes de venins. Plufieurs perfönes mont affermé que lors \& quantes ils anoyent cefte racine en la main, quils riauoyént peur aucunement des fer* Inje. pens,ny de tous autres infectes * veneneux, \& que dat. c'eftoit chofe trefcertaine que les ferpens \& vipeCe font res ne la peuuent regarder, mais s'enfuyent \& fe gcnera. lement routes bestes qui ont couppu- bouche gaftée, ou les dents pourries. Cefte plante reser fe- croift en lieux humides, \&e entre les arbres, princitaratiós, palement aupres de cel:x qu'ils appellent a Ange-
cömse $f_{e}$ : cŏme $\int_{e}$ lins, \& non gucres loing de la mer.
roit en-

arelate- Il fe troutre auffi vne troifiefme efpece du bois fe ér la de Coleutre en la mefme prouince, de la grandcur poiatrine ' 'vn gros arbre, de laquelle nous traicterons en vn

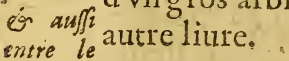

viétrete. năt l'vn s̀l awtre

\section{ANNOTATIONS.}

ferilemẽt

parpesis ces deux ejpeces de bois de Coleunre, auec celles de Garcomme cie, il verra facilement que l'vne ny l'autre ne lewr consöt mouf uient.

B'besgus- a Ie riayiamais pou çanoir quel arbre c'eft qu'Angepes,arai lin,encores que ie m'en fois enguis afjes curieufernent, non

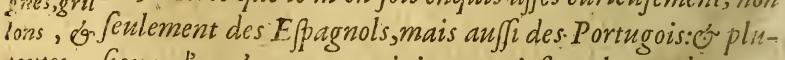
toutes fiewrs d'entrenx ont opinion, que c'eft quelque arbre porrjembia - ticulier de'cefte contrée là, qui nous eft incogneu, is m'e-
bies. Atonne comme nofire Autbeur n'en a point fait de diforipition. 
DES DROG. ET MED. LIV. III. IOI

Dubois des Molucques.

\section{I A p. XXXIII.}

$N$ trouue aux Molucques vn certain arbre ${ }^{O u ̀ ~ c r o i f t ~}$ N troulue aux Molucques vecerés domefțic, de la grandeur d'vn Coignier, les Sa defcrí feuilles duquel font femblables à celles des Mal-ption. ues communes, le firuict aux auellaines, mais toutesfois moindre, \& qui porte l'efcorce plus molle \&. noirafte.

On le plante \& cultine anec grande diligence dansles iardins, \& malaifement le troutue on aidleurs:les habitans en font figrand cas, quils ne le laiffent pas trefmes voir aux eftrangers.

Les liabitans du pays l'appellent Panaua. Or du Panaua. temps que le Sieur Louys de Taide eftoit Lieutenant du Roy en ce pays cy, ceft arbre futappellé de fon nom,d'autăt que ce fut le premier quînous en def́coumrit les proprietés \& vertus fungulieres. Car aduint qu'vn certaih gentil-hóme Portugois nommé Henri de Lima, du temps qu'il eftoit aux. Molucques, fe print garde auec quel foing \& diligence ceux du pays cultiuoyent ceft arbre, \& comme ils le prifoyent, \& partant defireux de fçauoir ric à ric les vertus de ce bois, en fin ils en apprint quelques vnes. Ayant donc recouuert vne piece du tronc de ceftarbre, il en fit prefent au gouuerneur fort fudieux de fçauoir les chofes hóneftes, $\&$ des fecrets de nature, comme d'vn medicament fort neceffaire, \& digne d'eftre cogneu, \& duquel par cy deuant on n'auoit point encores otiy parler.

$$
G G 3
$$


$102 \hat{C} H R I S T O P H L E$ DE I A COSTE,

Or liannee I g6 I .ce Lieutenant du Roy me de. manda $\mathrm{A} i$ auois appris quelque chofe de ceft arbre,ic luy fis recit de quelques vnes de fesproprietez, lefquelles $i$ auois apprifes des autres, me plaignant de ce que ie nauois iamais veu ceft arbre: Iors il me fut prefent de la piece qu'il en auoit, me commandant de l'experimenter auec iugement $\&$ raifon, $2 x$ que ie n'hazardalle la vie de perfonne, \& puisque ic luy filie rapport du fucçés, ce que luy promis de faire.Ie fis doncques l'experience dece bois,tát fur quelques malades que íavis aux hofpitaux, comıne auff à mon retour en Portugal en plufieurs maladies, lefquelles furuiennent foument ¿ ceux qui font des longues nauigations : aidé en partie de ce que i’auois ouy dire de fes facultés, \& methode d'é vfer, partic aufli par ce que ce gentilhomme m'ë auoit appris lors que i’eftois aux Molucques. I'auois veu quelque temps auparauant la femence dudit arbre laquelle m’auoit efté donnée I. fe- $^{-}$potri prendre des oyfeaux : car ils s'en feruent pour mence de la challe, non feulement en cefte contrée là, mais ciftarbre auffien plutieurs autres prouinces des Indes, aufbrofica pour quelle on la porte vendre pour celt effect. Ils en la prife meflent vin peu auec du riz cuict, \& le prefentent à des oy. manger aux oyfeaux fauuages:lefquel's s'ils en mäfeass. Gent, foudain ils tombent tous lourds \& endormis, ceux quien mangent plus, ineurét auant qu'on les puilic fecourir;qui fe fait en leur icttāt de l'eau froide fut la tefte. Les Geays entre tous les autres, meurent aulf toft qu'ils cn ont goufté.

vexus Venons maintenant à la falubre maticre de ceft s. ce arbre,d"vne petite quantité duquel, fe faist grande boss. eftime pour le iourd'huy.

Appliqué 


\section{DES DROG. ET MED. LI V.III. IO\}}

Appliqué au dehors, ou prins au dedans, refifte $l l \int e r t$ dé à toutes fortes de venins.

On fe trouue fort bien de prendre en breutiage, ${ }_{3}$ pijon. vne quantité raifonnable de la poudie d'iceluy, auec eau commune, ou boüillon d'oyfeaux, felon la nećeffité, \& naturel du malade, moyennant qu'elle n'excede pasle poids de dix grains, mais pluftoft moindre, on aualle cefte poudre auec eall, \& ell met on fur les playes pour remedier aux morfures des viperes, \& Roytelets (qui font vne certaine efpece de ferpens tresdangereux qui ont vine crefte)des Afpics, ferpens \& autres beltes venimeufes.

Ils en font auffi prendre en la mefme maniere, à cely qui font bleffés des flefches empoifonnées, defquelles fe feruent fort les habitans de ce pays là.

Ils font de la poudre de ce bois, en la rafpant auec vne lime faicte de peau de chien de mer, ou $v \int a g e d s$ auec quelque lime de fer denliée.

On en fait prendre pour döze aux plus robuiftes demy fcrupule deftrempé en eau rofe, ou commune tiede, ou auec vn boüillon tiede de poulle: mais il faut que ce foit de bon matin, ( \& faut que lon aye legeremét fouppé le foir auparauát)car il euacuë toutes les humeurs, principalement celles qui font groffes, lentes, \& melancholiques:il eft propre aux lógues fiebures quartes, aux continuës, aux Iliaques \& coliques, \& paffions, aux ventofités,à l'hydropifie,à la gratelle, aux difficultés d'v-j rine,à toutes les maladies caufées par furabondaince de cholere, \& autres maladics, comme aufi aux douleurs inueterées des jambes \& ioinetures, alix 
104 CHRISTOPHLE DE LA COSTE, Scyrhes, \& efcroüelles. Il tü̈ toutes fortes de vers, \& fait reuenir l'appetit perdu:que s'il euacuë Canja. par trop, il faut que le malade boiue vin demi plein verre de Canja, c'eft à dire de decoction dorge, ou qu'il mange vn petit oyfeau, tout foudain l'operation cellera, qui eft certes vne chofe fort remarquable, \& non commune à toutes fortes de medicamens, tellement que c'eft la puiffance du medecin ou du malade, de purger autant qu'on veut. Outre plus il n'eft point de mauuais prendre, \& ne donne aucune nauféc, ou crainte, mefmes qu'on le peut prendre fans vfer d'aucune diete, \& tenir' chambje, tellement qu'on peut faire fes affaires \& fortir à l'air, cóme i'ay appris \& remarqué en ceux qui eftoyent dans mefme batteau auec moy, qui ne fentirent aucune incommodité en fe purgeát, ains vefquirent à tout abandon.

Soy ex.

cellence.

I'ay auffi obferué \& recogneu l'excellence de ce modicamét, aux douleurs inueterées de teftè,en la migraine, en l'Apoplexie, bruict d'oreilles en la gonte, maladies de l'eftomach, fuffocations de la matrice,cōme auff aux Afthmes, \& partant ayant vne grande fiance en iceluy, ie l'ay mis heureufeinent \& fouuét en vagge,en diuers naturels,aages, \&. licux, fans aucune molefte: fi ce n'eft que ie me fuis apperçeu qu'il apporte quelque fafcherie aux tatures bilieufes, \& à ceux qui ont l'eftomach chaud, iufques à ce qu'ils euffent pris leur refeCiron, \& en d'autres qu'il excitoit à yomir:mais 'iay fait aucunesfois prendre cefte poudre aux bilieux; deftrempée auec du Sirop aceteux, ou auec du Carambolas confit, ou bien reduicte enforme de pil. lules auec du fucre rofat.

ll fe 


\section{DES DROG. ET ME D. L I V. III. 10,5}

Il le faut faire prendre de bon matin, \& ne faut permettre de manger ny boire, iufques à ce que la purgation foit fuflifamment faicte, \& alors il faut aualler vn boüillon de poule tiede, \& demy heu: re,ou vne heure apres, on luy permet de manger d'vn poulet, \& boire de vin bië trempé:puis il faut que tout le long de ce iour, il s'abftienne de boire iufques au fouper, quifera fort leger, \& de chofes de facile digeftion. Le iour fuyuant on luy faict prendre du fucre rofat deftrempé auec eau de bugloffe, ou commune, \& luy donne on vin cliftere pour lauer le ventre.

Il aduient auff parfois qu'il excite à quelques vins vne demangeifon \& efcorcheure au fondement, \& à d'autres(mais fort rarement)des hemorrhoides.

C'eft tout ce que i'ay peu voir \& apprendre de ce bois de Panaua : \&r maintenant ils s'en feruent fort en ces contrees là, \& en font fi grand conte, qu'ils en vent fans crainte d'aucun danger en toutes les maladies fufdictes. I'en ay pris par deux diuerfes fois en la cholique paffion, \& en la mygraine, \& ay troulé qu'il m'eftoit falutaire,\& fort profitable à ces deux maladies.

Au demeurant d'autant que pour fes fignalées, proprietés, les gens du pays le prifent fort,\& qu'ils tafchent de nous les cacher entant qu'en eux eft; lefquelles fans doute font beaucoup plus grandes, que colles que nous en fçauons, il faut efperer qu'auec le temps(qui defcoumre toutes chofes)nous aurons la cognoiflance des autres chofes, qui nous font iufques icy incogneuës, lefquelles nous raconterons fidellement dans ce traicté que nous

G G. 5 
106 CHR ISTOPHLE DE I A COSTE; auons en main, fi nous les pouuons apprendre, auant qu'il foit mis en lumiere.

Du Moringa.

\section{CHA P. XXXIV.}

Histoire E Moringa eft de la grandeur du Lentifque, du Mo- 1 auquel il a des feuilles fort femblables:il a fort ringa. peu de branches, qui eft l'occafion pour laquelle, il faict forr peu d'öbrage, il a beaucoup de nouds, \& eft fi fragile, que tant le tronc que fes branches, fe rompent fort-zifément: fes feuilles font d'vn verd obfcur,\& couleur viue : elles ont le gouftes feuilles de naueau : il porte vn fruict d'vn pied de long, de la groffeur d'vn raifort, embelly de huict angles, de couleur claire entre verd \& gris, blanc au dedans, moëlleux, \& diftingué en certains rece-. ptacles, dedans lefquels font contenuës certaines petites femences rondes, femblables à l'Ers, verdes $\&$ fort tendres, mais qui ont vn gouft plus acre que les feuilles. On mange ce fruict cuict auec de la chair, ou apprefté autrement.

Son a fa- La racine de ceft arbre fert au lieu de la corne de

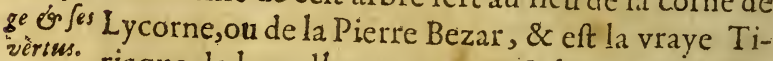
riaque de laquelle communemét les gens du pays fe feruent, tant contre toutes fortes de poifons, que contre la morfure des ferpens les plus venimeux, qu'ils appellent communement Culebras do Capillo, \& des autres infectes, \& beftes venimeufes, tant appliquée au dchors, que prinfe au dedans. I'ay recogneu cu'elle eft d'vne vertu finguliere en la Cholique pafion. Orila mefle parmy les remedes 
DES DROG. ET MED. LIV. III. 107 Moringa de Acofta.

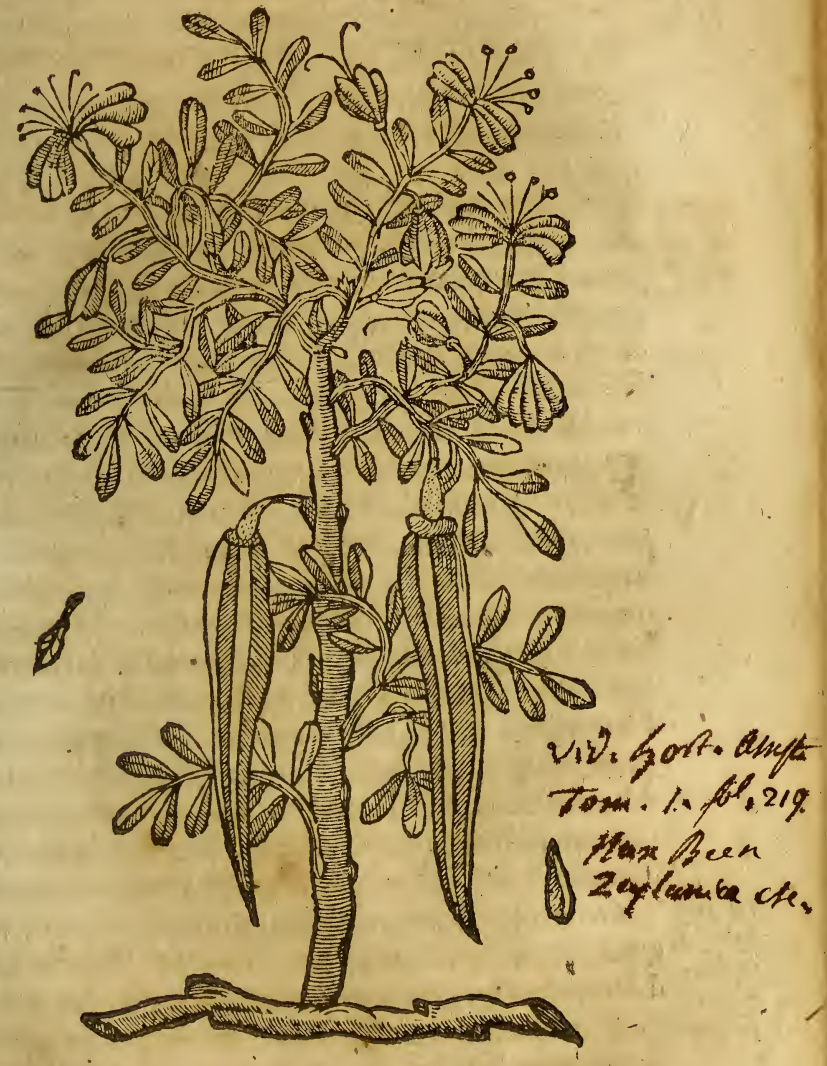

qui purgent l'humeur melancholique : \& eft fort cogneuë de ceuxi qui font affligés de ladrerie, de laquelle 
108 CHRISTOPHLE DE L A COSTE, laquelle on dit que plufieurs en font gueris par vit long vfage d'icelle.

Le lies. Il croift en diuers lieux, \& en fort grande abondance, mais principalement par toute la Prouince de Malabar, du long de la riuiere, de Mangate, où elle fe plaift merueilleufement, \& porte grande quantité du fruict, qu'on porte vendre au marché, ainfi qu'on faict les febues en Efpagne.

Diuers Les irabes \& Turcs l'appellent Morian:les Pernoms. fes Tame:\& ceux de Guzarate Turiaa.Ie t'ay fäit icy mettre la figure de l'arbre qui porte le Moringa,

\section{De la Pierre Bezar. C н A p. XXX.V.}

F Ncores bien qu'en vn autre traicté (que nous Lefperons de faire des beftes à quatre pieds, ferpens, oyfeaux, qui fe troument aux Indes)nous ferons mention de toutes les pierres precieufes dont on $\mathcal{\complement}$ fert en medecine $: i$ 'ay toutesfois troutué boin de faire en ce liure vne def́cription de la pierre Bezar, de laquelle tous ceux qui ont efcrit, ou qui

$\therefore \quad$ lont mife \& mettent en prattique, afferment d'vin

* . comnun accord, que ceft vn tref-excellent medi-

- camein \& Antidote à toutes fortes de venins, non - ferlement prife au dedans, mais auffi appliquée au idehois.

- Ia grof- On trouite de ces pierres de diuerfe groffeur, fila pierre gure, \& coulcur : car il y en a qui ne pefent qu'vne Bizar, demy drachime, d'autres qui én pefent douze, \& fa forme quinze, comme i'enay veu:\& dit on qu'il s'en trouor fes ue encores de plus grolfes : il y en a dauantage de vertus. rondes comme vne auellaine, d'autres auffi plus longues, de la forme d'vn ouf, ou bien d'vine pe-

tite 
DES DRO G. ET ME D. LIV. III. IO, tite colomne, d'autres qui ont trois quarrés, d'autres plattes d'vn colté,\& bolliës de lautré, comme les chaftaignes:finalement il y en a de couleur verde tirant fur le noir,d'autres qui font de la couletri des Verengenes, * d'autres font plus obfcures, ${ }^{*}$ Cés töd'autres font d'vne couleur verde plus claire, \& mes apquelques vines auffi font iaunes.

"Verengepellees certains animaux prefques femblables au bouc, de les Fran la grandeur d'vn gros belier, de couleur rouffe, cois, font prefues comme vil cerf, fort agiles, ils ont l'ouye appellées pretques comme vin cerf, fort ar les fort fubtile \& aiguë, que les Perfiës appellent $P a-$ traliens, $z$ an, qui fe trouue en diucres Prouinces des Indes, Petrancomme au Promontoire de Comorin, \& en quel- ciani. quesilieux de Malaca, \& auffi en Perfe, \& Corafo- Où; est ne, \& aux Ifles qui ont tiré leur nom de Vache: engendré femblablement en l'Amerique, comme racon- re. te Pierre de Ofma, en vine epiltre qu'il a efrrite Pazan. au Sieur Monard.Et tout ainfi que ces pierres font differentes en couleur \& figure, auffi elles varient en poids \& fubitance:car vous verrés des Bezar de té fó dif mefme grolfeur, qui feront plus lecers \& plus pe- firence. fans les vns que les autres, \& garnis de tuniques, lés vns plus, lés autres moins, \& quelques vins conrtinués iufques au centre, au milieu defquels on trouue vne certaine poudre, en d'autres quelque chofe qui refséble à vne herbe feiche, \& plufieurs au centre defquels on troutc tant feulement vne petite paille ou feftu deflié, autour duquel plufieurs penfent que la pierre fe forme.

Celle qui viennent d'Orient font eftimées les plus excellentes, \& entre toutes celles qui viennét de Perfe.Il y en a qui felon le dire d'aucuns, vient tous 
II 2 CHRISTOPHLE DE LA COSTE, I quoy tous les quinze iours de la poudre de cefte pierre, of profi- ayans opinion que par ce medicament les parties fe pierre vitales du corps, \& les membres qui feruent à la geBezar. neration font corroborés.

chaf- On affirme qu'au pays où fe trouuét les animaux seurs des qui engendrët cefte pierre, les vencurs font fl exermaxi- cés \& experimentés, que par le feul regard, ils maux peunét iuger quels des animaux ont des plus grofguiendrent fes pierres dedans leur ventricule, \& difent que cefte pier ceux qui portét des plus groflés pierres, font moins re. agiles, \& beaucoup plus melancholiques. Et que parfois on en trouue des morts,dedans l'eftomach defquels y a de fort grofles pierrés.

Excelle- Au demeurant ces pierres font de fi grand prix se de ce entre les Gentils, \& habitans de ce pays là, qu'ils
ste pierre ont accoultumé de dire:que bien queDieu aye creé routes chofes pour l'vtilité des hommes, toutesfois c'eltoir quafi dommage que celte pierre fullé conuertie en autre vfage, que des Roys \& perfonnes iffués de noble race, veu que pour livfage de la po. pulace en lieu du Bezar, Dieu auoit creé la racine de Moringa,de laquelle nous auons parlé au precedent chapitre.

\section{Del'Arbre Trifte.}

\section{C н A. X. XXVI.}

Swalité de lar. bre iriste, $\delta$ so qui eft de la grandeur $\&$. figure prefque d'vn Prulieu na nier,ayant plufieurs branches minces, diftinguécs d'vo petit nœud par certains intermalles, duquel d'vine 
DES DROG. EY MED. LIV. III. III

Arbre Trifte de Acofta.

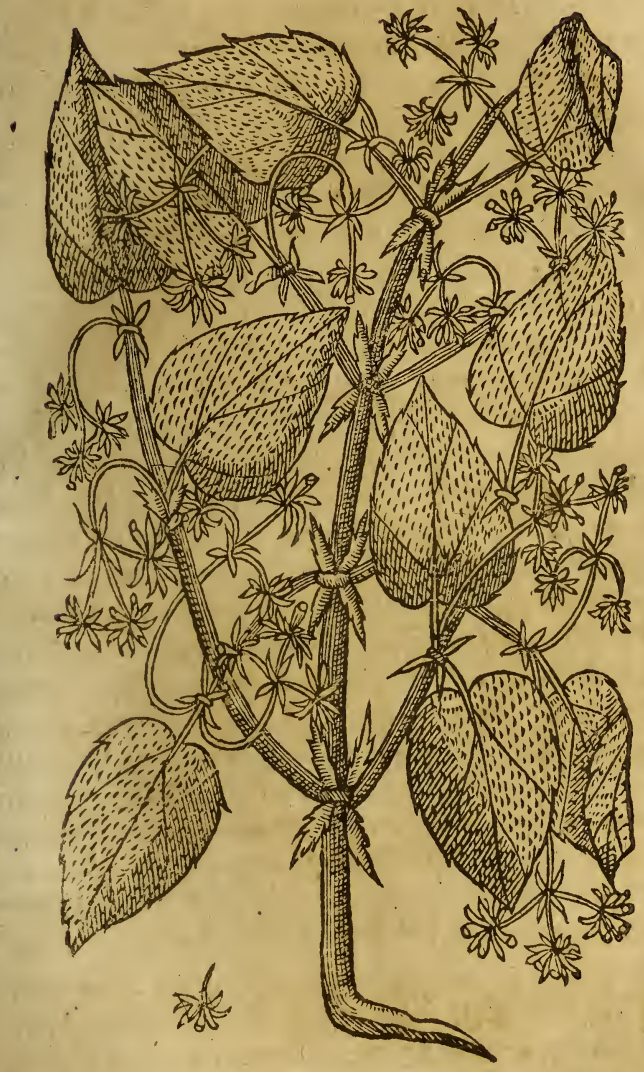

d'vne part \& d'autre fortent déux feuilles, qui font de la grandeur \& largeur de celles d'vn Prunier, molles, 


\section{$112 \mathrm{CHR}$ ISTOPHLE DE LA COSTE,}

molles, \& lanugineufes en dehors, comme prefque celles de faulge, \& verdes, \& vn peu afpres en dedaiss, non toutesfois fi dentellées aux enuirons, cóme celles du Prunicr,ny mefnes elles n'ont point tant de veines. De l'afinette de chaque feuille fort vn pecoul qui a cinq petites teftes au plus haut, qui font compofées de quatre petites feuilles rondes, du milieu defquelles fortent cinq fleurs blanches tref-belles, de grädeur \& figure des fleurs d'oréger, plus minces toutesfois, plus belles, plus defliées, \& plus odoriferantes, \& dót le pecoul tire pluftoft fur le rouge que fur le iaune, auec lequel ils donnent couleur a leurs viandes en ce pays là, tout ny plus ny moins, comme nous faifons auec le Saffră: fon fruict eft de la grolfeur d'vn Iupin, verdoyát, ayãt la figure d'vin cour eftăt couppé par le milieu tout de fon long, il a dẹảs foy vin certain receptacle d'vne part \& d'autre, dedans lequel y a vne femence, qui eft de la groffeur d'vn noyau de carrouges,ou Silique, retenant la figure d'vn cour, blanche,têdre, couuerte d'vne membrane vin peu verDiuers de, \& aucumement amere.

noms.

Ceft arbre eft appelle en Canarin Parifutaco, en Malayo Singadi, en Decan Pul, des Arabes Guart, söoteur. les Perfes, \& Turcs Gul.

Ceft vne chofe veritablement remarquable, de voir ce tresbel arbre, chargé de nuict de plufieurs fleurs, d'vne foüefue \& agreable odeur, \& des aufii toft que les rayons du Soleil s'efpendent fur luy, nơn feulement il iette à terre fes fleurs, mais atri il femble que tout l'arbre auce fes fleurs eft flctiri.

Et à la verité entre toutes les ficurs le fquellés iay iamais fenti, ie n'en troume point felon mon 
DES DROG. ET MED. LI Y. III. II 3 ingement que fe puiffent ef galer en odeux aे cellescy, principalement lors que du commencement, on entre foudain au lieu où c'eft arbre eft planté: car apres qu'ó les a touchées de la main, leur odeur fe perd tout incontinent.

Les gens du pays eftimét que les fleurs font propres à refiouir le cour, mais elles font vn peu amexes:car i'en ay mangé quelquesfoys, \& des fraichement cueillies, \& parmy les viädes, mais i'y ay toufiours recogneu quelque petite amertume. Les medecins gentils aufl, mettent la femence au rang de celles qui confortent le cœur,

Plufieurs Lieutenans de Roy, grands Seignetrrs, Vertu \& autres perfonnes priuées, ont voulu tranfporter fleurs, son c'eft arbre en Portugal,mais ç'a efté en vain. I'é ay de fa foaufi cogneu quelques vns, lefquels apres auoir mence. cueilly fa femence lors qu'elle eftoit meure, \& l'anoir mife dedans des vafes de terre verniffés \& bië boufchés, \& dans des vafes d'argent \& des boittes de bois, l'ont apportée en Portugal, où ils l'ót femée auec grand foing \& diligence, mais clle na iamais voulu croiftre.

Il croift auec telle facilité en Malabar, Goa,\& autres lieux circonuoifins, que chafque rameau qu'ors fiche dans terre prend.

Du Negundo.

\section{Cha r: XXXVIT。}

N troume deux fortes d'arbres en plufieurs Deux for lieux des Indes, \& principalement en la pro- tes deNe uince de Malabaz, qui font fort recommandées en gundo. 
II CHRISTOPHLE DE IA C OSIB, l'vlage de medecine, à caufe qu'ils ont des grandes proprietés contre plufieurs maladies

Defcri- La premiere des deux qui eft le malle,appellé par paprensie les Canarins Varabo Nigunda, eft de la grandeur re ejpece. d'vn amandrier, ayant les feuilles verdes fur le reply,\& au dedans lanugineufes \& veluës, commeles feuilles de la fauge, dentelées aux enuirons, tellement à qui les regarde dé loing, ellés reflemblent eftre feuilles du Suzeau.

L'autre efpece appellée Negundo femelle, des Portugois Norchila, des Canarins Niergüdi:en BalaSate Sambali,en Malabar Noche, l'vn \& l'autre tant malle que femelle, eft appellé des Arabes, Perfes, \& habitans de Decan Bache, \& des Turcs Ayt. Il croift de la mefme grandeur que le premier, mais il a les feuilles vin peu plus larges, \& plus rondes, \& non détellées aux enuirós, fẹmblables aux feuilles du Peuplier blanc.

Lès feuilles de toutes les deux efpeces,ont la fé. ceur \& la faueur de la fauge:il eft vray qui bien les \&ouftera, les troutuera vn peu plus acres $\&$ ameres: en plufieurs feuilles fur l'enuers, on void de grand matin, vne certaine efcume blanche, qui fort d'icelles la nuict. La fleur de l'vne $\&$ de l'autre eft de couleur grife, \& approche fort à la fleur du Rof. marin. Le fruict de l'vne \& l'autre eft femblable au Poyure noir, d'vin gouft acre, mais qui ne brunc point conme le Poyure, ains prefque pareil au Ginsembre.

Ils conftitnent l'arbre en vin degré moyennement chaut, \& attribueut vin peu plus de chaleur aे la fernence.

Yetzis, Les fcuilles, lesflcurs \& le fruit conqualiés \& boiillis 
DES DROG. ET MED. LIV. III. IIS Negundo mafle de Acofla.

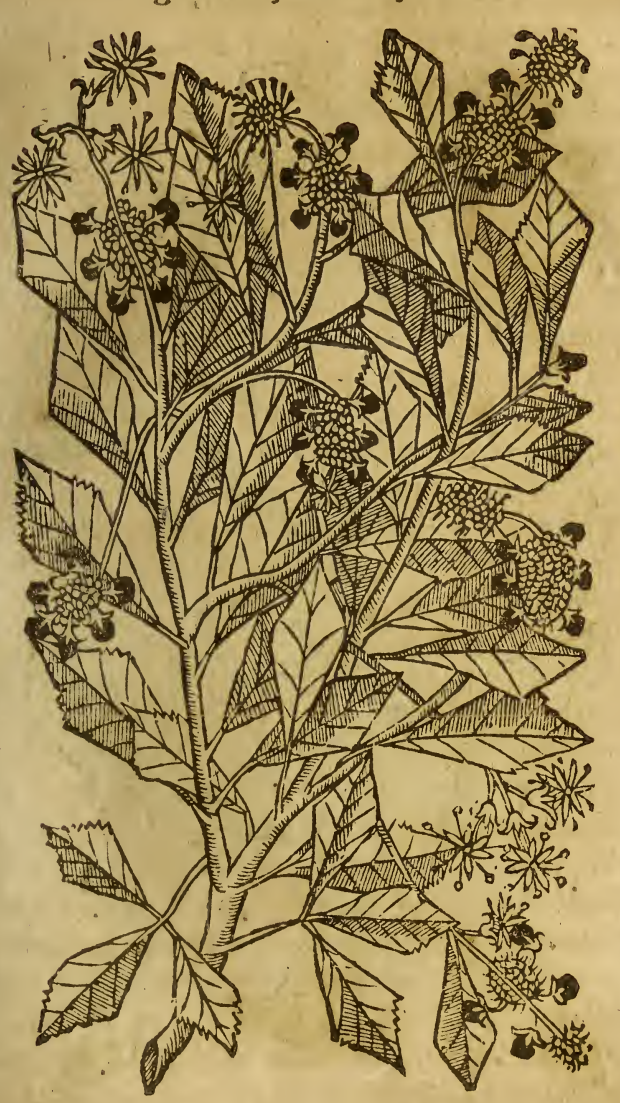

bouillis dans l'eau, \& fricaffés en huille, font ap. pliqués autec vtilité, fur toutes douleurs prouenan$\mathrm{HH}_{2}$ 
IIG CHRISTOPHIE DE IA COSTE Negundo femelle de Acofta.

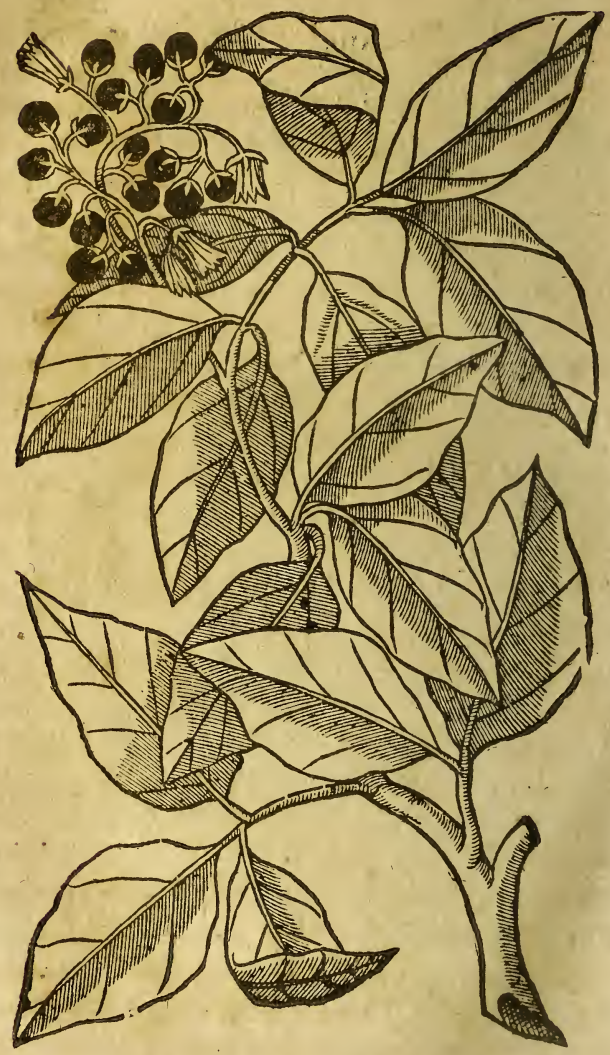

tes de quelque caufe que ce foit: principalement aux douleurs de joinctures caufées de froid, \& pro. duifent 
DES DROG. ET ME D. LIV. III. $1: 7$ duifent des merueilleux effects aux tumeurs \& contufions.

On applique auffi fur les vieux vlceres, les feuilles d'iceluy broyées auec vn heureux fuccés, d'autant qu'elles digerent ta matiere d'iceux, les mondifient \& les font cicatrifer, moyennant que le corps ne foit pas remply de mauuaifes humeurs. Et à dire verité ils recognoiffent vne telle vtilité d'icelles, en toutes playes, apoftemes \& cótufions, qu'à cefte occafion ils re peuuent fort facilement paffer des Chirurgiens.

Ies femmes en tout temps fe lauét tout le corps Decotitio de la decoction des fufdictes feuilles; \& ont cóçeu les. vne telle opinion, que les feuilles, fleurs, \& fruict du Negundo, aident à la conception, qu'elles lapideroyent volontiers celuy, qui leur voudroit faire. accroire que cela n'eft pas.

C'eft arbre auffi eft fort cogneu des fages femmes, lefquelles ils appellent Dayas.

L'vage de ceft arbre pour medicamentereft fil brest fiequent en ces pays, que fi par permiffion diuine fort $v_{0}$ les rameaux ne venoyent à renaiftre abondam- fusbo ment, à mefure qu'ils les couppent, il y a ja long temps que tous les arbres feroyent confumés ou certes ils feroyent de grand prix:mais tant plus on couppe les branches, tant plus il en renaif, qui font continuellement verdes.

Du Nimbo.

CнA в. XXXVIII.

T y a vn autre arbre duquel on fe fert en la me. decine, les Chreftiens, Gentils, \& autres habi- 


\section{CHRISTO PHIE OE LA COSTE,}

Diuseres rans de ces prouinces des Indes, en font fort grand appella- cas, toutes fois il eft bien rare:ceux quile cognoifsions. fent tappellent Nimbo, ceux de Malabar Bepole.

Defcri- Ceft arbre cit de la grandeur d'vn Frefnc,auquel ption de il femble eftre fort femblable quand on le regarde l'arbre de bien loing:les feuilles font verdes d'vin cofté $\&$ d'autres, n'eftans aucunemét veluës, elles font dęntellées aux enuirons \& pointues: les rameaux iettent grande quantite de feuilles, \& abondent en petites fleurs blanches, compolées de cinq feuilles, qui ont au milieu certains petits filets iaunes, \& fentent comme le Lotus faurage, ou Triolet odoriferant: fon fruict eft femblable à des petites oliues,iaunaftre, ayant vne efcorce fort defliće, croiffánt aux ailles des petites branches.

Veriss. Les feuilles de ceft arbre font vn petit aineres, \& font fort falubres mifes fur les playes fordides, cauerneufes, \& pleines de callus, tät d'hómes que des cheuaux, apres les auoir broyées, auec da fuc de limons, d'autant qu'elles digerét nettoyét, font regenerer la chair, \& les font cicatrifer.Le fuc auffi des feuilles eft tres ville, pris par la bouche dảs du vin, ou dans vin boïilló de poule, ou appliqué tout feul fur le nóbril, ou auec vn bien peu de fiel de bœuf, ou auec de l'Alö̈s, ou du vin aigre, pour tuer \& faire fotir du corps toutes fortes de vers : voita pourquoy ceft vin remede fort cö mun \& familier à tous les habitans de ce payslà,principalament de Malabar, dautant qui'ils font giandement fubiects aux vers. On fe fert aufli fort de fes fleurs \& fruicts, aux douleurs des nerfs, tumeurs, debilité,foiblelles de membres, \& aux apoftemes.

L'huile 
DES DROG.ET ME D. LI I V. III. IIg

Nimbo de Acosta.

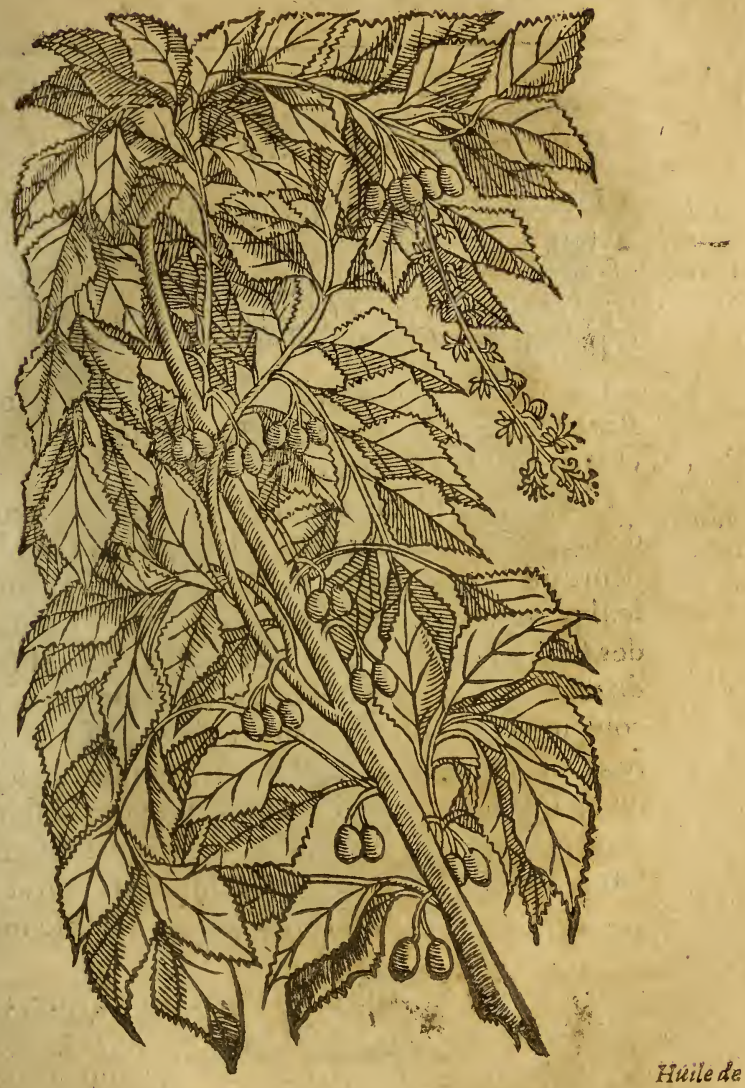

L'huile auffi qu'on tire de fon fruict, eft grande- Nimbo ment en vfage contre les douleurs de neifs : car profita. HH 4 
220 CHRISTOPKIE DE IA COSTE, ble aux auec iceluy ceux de Malabar gueriflent les picdesnerfs queures \& contractions.

\section{Du Iaca.}

\section{C н P. XXXIX。}

Le lieu TL croift $\nabla n$ arbre en quełques Inles des Indes, le où croist long des eaux : lequel bien qu'il ne foit d'aucur de Iaca. vfage en medecine, toutesfoys il ne le faut point laifler en arriere,à caufe de la grandeur d'iceluy, \& la beauté de fon fruict.

Noms Les Malabarois l'appellent Iaca, les Guzaratoi d'iceluy. Panax \& Iaca: les Canarins Panafu: les Perfes en changeant P.en F.Fanax.

Defcripition du Isca.

$C^{\prime}$ eft vn grand arbre portant des feuilles larges d'vn empä,de couleur verde, claire, ayans vne nerueure groffe \& dure, qui s'eftëd du long de la feuille:il porte vne pomme, non du germe ou affiette des feuilles comme les autres arbtes, mais il fort du tronc des plus groffes branches, long, gros de couleur verde obferre, coutuert d'vne grofle $\&$ dure,efcorce,entouré de toutes pars, comme de pointes de Diamans, lefquelles finiffent en v-ne efpine courte, verde, qui à vn efgrillon noir au fommet. fort femblable à l'efpine du Durion, mais non acerée \& picquante, encores qu’elle en femble menaffer.

Le moindre des fruicts que porte celt arbre, eft comme yne groffe courge, voire plus gros, principalement en Malabar, où croiffent les meilleurs: car ceux qui naiffent en Goa font moindres, pires, \& plus infipides. Quand ce fruict eft meur,il rend 
DES DROG. ET MED. LIV. III. II\$ Iaca de Acofta.

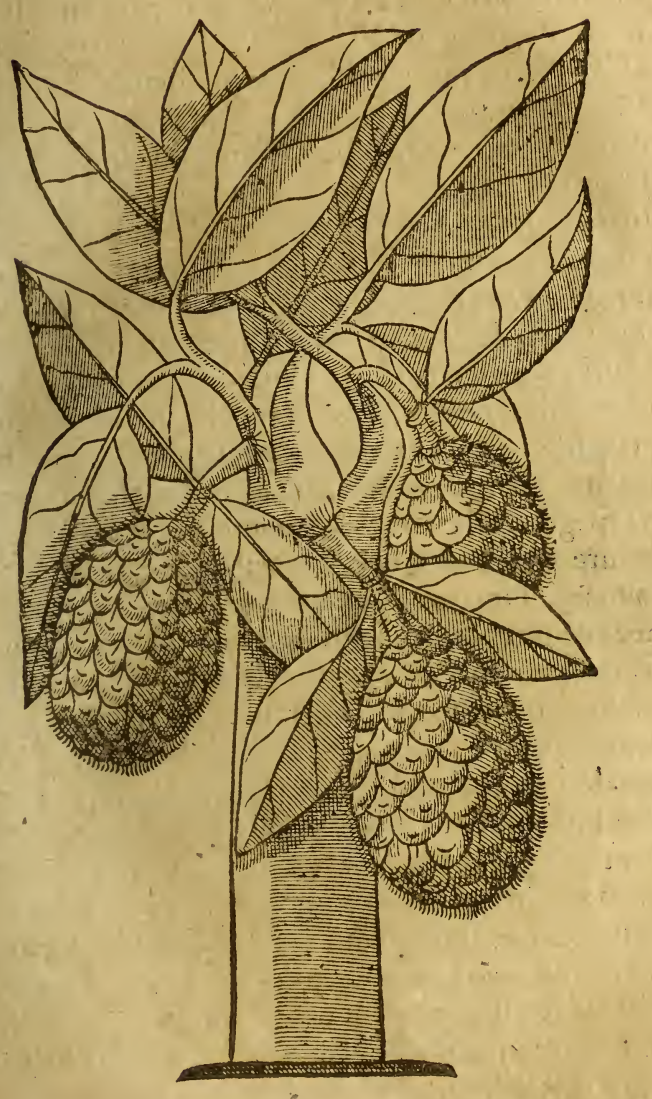

vne bonne odeur, \& d'iceluy font deux differences: l'vne qu'ils appellent $B$ arca, qui eft la meilleure: $\mathrm{HH}$ S 
$122 \mathrm{CHRISTORHLE} \mathrm{DE} \mathrm{LA} \mathrm{COSTE;}$ l'autre eft nommee Papa, ou Gyrafal, laquelle eft moindre:on cognoift cefte derniere par fa molleffe parce que quand on la preird à belles mains, elle eft molle.Le plus excellent \& meilleur fruict qui fe troume ne coufte pas plus de quarante marauedis,c'eft à dire vn peu plus d'vn Real de Caftille. Cefruict eftant couppé de fon long, il apparoit blanc, \& garny d'vne chair ferme, \& diuifé comme en petires cellules ou receptacles, pleins dechaftaignes, vn peu plus longues \& plus grollès que ne font les dattes, couvertes d'vine pelure grife, \&blanches au dedans comme les chataignes communes, d'vn gुouft afpre se terreftre : fi on les mange verdes, elles engendrent beaucoup de ventofités: mais fi on les roftit à la façon des chaftaignes d'Efpagne, elles font treffauoureufes \& excitent à luxure, voila pourquoy la populace è mange fort fouuent. Or toutes ces chaltagnes font enuironnées d'vne chair iaunafte, $2 \times$ acurement vifqueufe, refremblant quelque peua la pulpe du Durion, encores quils foyent differans: elle eft d'vne faueur agreable, principalement celle qui eft deSes fa- dans le Iaca appellé Barca, fort femblable à la chair cultés d'vn bon melon : toutesfois elle ẹt de dure digeruyf. Ation, chargeant fort l'eftomach: \& comme difent
bles. les medecins de ces Prouinces là, fi cefte chair fe vient à corrompre dedans l'eftomach, elle engendre des humeurs dommageables \& venimeufes: \& ceux qui en mangent fouuent,tombent facilemét,

Morxi en cefte mamaife \& peftilentielle maladie qu'ils maladic. appellent Morxi. 
DES DROG. ET MED. LPV. III. 129

\section{Du Durion.}

\section{C $\mathrm{HA}$ 月. XL。}

C'Eft vn fruict qui croift en Malaca, d'vne fa- Oìcroif ueur \& odeur fi agreable, quileft à preferer à $l e \quad D$ w tous les autres qui croilfent hudit pays, encores rios. qu'il y en croiffe beaucoup, \& bons. L'excellence duquel, ioinct nuffi que le docteur Garcie en a efcrit au thapitre du Datura, encores qu'il ne l'euft point velt,m'a inuité d'en efcrire, comme tefmoin oculaire, encores qu'il ne foit point en viage de medecine.

Ce fruict eft appellé en Malayo (qu'ert la Prouince ou il croif) Duriaon: fa fleur Buad:'arbre qui le porte Batan.

C'eft vn arbre grand, qui eft d'vine matiere for- La qua te \& folide, coutuerte d'vne groffe efcorce, garny lité de de plufieurs rameaux , \& portant bonne quantité larbre. de fruict:fes fleurs font blanches tirant fur le iaune, les feuilles de demy empan de long, larges de deux doigts ou dauantage, dentelées fort mentu aux enuirons, d'vn verd clair au dehors, \& au dedans d'vn verd obfcur,tendant aucunement fur le roux:le fruict eft de la grofleur d'vn Melon, entouré d'vne efcorce efpoiffe, tout heriffé de plufieurs aiguillons courts, gros, \& picquans, verd au dehors, \& ayant des rayes ou fillons tout de fon long comme vin Melon: au dedăs il a quatre chambrettes en long, dont chacune contient trois ou quatre receptacles, dans chacun defquels y a des fruicts fort blancs, comme la fleur du laict, de la groffeur d'vn coufde poule, plus fauouiteux \& de meilleur

fenteur, 
124 CHRISTOPHIE DE LA COSTE; Durion de Acofta.

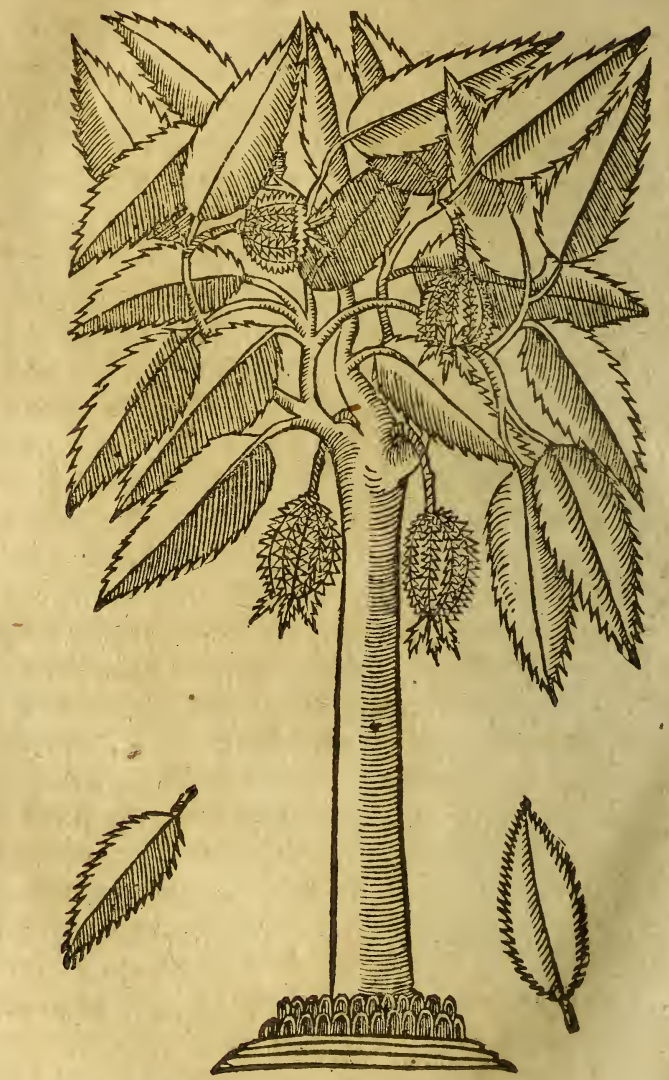

fenteur, que c'eft appreft que les Efpagnols appellent Maniar Blanco,non toutesfois fi mols se gluăs 


\section{ES DKOG. E T ME D. L \& V. III. I $2 \rho$}

car ceux quin'ont pas cefte blancheur, mais font iaunes, ils font pourris \& corrompus, ou par l'iniure de l'air, ou dela pluye : on eftime les meilleurs ceux qui ont tant fealement trois fruicts dedans chafque chambrette, puis apres ceux qui en ont quatre : car ceux qui en ont cinq, font eftimés de peu de valeur,comme auffi ceux qui ont quelques fentes ou creualfes: Or on ne troune pas en chaf- Le noyau que pomme plus haut de vingt fruicts, chacun def - de ce quels à fon noyau au dedans, du tout femblable à fruict est celuy des Pefches, non rond, mais vin peu plus afpre to long:ayant vin gouft infipide, qui rend le gozier af - ge point. pre,comme des Mefples verdes:c'eft pourquoy on ne les mange point.

Ce fruict eft chaud \& humide : ceux qui le veu- Faço de lent manger ont accouftumé de le fouler legere- manger ment auec le pied, \& le rompre à caufe des efpi-ce fruit. nes, defquelles il eft enuironné.

Ceux qui n'ont iamais mangé de ce fruict, dés qu'ils cornmencent à le flairer, il leur femble qu'ils fentent des oignons pourris:mais apres qu'ils l'ont goufté,ils le ttouuent de meilleur gouft \& odeur, que viande qu'ils ayent iamais mangé.

Ce fruict eft en fi grande eftime parmy ceux qui Le pris ayment les bons morceaux, qu'ils penfent que per- on va. fome n'en peut eftre raffafié, voila pourquoy ils leur dee luy donnent diuers furnoms \& epithetes. Il me ce fruici. founient d'auoir veu vn Epigramme compofé par vn excellent Poëte à la loüange de ce fruict:lequel (fi le lieu permettoit de le tranfcrire) ie m'alleure qุu'il aggreeroit beaucoup au Lecteur.

Toutesfois il y en a fi grande abondance en Malaca, qu'ils ne fe vendent que quatre marauedis la

piece, 


\section{26 CHRISTOPHLE DE I A COST}

piece,principalement aux mois de Iuin, luillet, \& Aouft:car aux autres mois ils encheriffent plus ou moins,à la fantafie des vns \& des autres.

Antipa- C'eft chofe digne d'admiration que l'Antipathe thie mer duesse du Betele auec ce fruict, laquelle certainement elt gris est ii grande, que fi quelqu'vn met des feuitles de Beentre les tele, dans vn nauire plein de Durions, ou dans vne feuilles maifonou magafin où ils foyent gardés, ils fe gade, berce fteront \& pourriront tous. Et fi quelqu'vn a l'eftofruict. mach chargé \& entlammé, pour auoir trop mangé de Durions, fi on luy applique des feuilles de Betele fur le ventre, foudain elles luy oftent cefte inflammation \& enfleure d'eftomach.

Et fi apres auoir mangé les Durions, on prend quelques feuilles de Betele, on ne fentira aucun dommage, encores qu'on en aye mangé beaucoup. De là vient, \&z de fon gouft foüef auffi, qu'on dit communemét que perfonne ne s'en peut raflafier.

\section{Du Mufa, a ou Figue des Indes.}

\section{C $\mathrm{A}$ P. XLI.}

Hifistoire E tresfbel arbre croift de la hauteur de dix \& an Mus- Wuict à vingt empans, le tronc duquel eft de fa. la grolfeur de la cuiffe d'vn homme, compofé de la conionction de plufieurs efcorces, couchées les vnes fur les autres: fa racine eft ronde, \& groffe, \& vn manger tres-agreable aux Elephans:fes feuilles font longues de neuf empans, \&r de deux \& demy de large, ayans vne nerueure afl'es grolle tout de leur long, anec des fibres qui s'efpindent en trauers, d'vu yerd obfcur au fommet, \& verd clair en 
DES DROG. ET MED. LI V. III. 127 Mufa ou figue des Indes de Acofta.

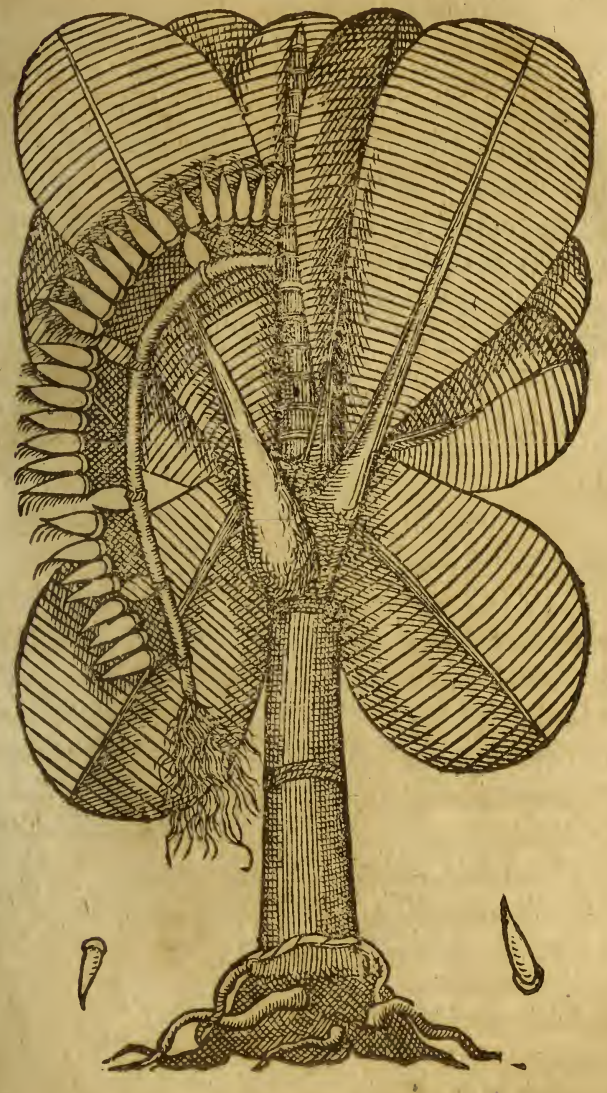

bas : en la cime de c'elt arbre croilt comme vne guirlande defleurs roages, ainfi qu'vne pomme de 


\section{C IIRISTOTHLE DE I A COSTE,}

de Pin: \& puis ne produit qu'vn feul rameau, de la groffeur du bras d'vn homme, diuifé en plufieurs nouds, de chacun defquels pendent dix ou quatorze figues, de forte que quelquefois on void des rameaux chargés, de cét ou deux cés figues.Les Portugois qui habitent en ces pays là, les diftinguent Diusvers en plufieurs \& diuerfes efpeces: car il appellent especes Cenorins, celles qui font bien iaunes, vnies, londe Mufa guettes, de faueur agreable, \& de bonne fenteur: mais celles qui font aucunement verdes,ils les ap. pellent Chincapanoës, \& font plus longues, \& auffi d'vn trefbon gouft. Dauantage on fait cas de cel. les qui croiffent en çofala, que les Ethiopiens appellent Inninga.

Noms. Le vray \& legitime nom duquel les Arabes \& Perfes,les nóment (comme ie l'ay appris d'vn trefexcellent medecin Perfiê natif d'Ormus)eft Mous, \& non $M u \int a$, ou Amufa: \& l'arbre Daracht mous, quãd aux autres noms, on les trounera dans Garcie du Iardin.

Façon On plante c'eft arbre vne fois tant feulement, d. plan. car de fa racine en renaiffent d'autres : vn. chacun ser cest defquels(comme nous auons dit cy deuant) ne produit qu'vne branche portant fruict, lequel ils couppent quand il eft meur, \& laiffent feicher la plante de foy mefme,comme inutile a l'aduenir : ou bien ils la couppent pour le fourrage des Elephans domeftiques.

I'vfage de e'est arbre.

Il y en a qui mangent les feuilles de dedans, \& les plus tendres auant qu'elies foyent effanouyes, \&x confifent les bouquets de fleurs, auec du Gingébre recent, Poyure, fel, vinaigre, $\&$ des ails, puis les mangent à la façon des Cappres. Et parce que les fucilles font larges, molles \& froides, ils en fót des 
DES D R O G. E I ME D. LI V. III. 129 des licts pour coucher durant les chaleurs : \& parfois en metrent fur les bruflures. Ruel fait mentis de ce fruict, fe feruant de l'authorité de Strabon, \& de Theophraite.

\section{A NNOTATIONS.}

* Il n'y a perfonne felon mon iugement, qui ayt mieux. de crit ceste plante qu Oniede foubs le no du Plane. Nous en auons faite la defcription en Lation, laquelle nous a. uons inferée dans nos Annotations furle chap.du $M u \mathrm{a}_{3}$ an fecond liure de Garcie du Iardin.

\section{Du Mangas. \\ C H A P. X L II.}

T'Eft arbie eft grand, garny de beaucoup de Deferibranches, \& porte vn fruict plus gros pour lation dis plufpart qu'vn cuf d'oye, pefant par fois en cer- Mangas. tains lieux des Indes, iufques à deux liures ou d'auantage : on void foutent fur vin mefme arbre ce fituict de diuerfe couleur:car les yns font d'vin verd gay, les autres iaunes, les autres verds tirant fur le rouge:ils font d'vn trebon gouft \& odoriferant:\& n'eftant point corrompu, il eft encores meilleur que les Auberges, lefquelles font appellées pommes coingșà caufe de leur chair iaune \& ferme.

Il croift en plufieuts Prouinces, comme en $\mathrm{Ma}$ - Le lises. labar,Goa, Guzarate,Bengala, Pegu,Malaca, \& autres lieux des Indes, \& en Ormus d'où vienment'les plus excellens.

On l'appelle Mangas:en Canarin Ambodes Per-Diuers 
$130 \mathrm{CH}$ IE IS TOBHLE DE B A COS T, fes \& Turcs Amba: \& demenre fur l'arbre depuis le mois d'Auril, iufques au mays de Nouembre, felon la nature \& fituation des lieux.

On mange ce fruict couppé en tranches, tremde man- pé dans du vin, ou fans vin. On le confit auffi en \& $r$ dap- fucre pour le mieux conferuer, \& l'ounrét par fois prester, auec vn couteau, \& iettent du gingembre recent, on- con-des ails, de la mouftarde, \& du fel, auec de l'huile, feruer ce fruit.

$\&$ du vin aigre, à celle fin qu'ils le puiffent manger comme des oliues, ou auec du rix. Ils le falent \& font boüillir, puis le portent vendre au marché.

sos fa. $\quad 11$ eft froid \& humide, encores que le commun - ruliez. le conftitue chaud, \& qu'il affeure qu'il engendre des grandes mordications dans l'eftomach de ceu qui en mangent.

Les niedecins aufi du pays l'ẹtiment chaud, \& le mefprifent difans quil engendre les dartres, eryfipeles, fiebures biliẹfes, phlegmons \& la rogne.Ce qui peut eftre aduient d'autant qu'il fe corrompt fort facilement dedans l'eftomach:mais en mefme temps qu'on trouue ce fruict, plufieurs qui ne mangent dụ tout point, ne lailfent de tomber aux maladies fufdictes, à caufe des grandes chaleurs qu'il faict.

A uant qu'il foit entierement meur, il eft d'vn gouft aftringent, \& ceite partie qui eft plus proche de l'os,eft plus afpre : mais ayant atteint fa parfaicte maturité, il eft doux \& fauoureux. Son noyau vn peulong \& gros, de la grándeur d'vn gland, blanc, \& coumert d'vne pelure bläche, ainer eftant crud, \& paur cefte occafion propre contre les vers, \& Alux de ventre, ayant le gouft du gland quand il eft rofi:\& eft couvert d'vne cocque fort dure, qui 
DES DROG. ET MED. LIV. III. I; II Mangas de Acofta.

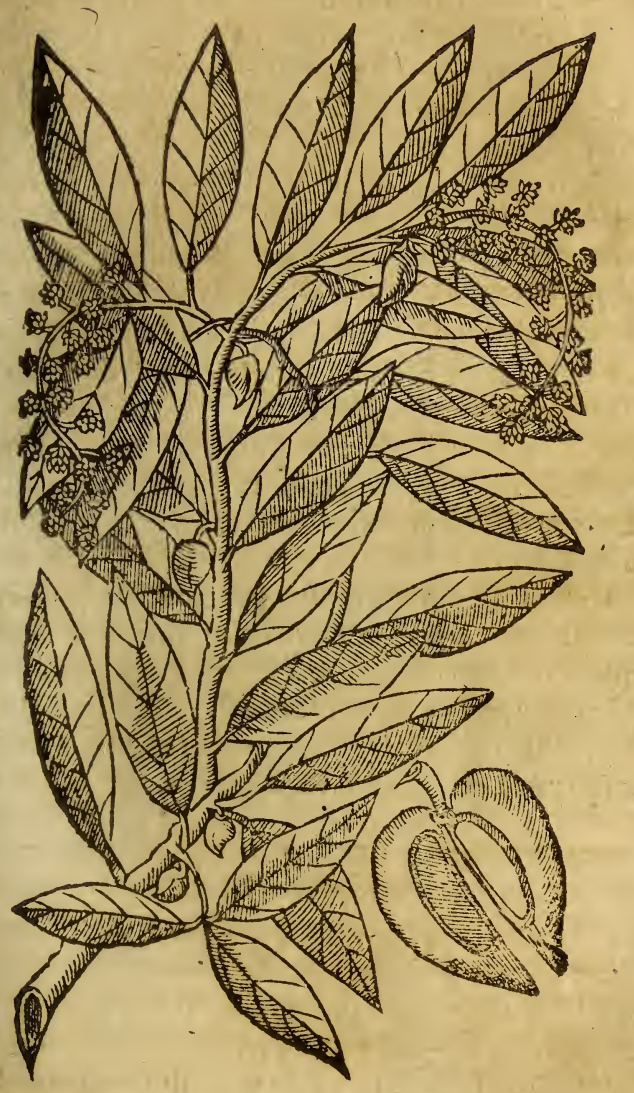

eft remplie au deffus de bourre, ou de fibres, qui vont de long, \&z de trauers.

\section{2}




\section{CHRISTOPHIE DE I A COSTE,}

Il fe trouue auffi vne efpece de ce fruict, qui n'a point d'os au dedans, qui eft d'vn tresbon gouft.

Il s'en troutue auffi vne autre efpece fauuage, la a Autre quelle ils appellent Mangas brauas, qui eft fi veni- Apece de meux, que les habitans du lieu s'en feruent pour fe

Mangas faumage faire mourir les vns les autres : car fi quelquivn en mange tant foit peu, il meurt fur le champ; ils y adiouftét par foys de l'huile pour accelerer fa verSes ver- tu, \& que plus foudain il faffe mourix: mais en sus. quelque façon qu'on le mange, il defpechefi foudain fon homme, que iufques à prefent on na peu. trouuer aucum antidote pour reprimer fon venin. Il eft d'vn verd clair, \& eft aucunement refplendif fant, il iette du laist, \& a fort peu de chair, car fon noyau dur \& chartillagineux, n'eft que counert d'vne grofle efcorce, il eft toutesfoys de la groffeur d'vn Coing.

Le lieu Ceft arbre croilt à foyfon par toute la prouince al il creist. de Malabar , plus perit que celuy qui eft donefti= que, \& quion cultiue, \& a les fueilles plus courtes $\&$ plus efpoiffes, Les enfans ont accoufumé de fe battre auec ce fruict, comme l'on fait des orenges au pays où elles font en abondance.

\section{Du Ananas. \\ C н A P. XLIII.}

I. lien $\mathrm{E}$ fruict eft eftranger, car de la prouince de oucroist CAnanas.

Son Fi: Roire. remét apporté aux Indes Occidétales, puis aux $\mathrm{O}$ rientales, aufquelles il croift maintenant en abondance. Il eft de la grolfeun d'vn petit Citron, fort ianune, 
D E DROG. E T MED. L I V. III I 33 Ananas de Acoftro

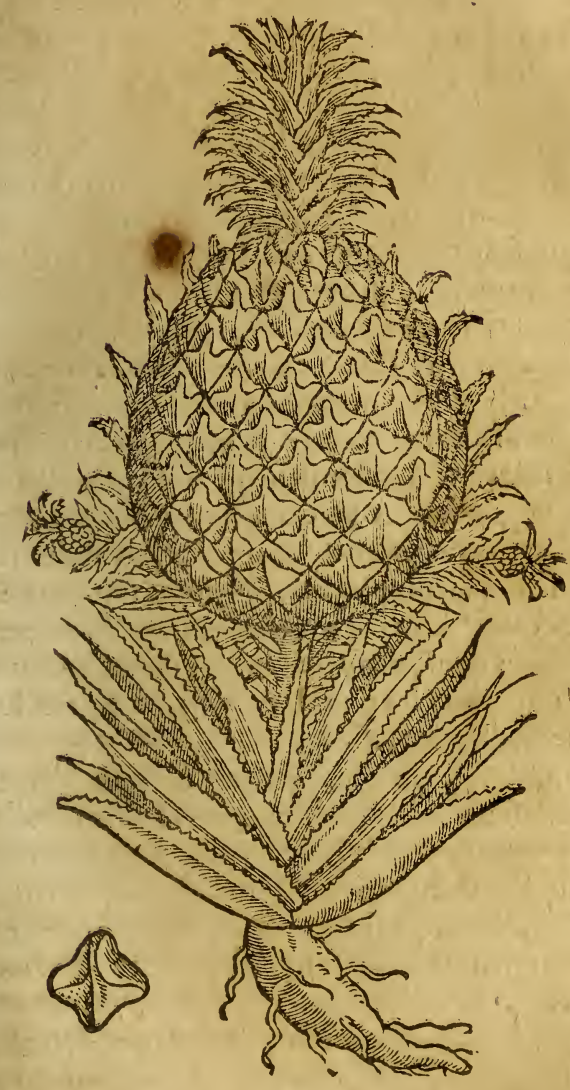

iaune, \& fi odorant quand il eft meur que les pasffans peutuent par fon odeur recognoifte la ma rori- 
$134 \mathrm{CHRISTOPHLE} \mathrm{DE} \mathrm{IAC'OSTR,}$ oùil eft:il eft plein de fuc, \& d'vn tresbó goult,il fé. ble vn artichaut à ceux qui le regardent de loing, mais il n'a point d'aiguillons poignans. Chatque plante'eft de la grandeur d'vn carde à manger, \& ne porte qu'vne póme au milieu prefque de la tige, \& tout enuiron d'icelle plufineurs autres bourgुeons, dont quelques vnes ont aufi leur fruict. Ceux donc qui cueillent les fruicts meurs, ont accoufumé de mettre dés aufí cof́ en terre fes rejectons:defquels croift par apres chafque plante, qui porte fa pomme comme la mere, lefquelles on re-

- cueilt au bout de l'an. Sa racine relléble fort à celle du Carde que l'ó mange, fes feuilles aufi ne font pas diffemblables, encores qu'elles approchét plus aux feuillesde l'Ananas fauuage.lls les appellét có. munemét Anaras:\& les Canarins Ananafa.Du cómécement que ce fruict fut apporté aux Indes, il fe vendoit dix ducats piece ou dauantage:mais à ceftc heure à caufe de la grande quantité qu'il s'en trouue(encores qu'ils ne foyent moins fauoureux \& 0 doriferanes que les premiers ) à peine fe vendent ils deux reales de Caftille.

Iufques icy or n'en a point vféen medecine, mais eft feulement recerché par la fouëfieté de fon gouft.Il eft chaud \& humide, \& fe mange trempé dans du vin,comme les Auberges, il eft de facile digeftion:toutesfoys pour en trop vfer, il engendre des inflammations, aufi bien que les Durions de Malaca.

Si on le-couppe par le milieu, s que derechef on le reioigne, ils fe reunit comme le concombre:eftát picqué auec vn couteau, fi on le laille dedansresilicte picqueure l'efpace d'vn iour, ou vne nuict, 
DES D\& G $\mathrm{G}, \mathrm{E}$ \& MED. I I V. III. is nuict, lon tromutra que cefte partie de coufteau qui auoit efté paflée dedans ce truict, lera toute confumée.

\section{ANNOTATIONS.}

* Vojez nos annotations fur le fecond livre des Dro. gues, au chap.du Mangas.

\section{Du Ananas faurage. \\ Ch A P. XLIV.}

T Ananas fauuage croift plus haut que l'autre: Defori- car fon tronc eft de la grandeur d'vine halle-ption do barde, vni, rond, \& de la grolfeur d'vn orenger, he - l'Anarillé d'efpines, \& dont les feuilles font garinies de uage. pointes clpineufes, \& aux enuirons d'efpines molles. Chafque arbre efpand rez pied, rez terre, vine grande quantité de feuilles, plus grandes que celles qui font fur l'arbre, lefquelles reffemblent aux feuilles d'Aloës,à ceux quil les regardent de loing, plus minçes toutesfois: \& garnies de plus d'efpines, lef quelles font d'vn verd clair. Cefte plante fe prouigne, \& s'eftend fur les chofes qui luy naiflent aupres, \& vine plante en produid vine autre, principalement aux hayes \&c clofures des iardins, lefquels s'en ferment tresbien. Les rameaux produifent des teftes de feuilles, roullées l'vne dans l'aurre,fort iaunes, \& tendres, d'vne merueilleufe odeur, qui ne font autre chofe que lafleur mefme: de chacune d'icelles fort vn efpy prefque femblable à celle d'vn roleau, mais plus groffe, plus fer-

$$
\text { II } \frac{1}{4}
$$


136 CHRIS TOPHIE DE IACOSI Ananas faunage de A cofta.

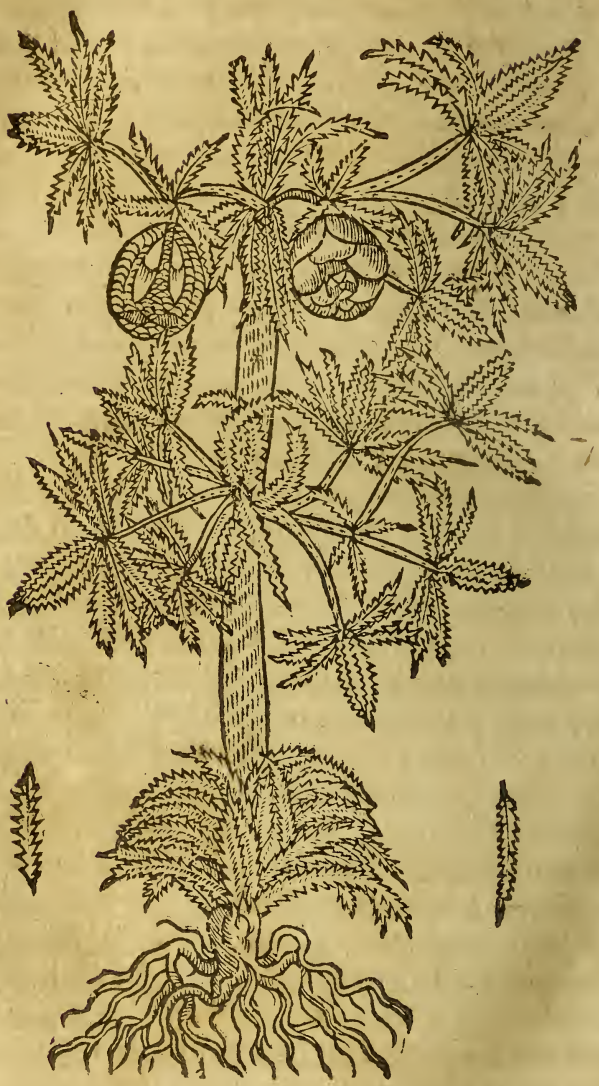

ree, \& pl' belle, de l'odeur du Cedre. Des rameaux pendent les fruicts appellés Ananas brawo, c'eft à dire, 
DES DR.O G. E T MED. LIV: III. I 37 dite, Ananas fauuage, d'autant qu'ils font aucuneinent femblables auec les domettiques, de la groffeur d'vin Melon, d'vne belle couleur rouge \& agreable à la veuë, tous diuifés en parties comme font les noix de Cypres,ou noix feiches, mais enuironnées par dehors, de plufieurs petites bolfes, $f_{1}$ bien quà ceux qui les voyét de loing, ils femblent des grolles pommes de Pin.

Les plus tendres feuilles ou fleurs des teftes, fe viertu mangent cruës, \& ont le gouft des Cardes, mais tempers elles font peu nourriflantes. Le fruict ( que peude ture de gens gouftent) eft d'vne faueur aucunement aggreable, tenant toutesfois un peu d'vne aftriction grande, \& peu aggreable au palais.

Toute la plante auec fes racines eft pleine de fuc.Six ou huict onces d'iceluy, prifes de bon matin auec du ficte, font vn tref-excellent $\&$ affeuré remede, contre les chaleurs du foye, $8 t$ ylceres $8 *$ chaleur de reins, contre les vrines pleines d'apofteme, \& efcoriatiós des vretaires:car cela les gue* rit en moins de trois iours.

On tient auffi qu'il eft profitable à ceux quìn'virinent que goutte à goutte : mais ie ne l'ay pas experimenté.

Les Arabes en font grand cas, l'affeurans eftre propre pour les fufdictes maladies \& eryfipeles, ils l'appellent 2 ueura, comme en Decan les Perfes Anana $\int_{a} \&$ Angali:la fleur( qui eft cefte tefte odorante tiffuë \& cōpofee de feuilles)les Arabes l'appellent Chuxtaid, les Perfes Pixcoxbutth: Les Turcs ne fçauent que c'erts 


\section{I3 CHRISTOPHLE DE IA COSTE,}

\section{Du Carcapuli. \\ CH A P. XLV.}

Histoire $>$ Arcapuli du malabarois, \& Garcapuli des Cadu Care -1 narins, eft vn arbre merueilleufement grand, capuli. portant vn fruict de groffeur femblable à vn orenge fans pellure,tant en grandeur qu'en figure, tour plein de petits grumeaux ( mais qui ne fe peuuent feparer les vns d'auec les autres, comme en Yorenge) couuert d'vue peau fort inince, vnie, \& luy fante, \& non par trop feiche, de couleur pafle \& dorée

- quandil eft meur, d'vn gouft fort \& acre:mais toutesfois aggreable, ̀̀ caufe d'vne certaine altriction qui l'accompagne,

"fage de Ils s'en feruent emmy leurs viandes, \& les gens ce fruid. du pays le loüent fort aux cures, mais entre toutes celles qu'ils ont experimenté, ils donnent le premier răg à celte vertu qu'il a de referrer toute forte de flux de ventre, principalement à ceux qui en. font affligés, pour auoir fans mefure habité auecles fempreston en prend le fruikt meur, ou du fuc d'iceluy auec du laict enaigri, ou la poudre d'iceluy feichée:quand il eft mixtionné auec du riz cuict,\&

- du laict enaigri, il faict merueilleufement recouurer l'appetit à ceux qui font degouftés. Le fuc auffi de ce fruis, ou la poudre d'iceluy deffeichée, eft grandement profitable, quand on a la veuë troublée \& couuerte. La poudre auffi du fruict eft fort commune aux fages femmes, car elles on accouftumé d"en faire prendre à celles qui font en trauail d'enfant,pour expulfer les fecondines, \& pour 
DES DROG. E T MED. LIV. III. 139

Carcapuli de Acofta.

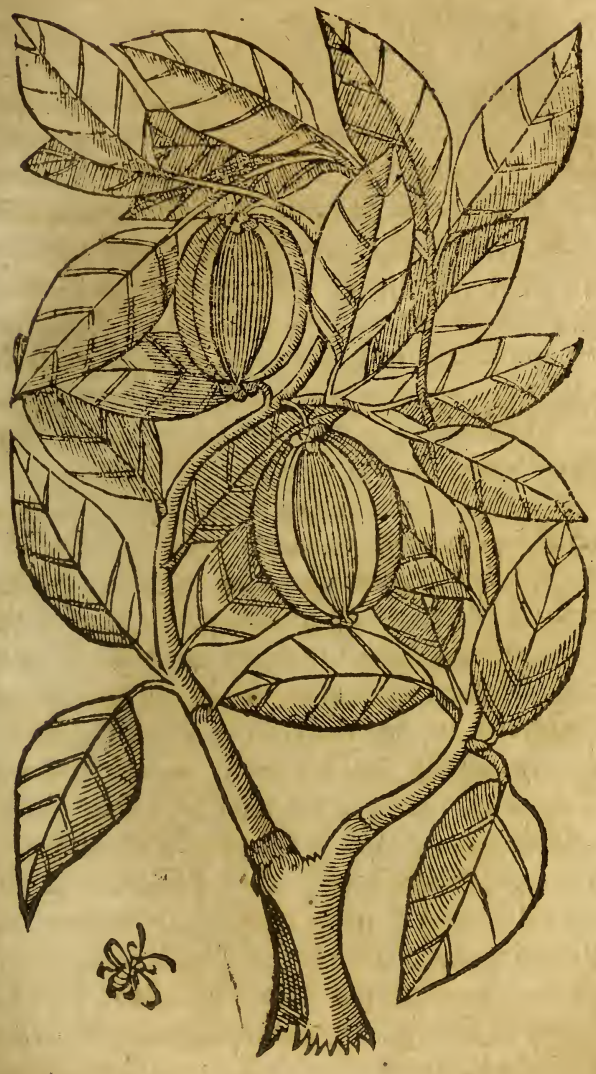

les moys, \& auffi pour leur faire venir quantité de laict, \& pour les faire ayfément enfanter.

Le 
140 CHRISTOPHLE DE IA COSTES Le fuc d'iceluy meflé auec d'autres plantes, eft appliqué fur le gros doigt du pied, du melme colté qu'on a l'œil affligé de cataracte, \& ce auec vtilité \& profit.

On tranfporte ce fruict feiché de Malabar aux autres prouinces.

\section{Du Carambolas. \\ CH A P. XLVI.}

Defcri- I E fruict quie les habitans de Malabar, \& les pion $d u$

Caram-

bolas. LPortugois appellent Carambolas, en Decan Camarix, en Canara Camarix, \& Carabeli, en Malayo Balimbas \& des Perfes Chamaroch:il croift fur vil arbre de la grandeur d'vn Coignier, ayant les feuilles femblables à celles d'vn Pommier; vin peu plus longues, d'vne couleur verde claire, \& aucunemét ameres: fes fleurs font petites, ayant cinq feuilles de couleur blanche tirant fur le rouge, qui n'ont point de fenteur, mais tresbelles à voir, \&rayantle gouf aigrelet comme lozeille. Son fruict eft gros comme vin auf de poule, iaunaftre, \& vn peu long, \& eft comme diuifé en quatre parties, ayant des rayes, \& feillons qui l'embelliffent : il contient au milieu certaines femences tendres, qui font aggreables au palaix par leur aigreur.

Son wa- On fe fert beaucoup de ce fruict en medecine, ge. \& aux viandes: carils l'ordonnent aux fiebures bilieufes, \& $\dot{z}$ le fond prendre confict au fucre, en lieu de Syrop Aceteux. Les Canarins ont accouftumé de faire des Collyres, meßés auec certains autres medicamens naiffans en ces pays là, pour ofter les

tayes 
DE S DROG. E T MED. LIV, III, IAI Carambolas de Acofta.
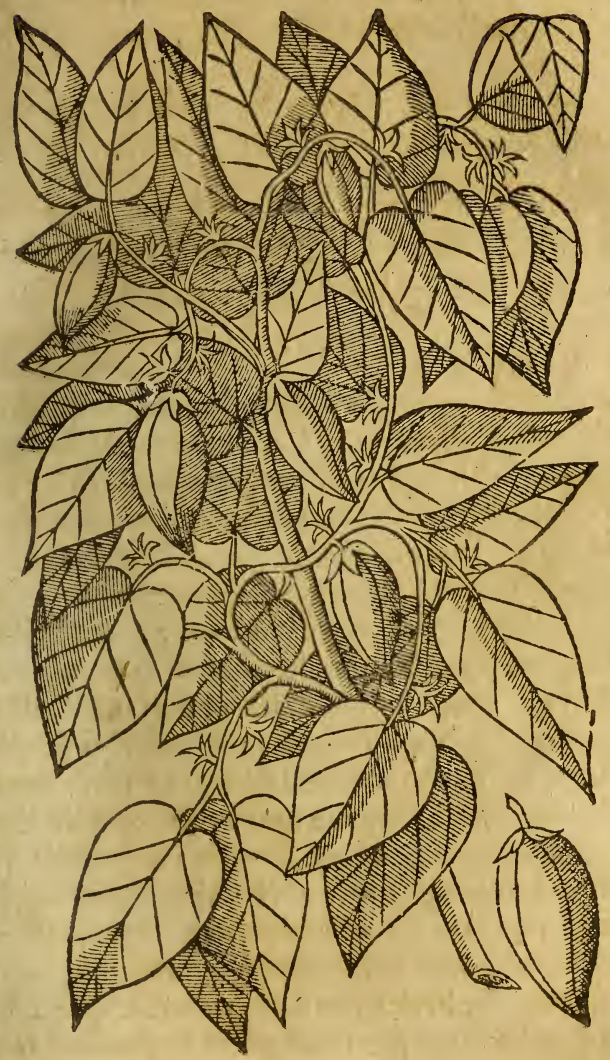

tayes \& petites nuées qui offufquent la veuë. I'ay yeu vne fage femme qu'ils appellent Daya, laquel- le fai 


\section{CHR ISTOPHLE DE IA COSTE,}

le faifoit prendre de ce fruiet fec, meflé auec des feuilles de Betele, pour expulfer larricrefaix \& faire fortir l'enfant mort hors du ýentre de la mere.

Il en vfent auff fort en compofte, dautant qu'il eft d'vn trefagreable gouft, \& qu'il excite l'appetit: tu en as icy la figure.

\section{Du Iambos. \\ CHA P. XLVII.}

Histoire dis lam bos.

T y a vn autre fruict aux Indes, qut merite bien 1 que nous en traictions icy l'hifoire, tant pour la beauté, fouefueté de fon odeur, \& goůt, cóme aufa pour l'vfage qu'il a en medecine.

Larbre qui porte ce fruict eft aufí gros pour le moins, que le plus grand Oranger qui naifle en Efpagne, ayant quantité de rameaux qui s'eftendent au long \& au large,\& font vn grād ombrage, d' vn tresbel afpect, le tronc \& les plus grandes branches sót couuertes d'vne efcorce grife, les feuilles font fort belles vnies, de la longeur d'vn empan ou d'auantage, ayans vne groffe cofte tout du long \& plufieurs veines qui trauerfent à cofté,elles föt d'vn verd obfcur en haut,en bas d'vn verd clair:fes fleurs sót rouges tirăt fur le pourpre, \& qui eft vine couleur fort viue, ayans plufieurs petits filets fur le milyeu, fort belles à voir, \& qui ont le gouft des bourgeós de vigne:le fruict eft de la groffeur de la poire, laquelle a efté appellée du nom de Roy, il y en a deux fortes: car l'vn eft d'vn rouge fi obfcur qu'il femble eftre noir, n'ayăt pour la plufpart au- 
D R.S DROG. IT ME D. LI V.: III. 143

Iambos de Acosta.

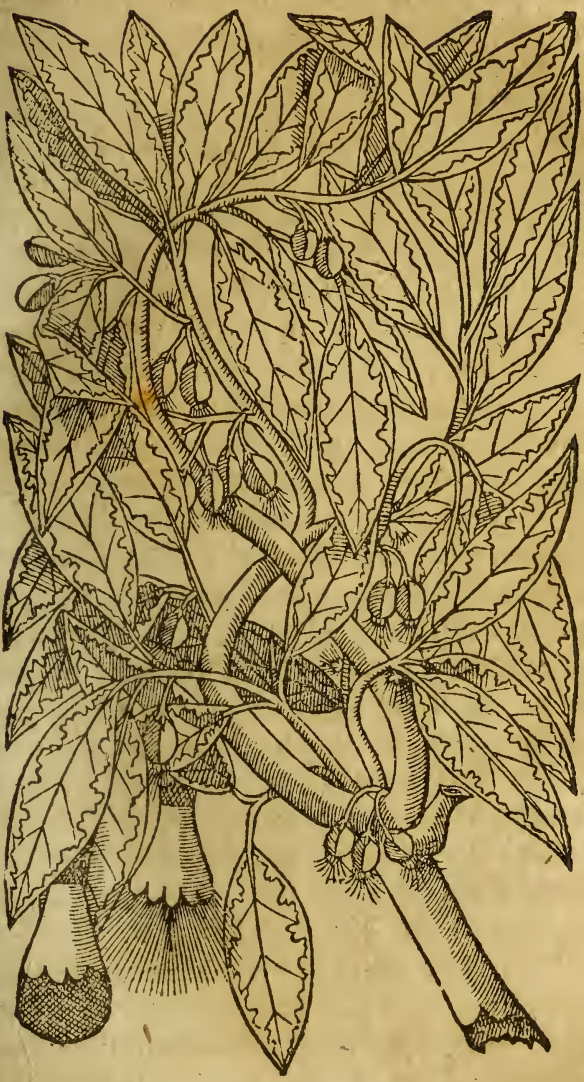

Eun noyau au dedás, \& eftant le meilleur en bon é de fuc.L'autre forte eft d'vn rouge blanc, \& a vn noyau 
Y44 C.HRISIO PH I E OE I A COSTE, noyau blác, dur, qui n'elt pas trop rond, de la grof. feur de celuy de pelche, vny $\&$ enuiroriné d'vne membrane blanche \& velué, qui encores qu'il ne foit pas fibon que le premier, fi eft-il pourtant d'vn gouft fort agreable, voire aux plus delicats: l'vn \& l'autre ont lodeur des rofes. "Il eft froid \& humide, \& fort tendre, couvert d'vne ef́corce fi mince \&z molle, qu'on ne le peut peler auec vn cour fteau.

C'elt arbre pouffe fes racines bien aulant en ter: re, $\&$ au bout de quatre ans porte fruid:il fe renouvelle plufieurs fois en vne année, \& ne le voit on jamais fans fleurs ou fruict, verds, ou meurs, veu que les mefines branches font prefque toufiours chargées de fruicts verds, ou meurs, fi bien que les feurs tombans à toute heure(tellement que la terre au delfoubs de l'arbre femble aucunefois teincte en rouge) il renailt d'autres fleurs nounelles, \& des fruicts, les vns naiffent, les autres meuriffent, $\$$ les autres font cueillis. L’arbre eftant efcroulé, ceux qui ont atteint leur parfaicte maturité , tombent fort facilement : mais fi on plie les branches pour cueillir le fruict, elles s'arrachent fort aiféinent de l'arbre. On a de couftume manger ce fruict à l'ẹtréé de table, \& aufi quelquẹois fur iour.

Diuers Ceux de Malabạr \& les Canarins appellent ce noms. fruit Iamboli, les Portugois demeurans audit pays Iambos, les Arabes Tupba Indi les Perfes Tuphat, les Turcs Alma :les Portugois appellent l'arbre Iambeiro.

Ies fa- On a de coufume confire les fleurs \& le fruict cestiés. 
DES DROG. ET MED. LIV. III. I 45 auec du fucre, \& en vfent fort founent aux fiebures bilieufes, \& pour eftancher la foif.

\section{Du Lamboloins. \\ C H A P. XL VIII.}

T A matiere de c'eft arbre eft couuerte d'vne ef- Hiftoirs Corce,prefque femblable en couleur à celle du bolons Lentifque, il a les feuilles femblables à celles de L'arboufier, mais elles ont le goult duMeurte verd: le fruict eft femblable aux oliues moures de Cordouë,d'vn gouft aftringent \& afpre.

Ces fruicts ne font aucunement en viage de son v $\int_{a-}$ medecine, mais on les mange auec du riz cuict, car ge. ils excitent l'appetit. Le commun l'appelle Iamboloins.

Du Iangomas.

\section{Cн А P. XL IX.}

TL y a vn autre fruict appellé Iangomas, reffem- Defcriblant quafi en coulcur aux Cormes, $\&$ de faueur ption dis aux prunes qui ne font pas meures: auffi a il les langofeuilles \& les fleurs femblables au Prunier, finon que l'arbre eft tout enuironné d'efpines.

Il croift de foy mefme dans les bois, \& par les le biew champs, on le cultiue auffi par les iardins.

Et encores bien que le fruict foit meur, fi eft ce soin v fac que premieremét il le faut amollir auec les doigts $g e$. amant quion le puiffe manger:toutesfois il ne perd K K. 
$146 \mathrm{CHRISTOPHIE}$ DE I A COSTE, pour cela $f$ grande aftriction : \& pour cefte raifon on s'en fert aux chofes où on a befoin d'aftrction.

\section{Des Pormes des Indes. C н $\mathrm{A}$ 户。 L。}

Yhistoire $C$ 'Eft un grand arbre chargé de quantité de desporm. mas des Indes. feuilles, da fleurs, \& de beancoup de fruict:
les feuilles ne font pas fi Iondes, que celles de nos Pommiers,encores qu'elles leur reffemblent aucu* nement, elles font d'vn verd obfcur, \& en bas elles font aucunement blanchaftres \& veluës, comme celles de la Sauge, d'vn gouf aftringent: fes fleurs font petites, blanches, garnies de cing feuilles, fans odeur ; les fruicts font femblables aux Iuiubes, plus grands les vns que les autres, \& plus ag greables au gouft, qui ne meuriffent iamais fi bien quils fe puiffent conferuer, \& porter aux auties pays, comme les Iuiubes : retenant toufiours quelque peu d'aftriction : d'où on peut recueillir quils ne font aucunement propres pour la poictrine, comme les Iuiubes. En Canara on appeile ceft arbre Bor,en Decan Ber,en Malayo Vidaras, les PorDiuers tugois Mançanas de las Indias, c'eft à dire Pommes noms. des Indes.

son ex. Celles qui croiffent en Malaca, font eftimées selberce. meilleures que celles qui viennent en Malabar: mais celles qui naiffent en Balagate, font encores eftimées meilleures que les autres,

On voit ordinairement en Efté ceft arbre chargé de formis qui ont des ailles, lefquelles chabou- 
DES DROG. ET MED. LIV. III. I4Z Pommier des Indes de Acofta.

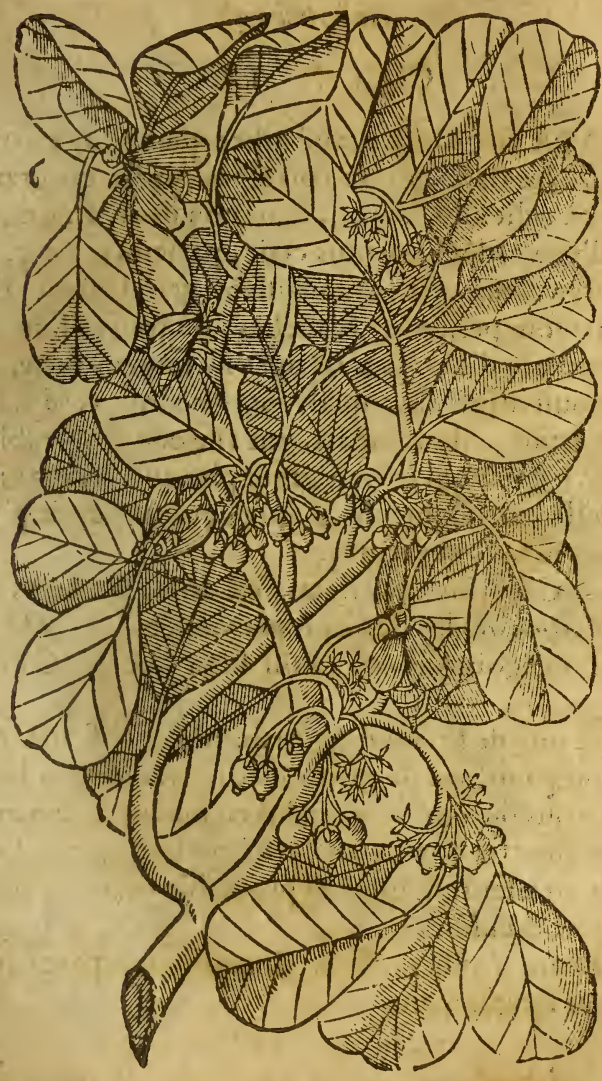

rent la gomme Lacque fur les branches d'icelay, tant que la faifon dure.

KK 2 


\section{CHRISTOPHIE DE I A COSTE,}

\section{Del Ambare. \\ CHA I. II.}

Defcri- C'Eft vn gros \& grand arbre que ceftuy cy, qui ption de ales feuilles fort correfpondantes en gran-

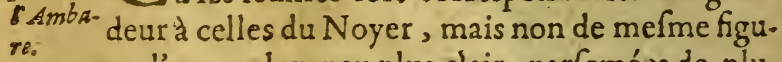
re,d'vn verd vn peu plus clair, parfemées de plufieurs veines, quil'embelliffent grandement: fes fleurs font petites \& blanches, fes fruicts font de la groffeur d'vne noix, ils ont vne fenteur forte, \& vn gouft afpre', lors qu'ils font encores verds, ils font iaunes, eftans meurs, ont vne odeur agreable, \& d'vn gouft qui a vne aigreur plaifante, ayans vne moëlle cartilagineufe \& dure, entretifie de plufieurs petites nerueures.

Nosss. Les Canarins appellent c'eft arbre Ambare, le fruit Ambares, les Perfes Ambereth,les Turcs Harb, les Portugois Ambares, auff bien que les Canarins.

Son vfa- A caufe de l'acidité aggreable dont ce fruict eft 8. accompagné,on le mefle auec les viandes en lieu de verjus our agrets, quand il eft meur, ils le mangent auec fel $\&$ vinaigre, caril donne appetit. Les Indiens affeurent qu'il eft profitable cótre les maladies bilieufes.

Maviere Eftant confit en fel \& vinaigre, on le peut condele $\vec{c}$ feruer longuement. 
DES DROG. E T MED. LIV. III. 249 Ambare de Acofta.

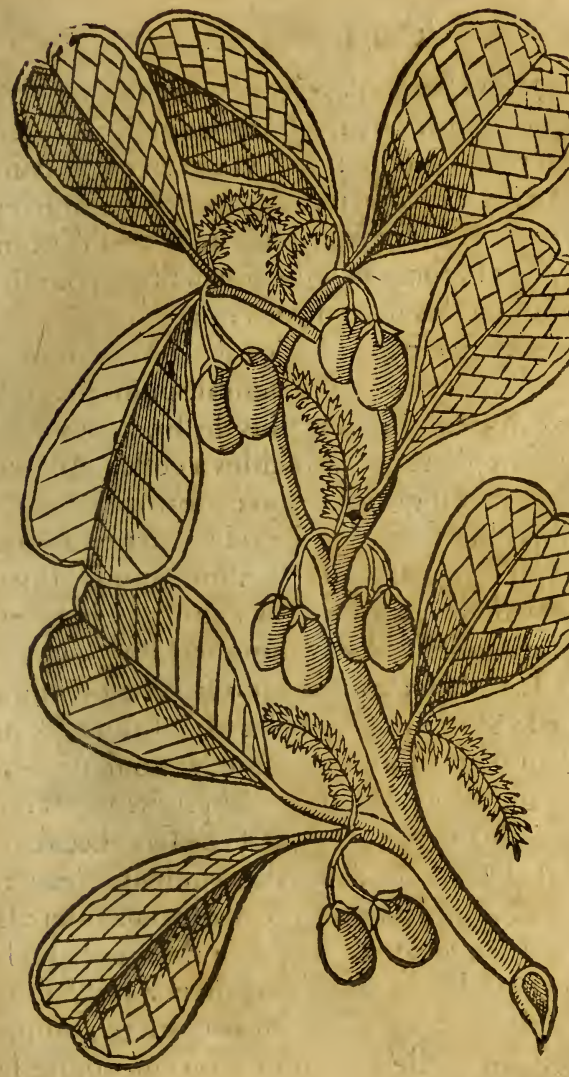

$\mathrm{KK}$ 


\section{ISOCHRISTOPHLE DE IA COSTE,}

\section{Du Datura. \\ CHA P. LII.}

Trois ef $7 \mathrm{~L}$ y a trois efpeçes decefte plante, nous defcripeces de I rous en preinier liẹ, celle de laquelle ils fe ferDatura. ucnt le plus foutuent: car l'viage en eft fi commun, quil y a bien peu de femmes abandonnées, qui n'en ayent bonne prouifion, \& ne la ferrent parmi leurs befongnes plus precieufes, pour-les raifons lefquelles nous dirons cy apres.

Defcri- La premiere efpece a la tige de la hauteur de la ptzon de Guymauue, \& qui ne luy reffemble point mal, elle miere eft toutesfois diuifee en plus de branches: fes eppece. feuilles font du tout femblables à celles du Stramonium,tant en grandeur, qu'en forme ou figure, toutesfois elles font plus dentelées aux enuirons, comme prefque celles du Xãthium (que les Efpagnols appellent Lampazos) fes fleurs font blăches, retirant du tout à celles du grand Lifec (dit des Efpagnols Correguela maior) fon fruict eft comme celuy de la Stramonia, ou Noix Metel, rond, \& de la groffeur d'vne noix commune, de couleur verde,tout enuironné de plufieurs efpines molles, \& qui ne picquent pas, rempli d'vne femence femblable à la lentille, \& de mefne couleur, de la figure du cour de l'homme, \& d'vin gouft amer: fa racine eft blanche, de l'odeur d'vn raifort, laquelle, fi on tient longuement pres du nez faict efternuer, fon efcorce eft aucunement ancre, moins toutesfois que celle qui coumre ou enuironne la te lien tige, \& les rameaux.

oì el'e Elle croift aux lieux ombrageux \& aulng des crisit. 
DESDROG.ET MED.IIV.III. ISt Datura de Acoftas

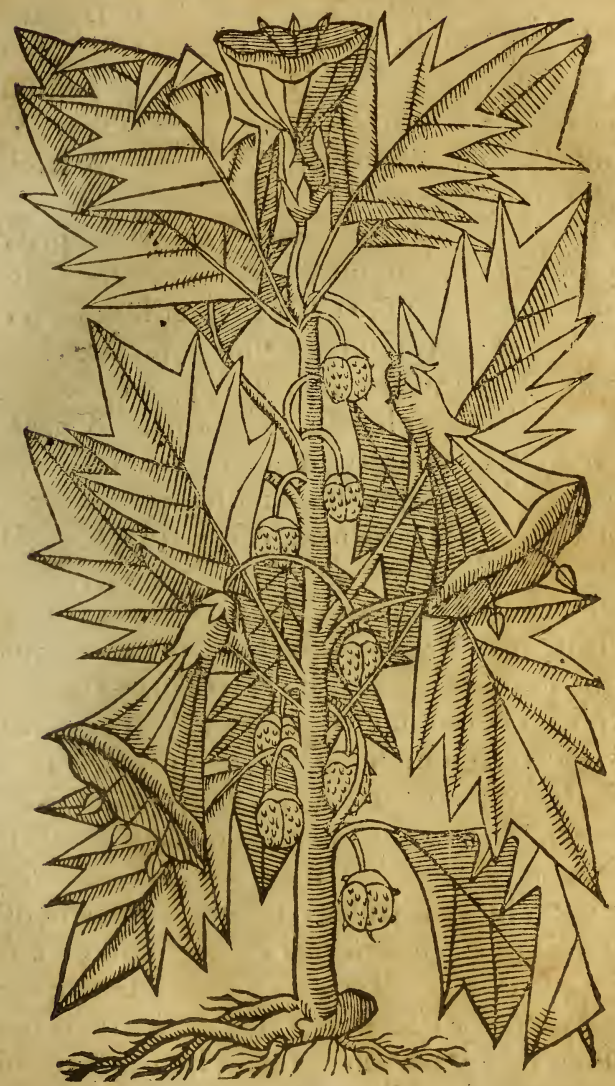

eaux. Les habitans de Malabat appellent cette sesntrs. plante Vrmata caya, en Canarin Datiro, les Arabes $\mathrm{KK} \quad 4$ 
IS 2 CHRISTOPHLE DELA COSTE, Marana, les Perfes \& Turcs Datula, \& les Portugois Datura, \& la Burladora, c'eft à dire facetieufe. Ses qua- medecins qui habitent ences pays cy, eftiment

La plus grand part des hommes doctes, \& des que c'eft la vraye Noix Mcthel des Arabes, \& $1 \mathrm{la}$ conftituent froide au troifiefme degré, \& feiche à la fin du fecond.

Ses ver. Les femmes quife gouuernent mal,ont pris cesus. Ite mauuaife coufume, de faire prendre dans du vin, ou autre matiere quil leur agrée le plus, demy drachme de cefte femence mife en poudre, le miferable qui l'a auallé, demeure lóg temps comme forcené, riant,ou pleurant, ou dormant, \& par fois deuifant auec vn autre, \& luy faifant refponfe,de forte qu'ils femble aduis qu'il foit par fois en fon bon fens, encores bien que cela ne foit, \& qu'il ne recognoiffe pas celuy auec lequel il parle, \& ne fe fouvient aucunement de fon difcours, quand il eft reuenuà foy. Il y en a de fi couftumieres à domner ce medicament, \& le fçauent fi bien mixtionner, quelles ofteront les fens iufques à certaines heures : plus ou moins felon qu'il leur plaift. Ie pourrois àla verité mettre en auant plufieurs exemples, que i’ay veu moymefmes, ou que iay ouy dire à d'autres; mais d'autant que ces chofes ne font à propos, ie les ay laiflées: ie diray feulement que ie n'ay iamais veu perfonne qui foit mort pour en auoir pris, bien que i'en aye veu quelques vns qui couroyentles ruës durant quelquesiours, ce qui polfible leur eftoir aduenu pour leur en auoir dóné grande quantité:laquelle fi elle eft par trop exceffiue, elle tuë celuy qui la prend; d'autát que cef́c femence eft accompagnée d'vne qualité pernicieufe, 
DES DROG. E I MED. L\&. III. IS 3 $\checkmark n$ autre eppece de Datura.

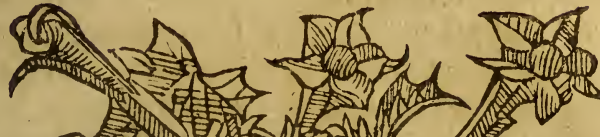
- 150

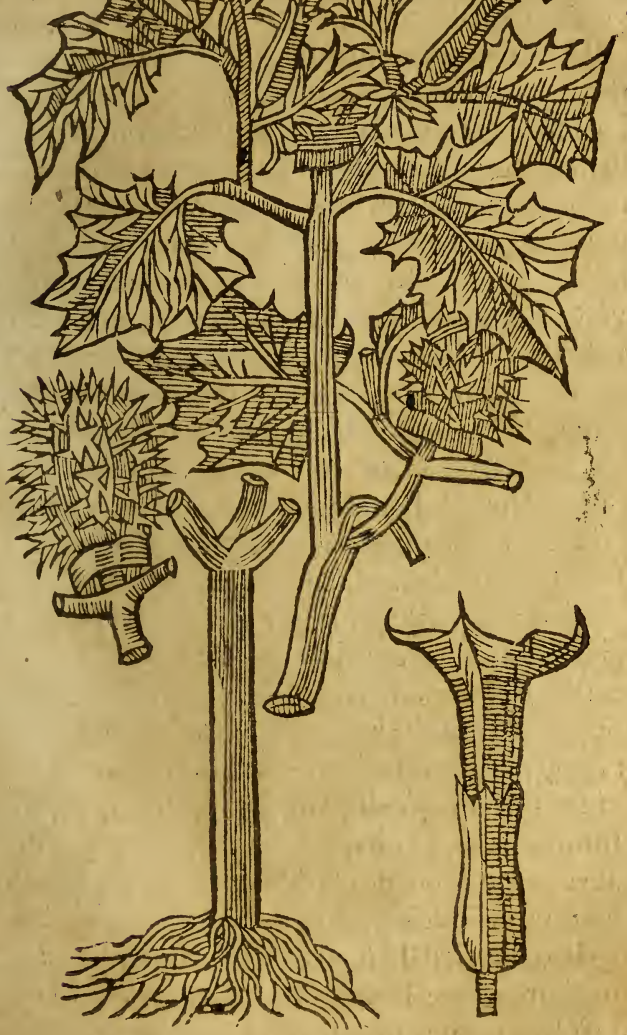

KK S 


\section{IS4CHRISTOSHLE DE LA COS TE,}

cieufe, encores que les Gentils s'en feruent \& en font prendre pour prouocquer l'vrine, melléc auec du Poyure, \& des feuilles du Betele.

Quand à moy ie ne l'ay iamais obferué, \& ne l'ay voulu experimenter, d'autant qu'il ne manque point de medicamens propres à cela.

Or fi les medecins Éfpagnols font appellés pour la guerifon de ceux quiont pris cefte lemence, ils leur font prendre des medicamens vomitifs, à celle fin qu'ils reiettent tout ce 'qu'ils ont dans l'eftomach, puis ils leur font prendre dés clifteres acres pour les euacuer, \& les liēt fort pour diucrtir, puis leur appliquent des ventoufes, \& leur oumrent la veine. Quand aux medecins Gentils \& Chreltiens habitans du lieu, d'autant qu'ils abhorrent la faignée \& les vențoufes, il ne leur font autre cholo que les faire vomir, les lier auec des ligatures fortes, \& les frotter : que fi cela ne leur fuffit, ils lcu ordonnent des bains auec de l'eau chaude pour les faire fuer:d'auantage apres le vomilfement ils leu font prendre du vin, auquel ils neflent du poyure auec de la canelle:pour le regime de viure, ils fon plus hardis que les Efpagnols : car apres auoir eua cué la matiere, ils leur donnent à manger des ge lines, \& à boire du vin doux. Vne drachme de 1 . racine de Datura mife en poudre, \& prife auec di vin,fait tomber celuy qui l'a auallé en vin profono fommeil: durant lequel fe font des fonges diuers auec vne infinité des fantafies eftranges qui fe pre fentent deuant les yeux.

Il n'y a rien de fi profitable contre les Harpe miliaires, que la femence d'iceluy, moyennan qu'elle aye trempé vne nuict dedans le vinaigre, 


\section{DES DROG. ET MED. LIV. III. ISS}

uis qu'on la mette en poudre fort denlée, pour $n$ faire liniment fur la partie affligée:cas ce reme- Seconde e les guerit tout incontinent.

Les autres deux efpeces font prefque \{embla- fiefme les en figure \& en fruict à la precedente, mais les. eurs font diuerfes en coulcur: encores que celles e la feconde, foyent femblables de figure à la preziere, fi eft-ce qu'elles font de couleur iaune, 8 ucuinement rouges pres du pecoul:les fleurs de la -oifiefme efpece, approchent plus à cellés de l' $\mathrm{Ha}$ ebane. Au refte on ne fe fert point de ces deux crnieres efpeces, fi ce n'eft pour fairemourir quelu'vn. Toutesfois les medecins Brachmanes fornent des pillules de la femence de Ia feconde efece(qui a les fleurs iaunes)de la groffeur d'vn grain e poyure, qui font à dire la verité d" yne grande efcace pour arrefter les flux de ventre accompagnés vne fiebure ardăte:comme auffi aux diffenteries. r on forme ces pillules en celte maniere.

Ils prennent vine drachme de la femence de la conde e(pece'qui a les fleurs iaunes) du poyure oir, du poyure long, fantal blanc, atrincar, * des wis par cincs de Bif (qu'on appotes attincar cines de Bifa, ( qu'on apporte de Bengala, \& des il enrena tontağnes de Patame) \& des feuilles de Bangue, le Bore chacun demy drachme, \& broyét fort tout cecy zec del'eau fur vn marbre, fur lequel les peintres nit accouftumés de broyer leurs couleurs, \& puis formét des pillules, defquelles ils en font pren- La Noix ce autant quil eft necelfaire.

Meshel

Ie fuis de l'opinion de quelques autres qui tien-eft le ent, que la Noix Methel n'eft autre chofe que le fruita ds uict du Stramonium, qui eft en tout \& par tout stramo mblable au fruict du Ditura:\& penfe que sil ctt quclque 
SSG CHRISTOPHLE DE I A COSTE, quèlque peu different d'iceluy, il le faut attribuer aे la diuerfité des lieux.

$$
\text { A N N O T A I I N S. }
$$

* Entant quion peut recueillir de la de cription de la Tasula. tula des Turcs qui habitent en Conftantinople, qui eft de fort grand vage entre eux.

Cefte eppece de Stramonium ne luy reffemble point mal, la femence de laguelle fut apportée premieremet à Vienne ex Auftriche d'Oeniponte, de la Cour du Serenifime Archiduc Ferdinand, puis communiquée aux Damoy felles du pays en l'année 1583. l'année en Juyuant creuft dans les iardins de plufieurs. Il ne m'a point femblé bors de propos de inferer icy la de fcription de la plante.

- Elle eft beaucoup plus grande que le Stramonium commur, of qui non feulement efgalle la hauteur d'vn homme, mais bien founent aufje elle la furpaffe:fes tiges font groffes, aucunesfois comme le bras, vnies, de couleur verde bien defcoumerte, ayans plufseurs aiflerons, anfquel: naiffent des feuilles larges of verdes, plus grandes que celles du commun, \& aufji plus efchancrées, comme prefque en certaines especes d'Atriplex ou bletteron fauughe principalement celuyqu'on appelle communement piea d'oye, toutesfois un peu plus larges : en chacune de fes ai. fes il ne fort qu'vne fleur, femblable voirement en couleur or figure à celle du Stramonium commun, mais plus pe. tite, \& prefque fans odeur:le fquelles eftant tornbées, for tent en place des teftes quine font pas rondes, comme cel. les du Stramonium ordinaire, mais vn plus longues, of dela grandeur d'vne groffe noix commune auec fon ef. corce, of comme diuifee par rayes of feillons, qui pren. nent tout de fon long garnie de certains aiguillons durs iantoft cours,tantoft longs, lefguelles effant meures $\int \mathrm{e}$ fen 
DES DROG. ET MED. LI V.III. IS7 ent par le baut en quatre pieces, de fcounrant buidt petioscellules, la femence estant au comencement roufaftre, uis noire, vin peu plus platte of ridée, laquelle eft aisézent abbatue par le vent, of ne tient point à la poulpe omme au commun,mais eft plus petite. Toute la plante a ne odeur forte, laquelle retire à l'odeur du Glayeul puär, u bien à celuy que nous appellons Xiris. Elle fleurit en Efté, fa femence fe meurit en Automne. ies Damoifelles d'Auffriche l'appellent Sconapflen. $\begin{aligned} & \text { Scona } \\ & \text { ofen. }\end{aligned}$

\section{$D u$ Bangue. \\ CHA P. LIII.}

E Bangue eft prefque femblable au chanure, Def $c$ duquel Diofcoride a fait métion au liure troi-prion ds efme. Sa tige eft de la hauteur de deux pieds \& Bangue. emy, quarrée, d'vne couleur verde claire, malaifée rompre, qui n'eft pas fi creufe que la tige du Chanure, de l'efcorce de laquelle fe peut aufi bien aire du filet, que de celle du Chanure: fes fueilles ont comme celles du chanure, verdes en haut, \& u bas veluës \& blanchaftres, d'vn gouft terreftre $\tau$ infipide $: f a$ femence eft plus petite que celle du hanure, \& n'eft pas fi blanche.

Les Indiens mangent la graine \& les feuilles, Son vtz. ant pour fe rendre habiles a l'acte venerien, que lité our leur faire venir l'appetit. De ce Bangue on ait vne compofition qui eft grandement vitée en es pays là en plufieurs maladies: car les grands eigneurs \& chefs des armées, afin de dormir plus eurement \& librement, \& oublier tous les trauaux compoaffés, prennent de la poudre des feuilles \& de la emence tant que bon leur femble, en y aliountane 


\section{I58 CURISTODHEE DE LA COSTE,}

\section{Bangue.}

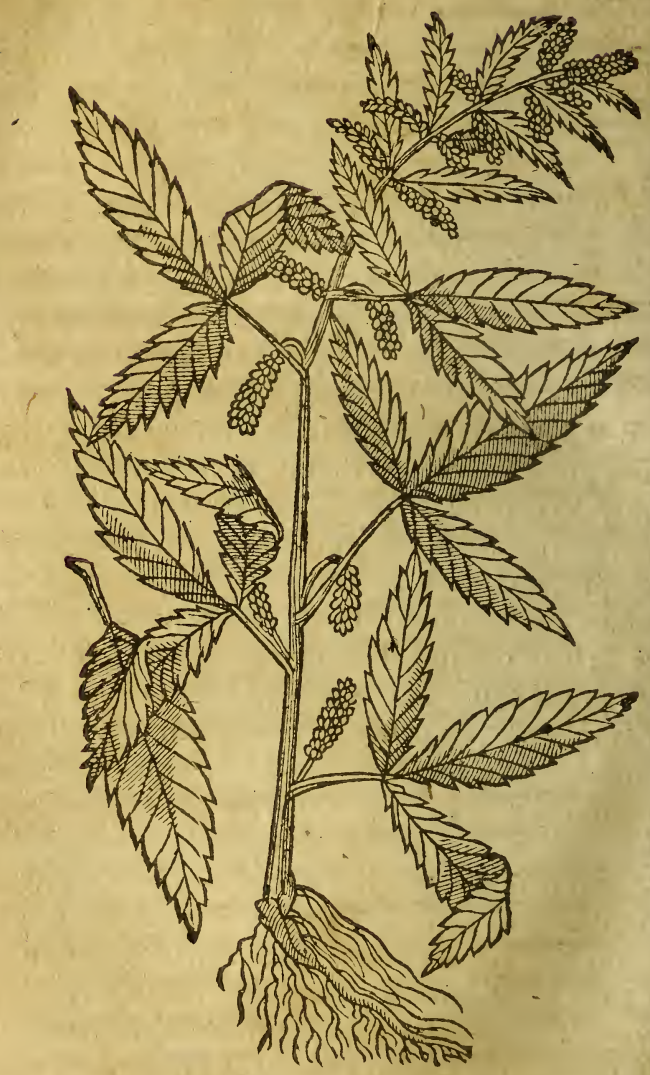

de l'Areca, ou auellaine Indique verde, \& quelque peu d'Opium à leur polte : ils auallent tout cela

auec 
DES DKOG. ET MED. LI V. III. I 59 auec du fucre:que fi ils ont enuie de voir plufieurs refueries \& illufions en dormant, ilsy adiouftent du meilleur camphre, fleurs de mufcade, gyrofles, $\&$ de la noix mufcade : que fi ils veulent eftre io. yeux \& facetieux, \& plus enclins àluxure, ils y adiouftent de l'Ambre du fucre, \& du mulc, \& en font vn Electuaire.

Plufieurs m'ót alfeuré que les feuilles \& femences de cefte plante, eftoyent d'vne merueilleufe efficace \& vertu pour prouoquer à luxure : d'où on peut affeurer qu'il n'a aucune affinité \& refséblance auec le Chanure, iaçoit qu'il foit fort femblable, veu que comme dit Diof coride au lieu cy deffus allegué, le Chanure cft chaud \& $f e c, \&$ efteind la femence genitale.

Les Arabes l'appellent Axis,les Perfes, ceux de Noms. Decan \& plufieurs autres regions Bangue, \&: les Turcs, $A$ farath.

\section{A N NOTATIONS.}

* Ce Bangue aufj femble anoirvne grande affinité auec Mafas. le Maslac des Turcs,qui babitent à Conftantinople : duquel ils fe feruent en plufieurs maladies:quelques ons auf $\sqrt{2}$ en mangent pour s'exciter à luxure.

\section{De l'herbe Viwe. CH A 8. LIIII.}

Ntrouue vne certaine plante en quelques endroits de l'Afie, qu'on nomme communement Herbe Viue, les Iogues, c'elt à dire charlattans, l'appel 


\section{$160 \mathrm{CHIISTOPHIE} \mathrm{DE} \mathrm{LA} \mathrm{OOST}$}

Sioms de l'appellent Herbe d'amour les Arabes \& Turcs $S u-$ Iherbe. luc, \& les Perfes Suluque.

Hiftoire Elle a vne fort petite racine, de laquelle fortent de l'her- fur terre huict petis rameaux; de la longueur de be vire. deux doigts, chargés de feuilles d'vne $\&$ d'autre part, rangées par ordre, \& qui fe correfpondent l'vne à l'autre, lefquelles approchent fort aux tendres feuilles de l'Ers, \& ne reflemblent point mal au premier Polipode, duquel Lacuna fait voir la figure au liure 4.chap. 1 27.mais elles font beaucoup plus defliées, ynies, \& polies d'vne part \& d'autre, ayans vne couleur verde tref-agreable à la veue, comme les feuilles des Tamarins: du milieu de la tefte de la racine fortent certains petis pecouls(car elle n'a point dé tige)en nombre de quatre, chacun defquels fouftient fa fleur, de couleur iaune rrefbelle à voir, qui reffemble aux petis œillets, mais fans aucune fenteur.

Le liew. Elle croift en des lieux chauds \& humides.

Merueil- La nature de cefte pétite plante eft fi efmerueilleuse na-lable, qu'on ne la peut comprendre par raifon huzure $d^{\prime \prime}$ - maine. Car lors qu'elle eft en fa plus grande vercelle. deur, \& qu'il la fait plus beau voir, fi quelqu'vn la veut prendre, tout auffi toft elle retire fes feuilles, \& fe cache deffoubs fes petits rameaux, \& s'il l'empoigne, elle deuient tout à l'inftant fi fleftrie, qu'il femble qu'elle fe defieiche tout à coup:mais ce qui eft encores plus efmerueillable, eft, que fi celuy qui qui la empoignée retire fa main, tout auff toft elle recounre fa premiere beauté, fe fleftriffant ou reuerdoyant tout autăt de fois, comme on l'a prend, ou qu'on retire la main. On m'a taconté arivn certain Philofophe de
Mala 
DES DXOG. ET ME D. LIV.III. 16 I L'berbe Viue de Acofta.

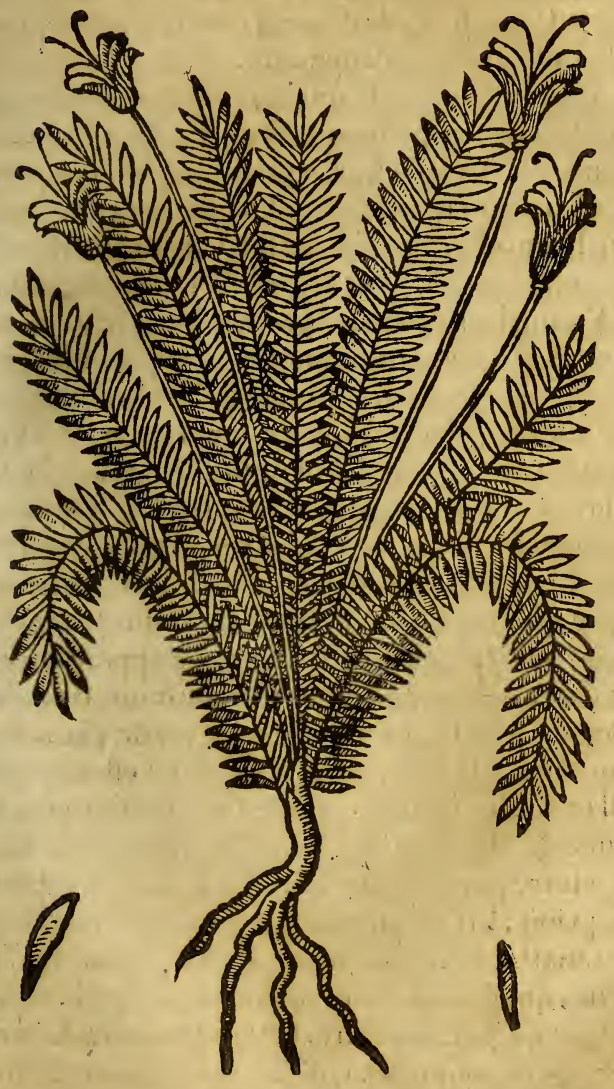

Malabar, voulant par trop curieufemét efplucher la nature de cefte plante, en auoit perdule fens. I L 


\section{$162 \mathrm{CHR}$ ISTOPHIE DE I A COSTE,}

I'ay veu cefte plante, \& l'ay tirée hor's de terre auec fon gazon fans la toucher, \& la tranfportay en vin certain iardin, où elle demeura;mais ie ne vis point celuy qui en eftoit deuenu fol.

Fertus M'eftant enquis de quelques medecins du pays, dé cest s'ils fçauoyent point quelques facultés de cefte plante, \& fi elle eftoit vfuelle en medecine, ils in'affeurerent qu'elle eftoit fort propre pour r'ctablir le pucellage perdu des filles (ie m'en rapporte à ce qui en eft) \& pour reconcilier lamitié perduë.

Vin medecin gentil affes docte pour le pays, me voyant grandement conuoiteux de fçaunir les proprietés de celte herbe, me dit qu'il menfeigneroit vne auff certaine \& affeurée, qu'il mettroit fa tefte en gage en cas qu'ainfi ne fut. A fçauoir que if ie luy nommois quelque femme que ce fut, qu'il feroit en forte qu'elle m'obeiroit en tout ce que ie voudrois, moyennăt que i'vfalfe de ceft' herbe à la façon qu'il me diroit. Mais ie ne voulus point vne chole fillicite. Ie n'en ay donc peu apprendre auere chole apres vne diligente inquifition, fi ce n'eft que les Gentils, principalement les Brachmanes, Canarins, \& Iogues, en font vin grand eftat.

$11 \mathrm{~m}$ aduint vn iour comme i'herborifois pres $\mathrm{d} u$ feuue de Mangate,que ie vis vn certain Gentil affis à terre marmottant quelques paroles comme s'il prioit:l'ayant arraifonné il ne me refpondic rien,mais il fit certain figne de la main au truche ment, que íauois mené auec may, lequel entendant ce quil vouloit dire, fe retira tout foudain de li, \& me fit auff retirer, difant que ce Gentil eftoit l'enchanteur du Capitaine ou gouncneur de cefte contráe, lequel ils appellent Caymal, \& qu'il iettoit 
DES DROG. ET MED. LI V. III. $x 6_{3}$ des charmes fur l'herbc Viue : ce quion auoir accouftumé de faire,apres auoir bien premieremét nettoyée la terre autour de ladicte plante, de la lógueur d'vn homme, \& qu'on proferoit certaine, forme de paroles attendant le premier oyfeau, ou chole animée qui paffaft aupres de cefte plante,au mefme temps qu'il proferoit lefdictes parolles, du fang de laquelle(fi on la pounoit prendre)il falloit arroufer cefte plante, finon d'vn autre animal de at mefine efpece, \& ce faifoit auec plufieurs cerimonies lefquelles ie laiffe en arriere, pour eftre indignes d'eftre mifes en efcrit.Du depuis i'ay veu cefte pläte entre les mains d'vne putain publique.

\section{A NNOTATIONS.}

* Il fernble que ce foit celle-là que Garcie du Iurdin en fon liure des Drogues defcrit anoir les fenilles du Polipode,ne Iuy donnant aucun nom. Peut eftre aufir n'eft elle gueres differente à celle qui eft appellée par Apollodore AefchiEfchinomene, laquelle dés auffi toft gu'on en approche nomen. la main, elle retire fes feuilles cöme dit Pline, au liure 24. chapitre 47.

\section{De l'Herbe Mimofa. \\ C н A r. I V.}

L. fe tronue vne autre plante en certains iardins, yistotr. qui a cinq empans de long, laquelle s'appuyc fur de l'herles arbrilleaux ou murailles, voifines, ayant vne ti- $\int_{a}$. gegrelle, d'vne couleur verde bien belle, \& nö rrnp ronde, parfemée par interualles de petites efpince 
164 CHRISTOPHIE DEIA COSTE, Herbe Mimoja de Acofta.

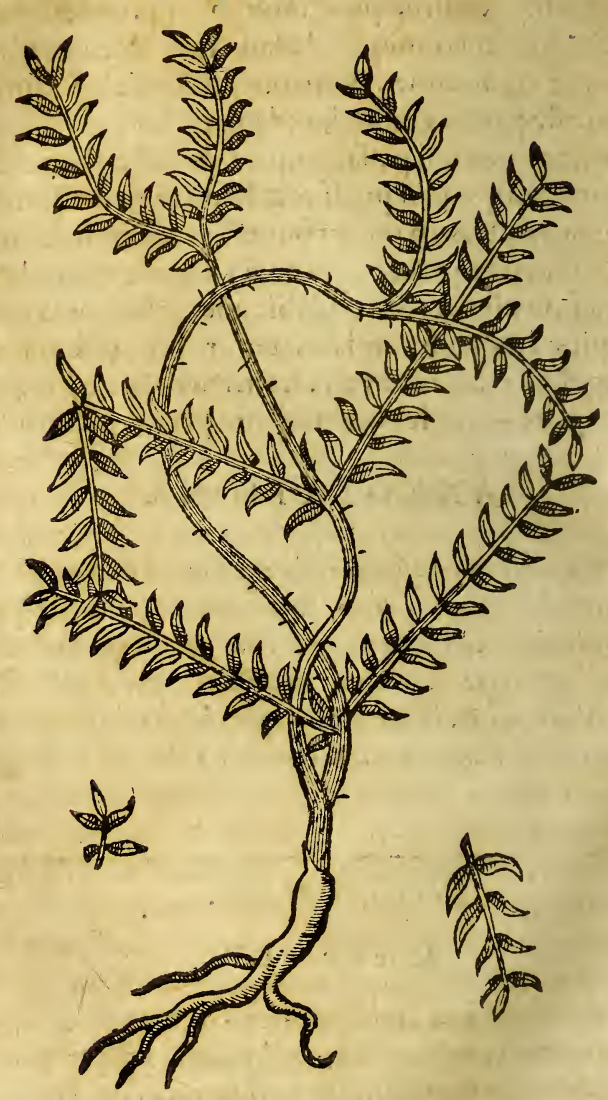

picquätes, \& dont les feuilles d'enhaut reflèmblent asx feuilles de la Fougere femelle.

Elle 
DES DROG. E T ME D. LIV. III. $16 \mathrm{~s}$

Elle fe plaift aux lieux humides \& pierreux : \& Le liss. s'appelle Herbe Mimo $\int e$, d'autant que quand on la touche de la main,elle fe fleftrit, \& quăd on la retire, elle recouure fa premiere couleur naifue, mais non fi foudain que la precedente.

Elle a vne nature beaucoup differente de celle ${ }_{\text {re. }}^{\text {Sa }}$. de l'arbre Trifte : car chafque nuict au Soleil couchant, elle flefrit \& delfeiche aucunement, $f$ bien qu'il femble aduis quelle foit entierement morte, mais au Soleil leuant,elle reprëd derechef fa premiere vigueur:\& tát plus que le Soleil eft ardant, tant plus elle reuerdift, tournant tout au long du iour fes feuilles vers le Soleil.

Elle a la fenteur \& faueur du Rigaliffe, \& les \&o odeurs gès du pays mafchent communement fes feuilles ueur. cótre la toux pour fe purger la poictrine, \& fe faire auoir la voix plus claire:on tient aulfi qu'elle eft Vertus. profitable aux douleurs de reins, \& quelle confolide les playes recentes.

\section{ANNOTATIONS.}

Cefte plante convient fort bien en plufieurs marques, au Fonu-grec Jaunage de Tragus, on Poligalon de Cordus, Auee ou auec la Rigaliffe faunage de Gefnerus, car $f i$ vous gou - plantes J'és fes ferilles of fes racines, elles ont le gouft du Regalif-elle corbfe:car fes feuilles fe retirét aucunefois la nuict (ce qui ad-uient. uient à plufieurs plantes leguminenfes) mais la tige n'a point d'efpines, fi ce n'eft quion verille prendre pour ejpim nes,ces appendices deflices eo poinctuës qui font attachéc. au pied des ferilles.

I I 3 


\section{$166 \mathrm{CHRISTOPHIEDEIACOSTE}$}

\section{Des Pignons de Malaca. \\ C н A P。 L VI.}

Defcri- $N$ cultiue \& entretient en certains iardins pison des

Pignons

de $\mathrm{Ma}$

back. de Malabar, cóne il croift auffi de foy mef-
me en quelques forefts, vn arbre de la grandeur
d'vn Poirier, les feuilles duquel au deflous font leurverde obfcure, lefquelles font fort tendres \& molles,acres au goult, \& picquent long temps la langue: fon fruict eft triangulaire de la grofleur d'vne auellaine, diltingué au dedans en plufieurs petites cellules,dedans lefquelles y ane femence blanche, folide, ronde, femblable en grolleur a ux pignons de ce pays, apres qu'on leus a ofté leur cocque.

Lew v- Les Indiens metrent foutent en vage ce fruict, fage. tant pourla guerifon de quelques maladies, que paur en faire plufieurs mefchancetés. Ils prenent deux de ces Pignons, aufquels ils oftent cefte pel. licule defliée qui les couure, \& les piflent pour les mefler aux clyiteres, communs, corre la Scyatique, difficulté d'vrine, ou bien ils les font prendre auec vo bouillon de poule, pour faire fortir hors les puirides, lentes, grofles, \& froides humeurs, \& pour guerir les Afthmatiques, pour la guerifon de laquelle maladic ils en font grand eftit, \& sien fer. uent ordinairement. Si on les broye dans l'cau, \& qu'ó en oigne les grattelles, apies toutesfoys auoir faict des frictions fur la partic, affin de mieux ouurir les pores du cuir,dans peu de temps elles fort bien gueries: mais iay aufi appris par experience qu'ids bruflent eftrangement. 
DES DROG. ET MED. LI V. III. 167 Pignons de Malaca de Acolta.

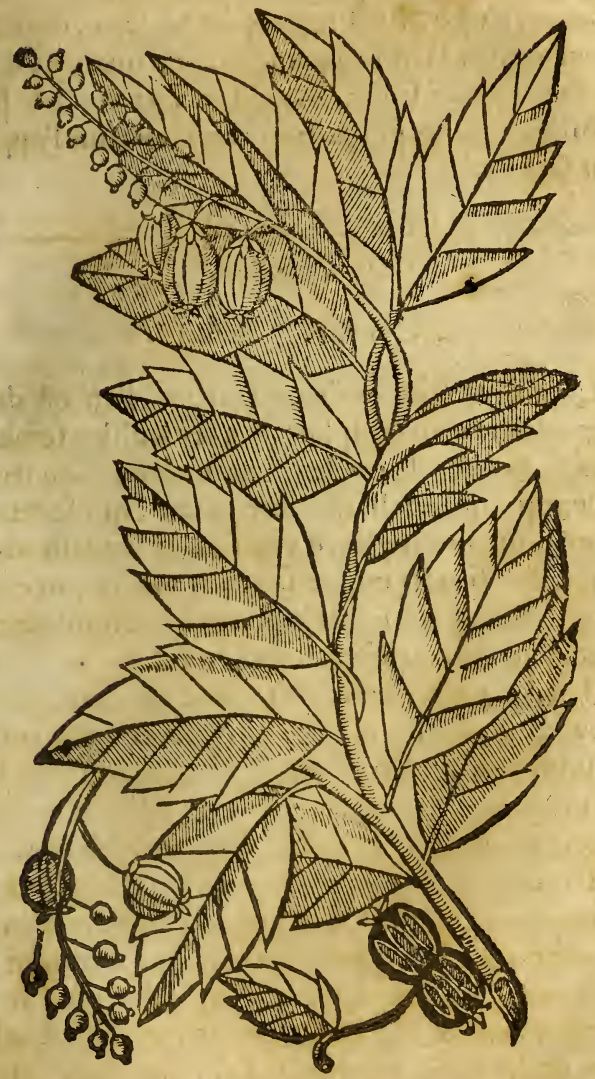

Auffi les mefchantes femmes de ces quartiers li, fort manger auec peu d'eau,quatre de ces Pignons L. L 4 
IG8 CHRISTOPHLE DE C A COSTE. à leurs maris,à celle fin de les faire mourir.

Ce fruict eft appellé communement Pinnones de Maluco, c'eft à dire Pignons de Malaca, d'autant qu'en ce lieu là il fe trouue grande quantité d'arbres portans ce fruict, \& qu'il eft fort vfuel \& fort familier en leurs purgations : les Canarins l'appellent Gepalu.

\section{Des Charameis. \\ С н Р. . L VII.}

Dessx ef- T I y a deux efpeces de c'eft arbre, l'vn eft de la peces. grandeur d'vn Mefplier, \& a les feuilles femblables au Poirier, de couleur verde claire, fon fruict Defcrio reffemble aux auellaines, fort iaune, qui fe termiption de ne en plufieurs angles, d'vne faueur laquelle accómiers. paigne les fruicts qui ne font pas meurs, auec vne acidité trefagreable, ils le mangent communemét meur, ou non, ou bien confict en fel.

Defcri- L'autre efpece eft de la mefme grolfeur que le ption de precedent, il a les feuilles plus petites que celles du Pommier,\& le fruict plus gros que le precedét les medecins Canarins fe feruent de la decoction d'iceluy auec des Sandaux contre les fiebures,

Or. il Il croift aux forefts \& montaignes efloignées de croifl. La mer:les Canarins \& Decanois choififfent d'entre Commët les arbres de la premiere efpece qui croilfent le it's met- long des eaux, ceux qui font plus efloignés de la. sone en mer:prenans de l'efcorce de cefte racine (laquelle vage la iette du laict ) la l'ongueur de quatre doigs, ils la premiere broyent fort bien auec vne drachme de mouftalde, \&la font prendre aux Althinatiques, car cela purge 
DES DROG. ET MED. LIV. III. 169

Charameis de Acofta.

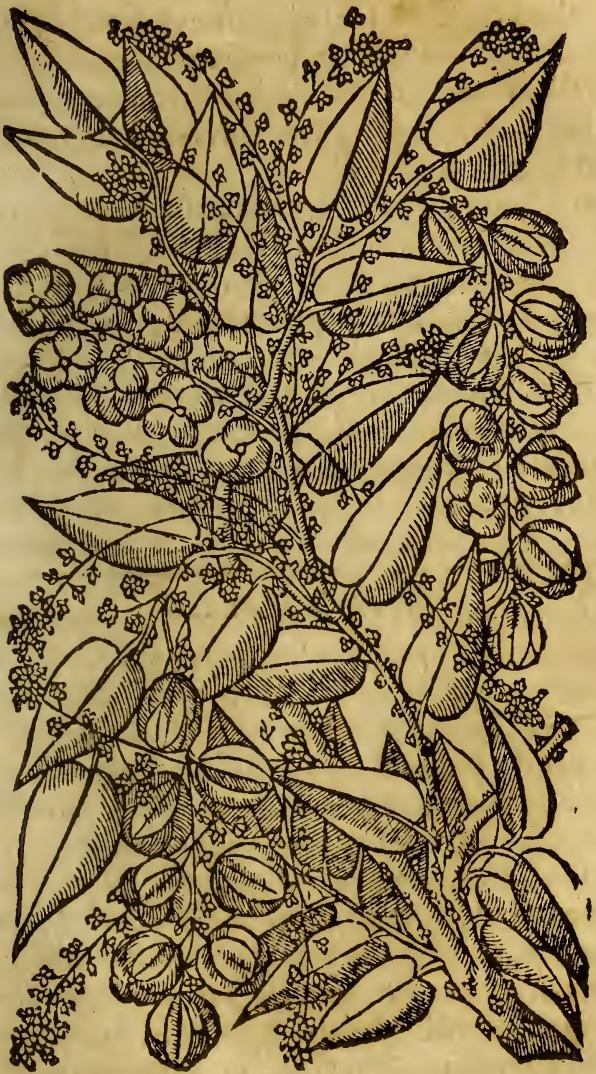

putge fort par le bas \& par le haut.Ques'il s'en enfuit vne euacuntion trop grande, ils leur font manL L s. 


\section{I70 CHR ISTOYHLE DE IA COSTE,}

manger vn fruict de Carambolas verd, ou boire vir traict de vin-aigre Canarin (qui n'eft autre chofe que la decoction de riz, gardée yn ou deux lours iufqutes à ce qu'elle s'enaigriffe, qui fert aux Canarins de vin aigre, \& s'en (eruent en medecine ) que fi le flux de ventre ne cerle, ils lauent la tefte au malade de l'eau froide.

Ils fe feruent fort de ces Charameis en ces contrees là, \& on accouftumé de les máger nó meurs, falés, ou conficts en fol \& vin aigre, comme nous auons dit cy deuant pour fe metre en appetit: ou ils les meflent auec quelques autres viandes, leiquelles ils veulent rendre aigrelettes.

Onles appelle en Canara \&r Decan Arazaauali; \& communement Charameis, les Arabes, Perfes \& Tures Ambela.

\section{Del'Herbe de Malaca.}

\section{C н а г. LVIII.}

Sès söss. Hiftoire de l'her be de Ma back. elle a vne couleur verde bien belle, vne tige mince, tendre, aucunement creure foible, \& laquelle fi on ne la foubitient comme le Iofmin auec des perches, s'eftend \& efpard fur terre comme fait le tierre;elle ietce beaucoup de rameaux quis'enracincent comme la Menthe \& melilie, ils rampent de telle forte, qu'vne feule plante, ou rameau tranfplanté,occupe vn grand lieu en peu de temps: fies fenilles font fort molles \& tendres, dentelées aux cunirons, 
DES DROG. ET ME D. L I v. III. I I

Herbe de Malaca de Acofta.

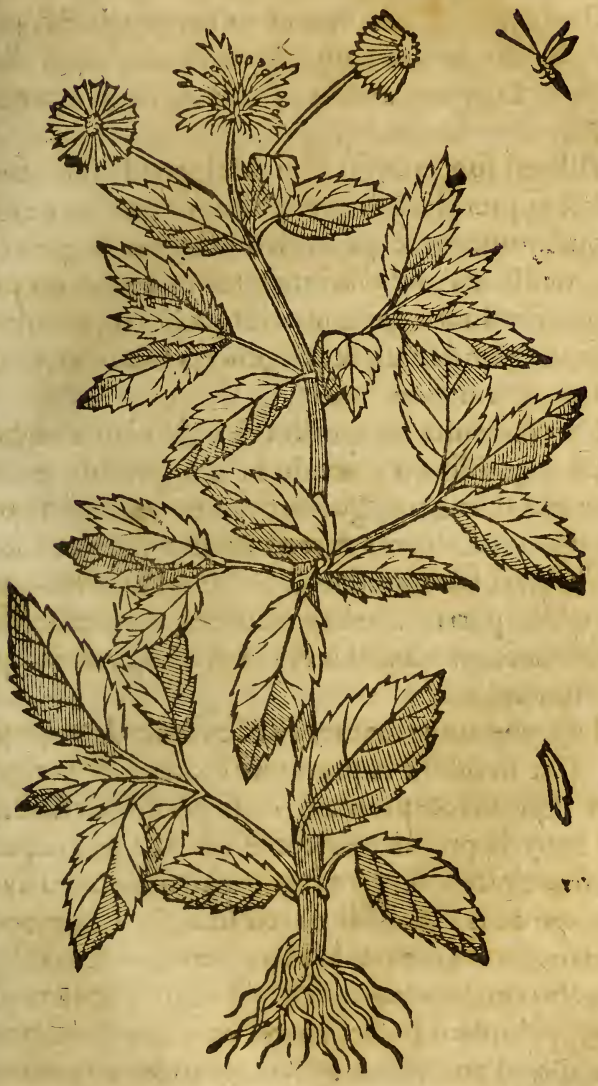

nuirons, reffemblane de grandeur.\& figure au Sucau:fa fleur elt iaume, fort fensblable à celle de la Chamo 


\section{CHRISTOPHLE DE LA COSTE,}

Chamomille, toutesfoys vn peu plus grande. Elle eft verde tout le long de l'annee.

Ses sös. On l'appelle communement le remede des pauures, \& la ruine des Chirurgiens, les. Canarins l'appellent Bringara aradua, c'eft à dire qui a la fleur iaune.

$v$ faged'i Elle eft fort en vfage en Maluco (d'où on tient qu'eft fa premiere origine, d'autant qu'elle y croift abondamment, \& qu'on en melle grande quantité aux medicamés de Chirurgie) \& en toutes les prouinces des Indes, par toutes lefquelles on la cultiue auec vn grand foing \& diligence, y eftant en grand eftime, \& non fans caufe.

Vingrent L'on fait cuire les feuilles de celte plante en huycomposé le, \& l'époiflit-on auec de la cire en forme d'vn-
deceste berbequi guent:c'eft vnguent guerit merueilleufement touane tes efpeces d'vlceres recens \& inueterés, encores merueil-qu'ils foyét fanguinolens, fordides, cauerneux, maleufe ver lings, \& putridés:ie l'ay tronué d'vne merueilleu-

fe efficace, aux vieux vlceres de iambes, \& aux playes noumelles.

Autre Il y a vne autre maniere de fe feruir de cefte pláfacon tc. Car ils oftent la premiere efcorce, \& la tige \& d'vferde aux rameaux, \& prennent celte pellure defliée, qui cefte plä- eft entre la premiere efcorce, \& la tige, laquelle mefme s'olte ay fément comme au Chanure:l'ayant trempé dans l'huile de noix d'Inde, ils l'enuelopent dedans les feuilles de la plante meíme, \& la mettét fous les cendres:lors qu'elle eft chaude \& ramollie, ils l'appliquent fur les playes recentes \& faigneufes(apres l'auoir bien broyée) grandes ou petites:\& les confolident en peu de iours auec grande admiantion,fans aucune inflammation ou apofteme:Car 


\section{DES DROG. E T MED. LIV. III. I73}

elle adoucit les douleurs, $\&$ arrefte le fang, redui- Plufieurs. fant à cicatrice en brief toutes fortes de playes, verius fans y adioufter aucun autre medicament : on dit auffi que c'eft vn fingulier remede contre toutes picqueures de nerfs \& playes.

On cn vfe aufin de la mefme maniere en vne apofteme ouuerte,tant pour la nettoyer, engendrer la chair, \& cicatrifer: comme aufie en toutes playes inueterées \& cauerneufes, aufquelles on l'applique mife feulement en poudre.

Dauantage, d'autant que les remedes de cefte plante font trefcertains, communemét ils en vfent en toutes ces prouinces, \& en font grand eftat:plufreurs auffi de ceux qui viennét par mer de ce pays là,ont accouftumé d'apporter de l'vnguent com- Vkgsen pofé de cefte herbe,auec huyle \& cire, ayans vne lequel ils telle creance en iceluy, comme s'ils auoyent auec woir les eux tous les remedes des Chirurgiens, \& partant vertusde en quelque occafion que ce foit, en laquelle on tous les peut recercher la main du Chirurgien, foudain ils autres ont recours à l'vnguent de l'herbe Malucane, com- chirurgi me à vn trefcertain \& indubitable remede.

caux.

\section{Du Sargaço. \\ С на в. IIX.}

F $N$ cefte tant renommée \& non moins dange- oì fe reufe nauigation du Sargaço(car ainfi ceux qui ois $\int_{\text {trouse }}$ nauigent aux Indes appellent ils toute cefte eften- Sargago. duë de mer, defpuis le dixhuictiefme degré, iufques au trente \& quatriefme, prenant depuis l'Aquinoxe iulques au Septentrion)l'on voit vne profonde 
174 CHRISTORHIE DE LA COSTE, fonde \& f pacieufe mer couverte d'vne certaine herbe appellée Sargaço,longue d'vin empan,enmócelée en pelotons par des rameaux fort defliés, ayant les feuilles eftroittes, minces \& longues de demy once, fort dételées aux enuirons, d'vne couIcur roulfaltre, d'vn gouft infipide, ou d'vne mordication infenfible, qu'il femble tirer pluftort de la falure de la mer, que de la propre nature de la pläte. A chafque lieu d'où la feuille fort, eft attache vne femence ronde, comme feroit vin grain de poyure leger \& vuide, toute ouuragée de Coral blăc, \& par fois de Coral rouge \& blanc, elle eft fort tendre lors que premicrement on la tire de l'eau, \& dure fi on la laiffe feicher, mais fort fragile, à caufe qu'elle eft fort mince, \& remplie d'eau falee. On ne voit aucune racine en cefte plante, mais feulement la marque par là où elle a efté rompuë, $\&$ eft croyable qu'elle croift aux plus profonds, \&2 fablonneux canals de la mer, \& $\dot{q}$ qu'elle a des racines bien deniées, encores què quelques vns ayent opinion que par le cours rapide des eaux qui tombent de plufieurs Ifles dans la mer, cefte herbe eit arrachée \& tirée auec elles. Ce que nous voulant faire accroire opiniaftrement le patron de vaiffeau, il s'elleua vne telle bonace en mer, cepédant que nous nauigions, \& entant que noltre veuë $f_{e}$ pounoit eftendre, nous la vifmes toute counerte de cefte herbe, \& ayans defcendu en bas quelques ieunes mariniers,à celle fin de ietter loing du vaiffeau cefte herbe,\& quils nettoyaflent l'eau, nous $v$ if mes clairement les pelotons de cefte herbe en$m$ oncelés enfemble, qui fortoyent du plus creux de la mer, où ayans mis la fonde en bas, nous ne 
DES DROG. E I MED. LIV. III. ITs Saganço de Acofta.

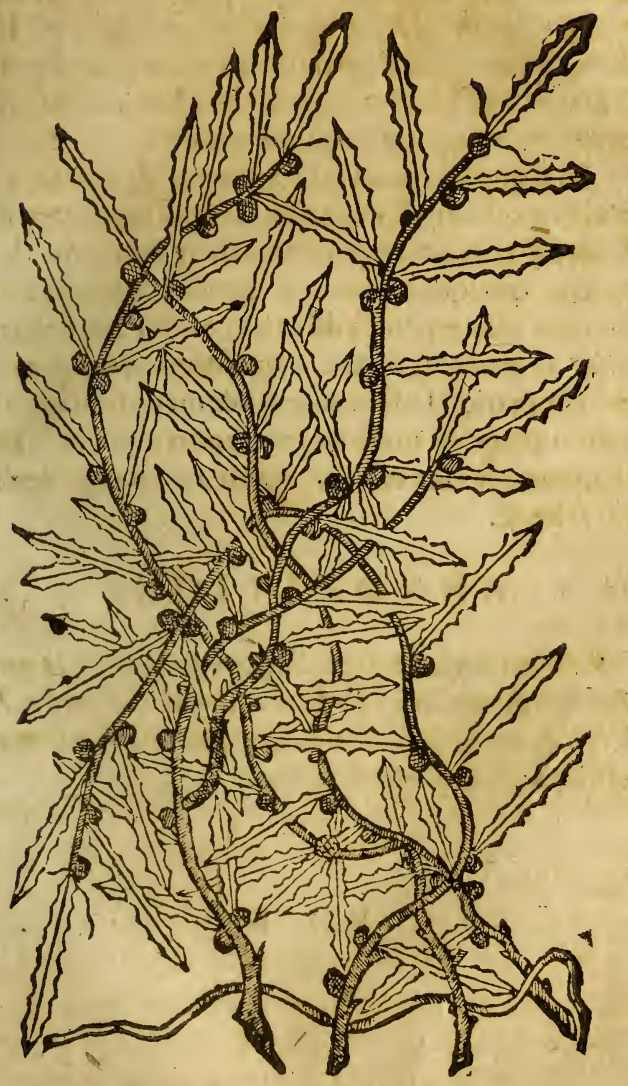

trouuafmes aucun fonds.

Cefte plante conficte en fel \& vin-aigre, eft du mefine 


\section{CHRISTO PHIE DE LA COSTE,} Exeelleh melme gouft que le fenoüil marin, \& en pourroit on bien vfer au deffaut d'iceluy, comme auffi ceux Je plare se. qui nauigent la pourroyent bien manger en lieu de Cappres. I'en fis donner de toute frailche aux Cheures que nous auions dans noftre vaiffeau, qui certes en mangeoyent euidemment.

Ie n'ay pas remarqué aucunes de fes vertus, mais un certalin de nos mariniers affligé d'vne difses ver ficulté d'vrine,mefmes que parmy for vrine il exsus. pulfoit quelques fables \& grofles humeüs, en mangea fansy penfer de cruë, \& de cuicte, parce qu'il la trouuoit bonne, quelques iours apres il m'alfeura qu'il fe fentoit grandement foulagé d'en auoir mangé, \&e mefmes en emporta quantité auec foy,pour en vfer en terre ferme,ce voyage de mer paracheué.

\section{A N NOTATIONS.}

* Il faut confiderer fi ce Sargaço feroit point la petite Yotite Lentille demer, qui a les feuilles dentelées de noftre Lorentille bel, la figure de laquelle il baille entre les plantes mariMarine. nes, fur la fin de fes Obferuations.

$$
\text { F I }
$$




\section{T A B LE DE S M TIE- RES CONTENVES AV}

\section{I R E D E CH R I.}

Atophle Acofta.

A

\section{A Efchinomene}

L Alma
Aloës, \& fon vage 9 Confectin de la doze, \&o des feuillesibid. Maniere de la préndre

ibid. Auellaine des Indes of fa Ambare \& fadefcription 148 fa figure 149 fon vage, or maniere de le confire 148 Anacarde fa de fcription \& $v$ tilité 174 fon buile, \&.à quoy fert 75 vertus $d u$ fruict ibid. Ananas,où croift, \&o fon biftoire 132 fa figure 133 fon vSage

134

Ananas Jaunage, or fa defcription ris fafigure Annuale Arare 136 65 ibid. Arbre Trifte fes qualités, liew natal I 0 figure III Odeur I 2 \& vertus de fes fleurs \& Sernence

II3
Areca

Aretca

Arifiora

Aritiqui

A Jarath

50.58

67 ibid.

65

159

63 defcription 56 fafigure 57 Comment la faut conferuer 58

Axis

B

159

12 Andan Ifle

37.

13 angue is 7 fa figure is 8 vtilité \&ن compofition 157

Bar

16

Bellerics

65

Bepole

118

Ber

146

Betele, \& fadefcription 36 Bois de Coleunre de deux plïtes 96 defcription de la premiere ibid. \& la figure 97 \& fes vertus 96 figure. de la feconde 98 fa defer MM 


\section{T A B L E.}

ption

Bois des Molucques, où il croift, \& fa defcription Io I à quoy propre fa femence 102 fes vertus \& vage 102.103 fon excelléce 104 Bor

C

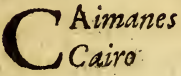

Caju

146

Cajus, fon bifloire 76 defcription de fon fruict, of vitili. té d'iceluy 77 où il croift ibid.

Caloins

60

Camphre, \& tablettes faictes du bois I 6 Quel eft le plus excellent?

ibid.

Candil

71

Canelle, fon biftoire, sic ean 30 figure de larbre 3 i fes vertus

Canja 32

Canje 104

Canta ville trof-narchande o port celebre

Cantabriens font les $2 \mathrm{~V}$ auar. rois

67

Carambolas, $\int a$ defoription, of vage 140 fa figure

Carcapuli, on biftoire, if '?age 138 fafigure
Caffe laxatiue, fon biftoire, ou croift 7 I Diners noms 73 fon vjage ibid.

Cate

I 6

Charameis, fes deux eppeces, defcriptio des deux $168 \mathrm{fi}$ gure 169 lien où croift 168 Checani

58

Chepules

67

63 Chine Royaume of de fon ex$6 \quad$ cellence 17 marchandifes qui en font apportées ibid. Coccus de Naledine 64 o fes efmerueillables vert us ibid. fa difference d'auec le corn. mun

$6 I$

Comalamaja

Copra

63

Corn, fa defcription of noms diners 4.9 fes vert us ibid. \& s I àquoy profitët les feuilles

ibid,

Cranganor riuiere 20

Crocodilles ibid. on les prend auec bouffines d'Auellaine Inde

58

Cubebes

56

Curcum

D

98

Dante

Datura of de fes trois eppeces 150 defcription de la premiere ibid. ou il croift ibid. 


\section{T A B L E.}

ibid. Ses noms, qualités of Goa ville

vertus I 52 defcription de la fecöde er troifiefme iss

Dayas

Dialacca

15

Durion ou croift I 2 ; la qualité de l'arbre ibid. Sa figure 124 façon de manger le fruict 125 ce fruiti of le Betele ont grande Antipathie

126

\section{E}

TL Lephant of fon biftoire L 22 . Ja figure 23.Ils s'êtendent l'vn l'autre 24 Ils parlent quelquefois ibid.sot memoratifs des bien-faits 25 leur maladie ibid.Indice d'icelle on furenr, of le remede 27 font defreux de gloire of vindicatifs 28.29 Eleui

61

\section{F}

G Anax

Figure des Indes voyez Muja

Fula.

\section{G}

60 vage

Guapard de la Croix de l'bifoire de la Chine

$\mathrm{H}$

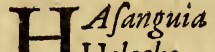

1 Helecho

Herbe d'Amour

Herbe de Malaqua, \& biftoire 170 fes nos ơ vage d'icelle 172 \& figure 171 plu. fieurs vertus

173

Herbe-vine, fes noms, biftoire; o lieu natal 160 figure 161 merueillenfe nature. 160 \& fes vertus 162

Huile d'Anacarde, \&̛ à quoy tl fert

$\coprod_{\text {Acafruizt }}^{1}$ ption 120 groffeur ibid. figure 12 les facultés 122

Iagra

60

Iamboli 144

Iamboloins, leur biftoire of for

Iambos 142 fa figure 143 diuersnoms of facultés $\quad 144$ langomas, fadefcription, liew natal, \& vage ibid. Inde $f$.

Insecta quoy

MM 2 $\begin{array}{ll}\text { l'v Jage, \& fes vertus } & 93 \\ \text { Gingemabre or defcription } & 94 \\ \text { Jafigure } & 95\end{array}$ 


\section{T A B L E.}

\section{Iogues}

\section{L}

I Acque o maniere de la 1. faire is fon vtilite. ibid. Comme elle fe falfifié I 4 n'est le Cancame ibid. Il $y$ en a d'artiffielle 16 fon vfage

L auandou

Lentille marine ibid. 91

Lezard d'ermus poifon plus subtile

\section{$M$}

Acer, \& fon biftoire $4 \mathrm{I}$ M propre aux difsetteries 44 vomiffemens ibid. D'ò̀ s'apporte

Macis differe an macer $4 \mathrm{I}$ o 47

Macré

Mambu 20 fon vititité ibid. Mangas 74 of 129 fa defrription, lieu \& noms ibid. facultés 130 \& figure $13 \mathrm{I}$ Mangas Saunage fes vertus, lien où il croift

Mangate flewre

Manne, fes vertus, Eo moyen de la garder 18 fallffée 19 Majlac

Moringa fon biftoire, vfage, o vertus 106 figure 107 lien natal, \& noms diners 108
Morximaladie

122

$\mathrm{Mu} a$, \& söbiftoire 125 figure 127 Diuerfes eppeces 128 Myrobalans o de fes cing eppeces

\section{N}

65

T Aledines Ifles

1 Narel

Negundo y en a de deux fortes 113 Defcription of vertus I 4 figure du male IIs de la femelle 1 i 6 decoction de fes fueilles

I 17

Nimbo I 17 fa defcription,vertus 118 figure I I 9 buile à quoy profitable ibid. 6 I 20 Nimpa

Noix metbel gu'eft

Noix mufcade \& de fa fleur 37. Jes figures 38.39 .40 so buile of vertus 37 fes diuerfes appellations 39.40 O Lla
Opium on vage, où il
croift, ơ à quelle choje il eft

propre

I 2

Orraca

60

\section{$P$}

DAlme-Indienne s9 Di1 uers noms ibid. deux efces 60 à quoy feruent. ibid. quel eft fon fruidt 6 I figure 62 fas 


\section{T A B L E.}

G2 fa noix 61 ci fon vage 63

Panaud

Panaju

Panax

Parafitaco

Panate guerit les eryfipeles $5 \mathbf{I}$ fa defcription. ibid. Sa figure 52

Pierre Bezar \& fa groffeur 108 où s'engendre $109 \mathrm{fa}$ varieté ibid. à quoy eft profitable II 2 fon excellence ibid.

Pignons de malaca, of v vage I 66 fa figure

Pommes des Indes, figure de l'arbre \& biftoire, diners nös, co de fon excellence

47

Poyure de deux especes 53 de$\int c r i p t i o n d u$ domeftique $\$ 4$ figure du noir 55 vertus dës fenilles of façon de le
Pul

planter

s6

$\mathrm{R}$ racine

Rezanuale

$R$ bubarbe ou croift 84 erreurs ibid.

65 touchant fa preparation \&s $S$

Affran des Indes, of for $\checkmark$ biftoire 89 fa figure 90 Saincte Croix Ifle 41 Cité 44 Sambarane 34

Sargaço, oì fe troune 173 figure 175 Excellèce de cefte plante fos vertus $\quad 176$ $T$

MAbaxir of fon biftoire 20 1 Tamarins \& biftoire 67 figure 69.69 vertus des feuilles of diuers noms 70 l'ombre eft nuyfible ibid.

Tatula

Is 6

Tame

108

Tupba-Indi

Tuphat

144 ibid.

Turiaa

108

\section{V} $\bigcup_{17.18}^{A \int a \text { murrbyna que fon: }}$

Vasaueli

Verengenes pommes 109

Vidaras

X

Xareta

$$
\text { F I } N \text {. }
$$







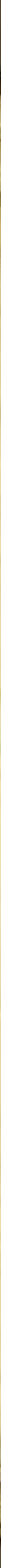




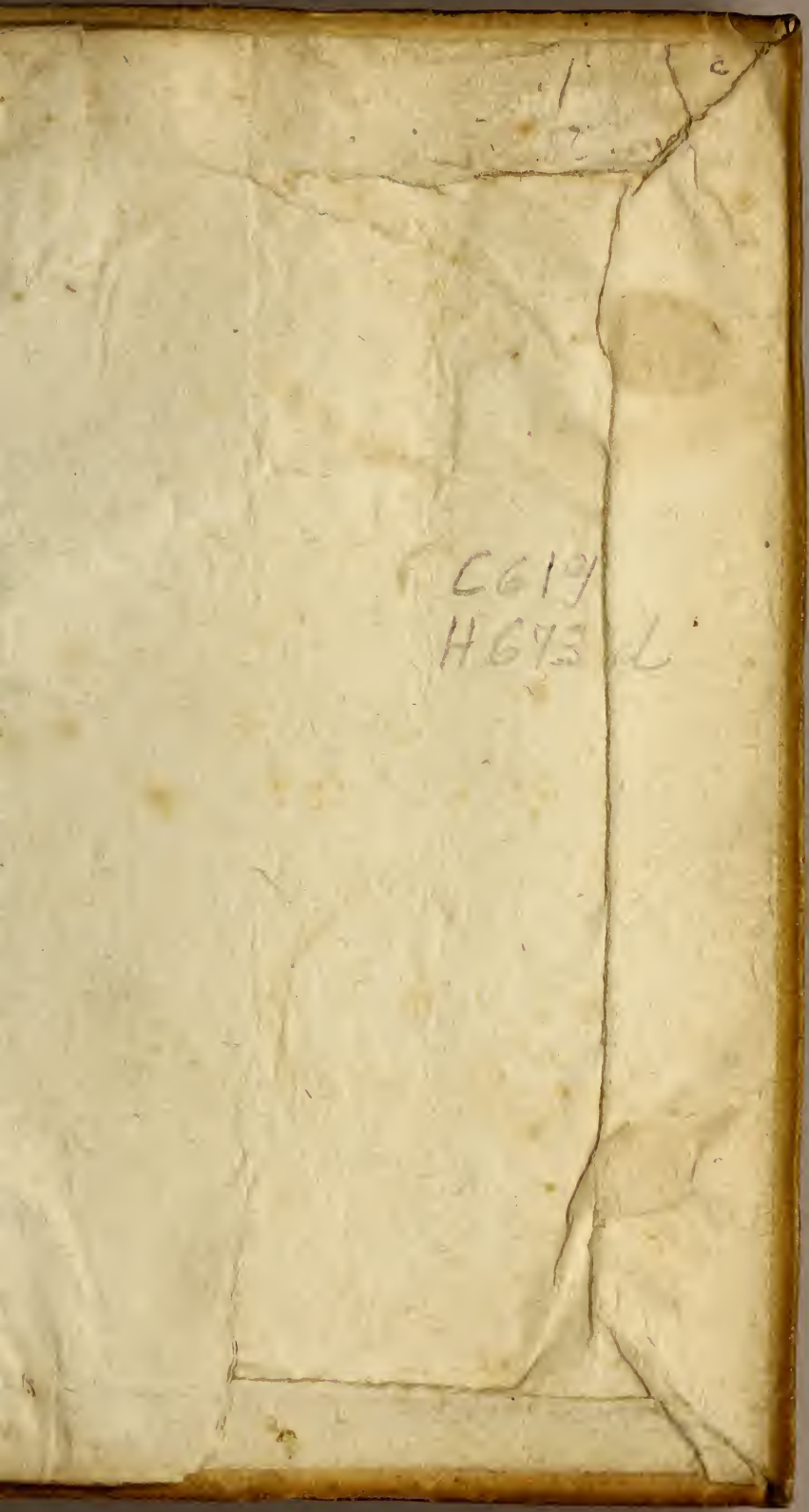


2
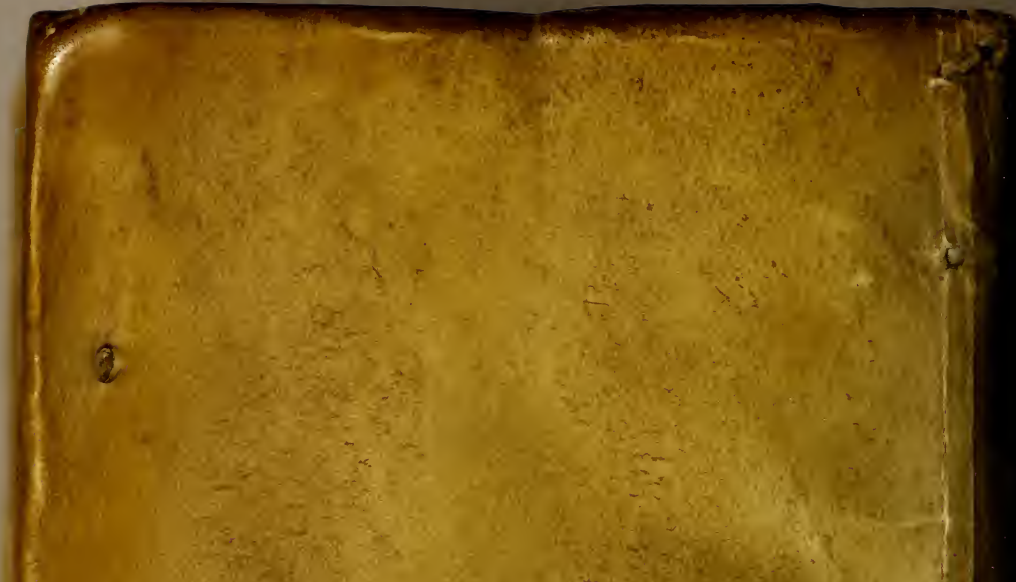

$v$ 